University of Louisville

ThinkIR: The University of Louisville's Institutional Repository

8-2013

\title{
A paradox of American tragedy : Long day's journey into night and the problem of negative emotion in theatrical performance.
}

Jeremy Killian

University of Louisville

Follow this and additional works at: https://ir.library.louisville.edu/etd

\section{Recommended Citation}

Killian, Jeremy, "A paradox of American tragedy : Long day's journey into night and the problem of negative emotion in theatrical performance." (2013). Electronic Theses and Dissertations. Paper 749. https://doi.org/10.18297/etd/749

This Doctoral Dissertation is brought to you for free and open access by ThinkIR: The University of Louisville's Institutional Repository. It has been accepted for inclusion in Electronic Theses and Dissertations by an authorized administrator of ThinkIR: The University of Louisville's Institutional Repository. This title appears here courtesy of the author, who has retained all other copyrights. For more information, please contact thinkir@louisville.edu. 


\title{
A PARADOX OF AMERICAN TRAGEDY: LONG DAY'S JOURNEY INTO NIGHT AND THE PROBLEM OF NEGATIVE EMOTION IN THEATRICAL PERFORMANCE
}

\author{
By \\ Jeremy Killian \\ B.A. Pensacola Christian College 2001 \\ M.A. Pensacola Christian College 2003
}

\begin{abstract}
A Dissertation
Submitted to the Faculty of the

College of Arts and Sciences of the University of Louisville

in Partial Fulfillment of the Requirements

for the Degree of
\end{abstract}

Doctor of Philosophy

Department of Humanities

University of Louisville

Louisville, Kentucky

August 2013 



\title{
A PARADOX OF AMERICAN TRAGEDY: LONG DAY'S JOURNEY INTO NIGHT AND THE PROBLEM OF NEGATIVE EMOTION IN THEATRICAL PERFORMANCE
}

\author{
By \\ Jeremy Killian \\ B.A. Pensacola Christian College 2001 \\ M.A. Pensacola Christian College 2003 \\ A Dissertation Approved on
}

August 8, 2013

By the Following Committee Members

John Gibson, Committee Director

Osborne Wiggins

Ying Kit Chan

Andrew Cooper 


\section{DEDICATION}

This dissertation is dedicated to my parents

Eddie and Jill Killian,

who taught me to love wisdom,

to my wife

Haley Killian

whose loving sacrifice has made this project possible

and to my children,

Zoey and Gwenyth Killian. 


\section{ACKNOWLEDGMENTS}

I would like to thank my dissertation director, John Gibson, for his constant affirmation and guidance through this project. His imagination and philosophical courage has served as a model that I hope to embody in my academic career. I would also like to thank the other members of my committee, Osborne Wiggins, Ying Kit Chan, and Andrew Cooper, for their patience and guidance in this project. To my wife, Haley Killian, I owe perhaps the most significant debt of gratitude, as she has believed in me through the roughest times of this project and is a constant source of love, inspiration, and humor. 


\title{
ABSTRACT \\ A PARADOX OF AMERICAN TRAGEDY: LONG DAY'S JOURNEY INTO NIGHTAND THE PROBLEM OF NEGATIVE EMOTION IN THEATRICAL PERFORMANCE
}

\author{
Jeremy Killian
}

August 8, 2013

In this dissertation I examine a philosophical problem referred to as the "paradox of tragedy" as it presents itself in the context of the positive reception of Eugene O’Neill's Long Day's Journey into Night. This play depicts a harrowing day in the life of the Tyrone family, where each of the family members cope with failure, addiction, and disease. The emotional tone is bleak and pessimistic, yet people often describe their responses to this tragedy in terms of pleasure, and one can easily imagine someone claiming to "enjoy" the play. How is this possible? Moreover, what motivates one to pursue Long Day's Journey into Night when they would endeavor to avoid negative emotional stimuli in real life?

In chapter 1 of the project, I survey a family of theories as proposed resolution of this problem. I examine a theory derived from Stoic philosophy, David Hume's "conversion" theory, and John Morreall's "control" theory. Utilizing evidence drawn from analytic philosophy as well as cognitive psychology, I rule each of these theories out. This allows me to establish acceptable criteria for any resolution to the problem. In chapters two and three, I turn my attention to the claim that Journey on the whole elicits 
more good than bad emotional states. Using a method of emotional analysis proposed by Nöel Carroll, in chapter three, I construct a close reading of the emotional address of the play, concluding that the claim that the play elicits more positive emotion than negative is likely false.

In chapters four and five, I construct a thematic reading of the play by first establishing the connection between the writing of Eugene O'Neill's writing and the work of Friedrich Nietzsche. I perform a second close reading of the play to validate a Nietzschian reading, and then utilize this data as a feature of my own resolution to the problem. In chapter six, I conclude by presenting two theories that account for all the conditions I have established as a candidate solution and defend a "meta-response" style solution to the paradox of Journey. 
TABLE OF CONTENTS

Page

ACKNOWLEDGMENTS ........................................................

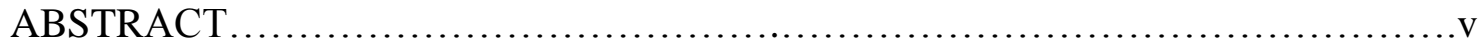

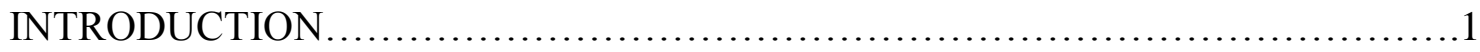

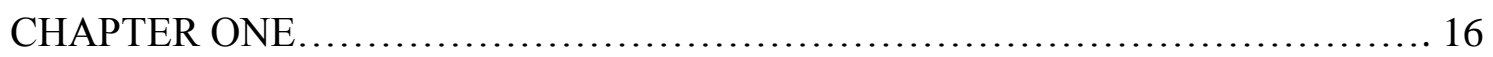

CHAPTER TWO .............................................................. 40

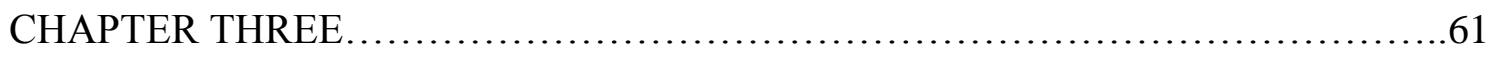

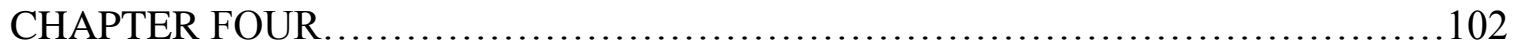

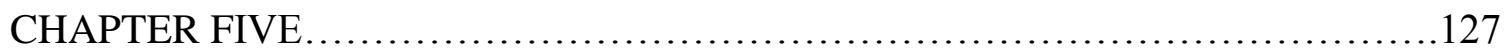

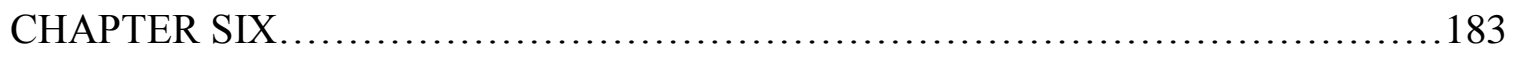

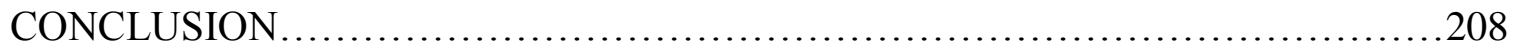

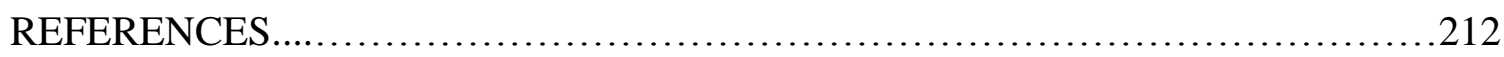

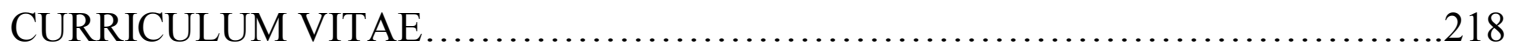




\section{INTRODUCTION}

In 1956, Long Day's Journey into Night appeared on the American stage for the first time, and most heralded this play as the greatest of Eugene O'Neill's career. John Chapman of the New York Daily News described the opening of the play as exploding "like a dazzling skyrocket over the humdrum of Broadway theatricals." With few exceptions, the critical response to the play was overwhelmingly positive, with critics asserting that with Long Day's Journey, "the American theatre acquires size and stature."2 When Journey premiered in Paris, despite the fact that the theatre was without air-conditioning in July and the play ran from 8 PM until 1 AM, the Herald Tribune reported that "there was a five minute ovation, marking the most enthusiastic reception ever accorded an American play in France."3

When one considers the nature of the play, a philosophical problem emerges. The overwhelming response to O'Neill's masterpiece was - and continues to be in contemporary performance - expressed in terms of pleasure. There is nothing apparently contradictory in an audience member stating, "I really enjoyed Long Day's Journey," but how can this be the case? The play depicts the terribly dysfunctional relationships of the members of the Tyrone family, each of whom struggles with some form of addiction and

\footnotetext{
${ }^{1}$ Qtd. in Jordan Miller, Playwright's Progress: O’Neill and his Critics, (Chicago: Scott, Foresman, and Company, 1965), 133.

${ }^{2}$ Qtd. in Brenda Murphy, Plays in Production: Long Day's Journey into Night, (Cambridge: Cambridge University Press, 2001), 47.

${ }^{3}$ Ibid., 48.
} 
malady, each of whom is at once oppressed and the oppressor of the other four members . When one interrogates her emotional response to the play, she is likely to recognize that she experiences so-called "negative" emotions as a result of the events depicted. If she feels empathy toward these characters. ${ }^{1}$ By negative emotion, I refer to the fact that the viewer finds herself experiencing anger, despair, and pity, emotions whose qualia are typically those we wish to avoid in our daily lives. Through the course of the play, the audience member receives little relief from these emotions. The philosophical problem, then, is how to understand what goes on when one characterizes the experience of Journey as one of enjoyment. Moreover, why would an audience member willingly subject herself to the negative emotions aroused by Long Day's Journey into Night when she would not likely subject herself to such negative emotion in real life?

Students of David Hume's aesthetics will recognize this problem as a localized version of what has come to be called "The Paradox of tragedy," Hume describes the phenomenon of tragic enjoyment in his essay "Of Tragedy:"

It seems an unaccountable pleasure which the spectators of a well-written tragedy receive from sorrow, terror, anxiety, and other passions that are in themselves disagreeable and uneasy. The more they are touched and affected, the more are they delighted with the spectacle...the whole art of the poet is employed in rousing and supporting the compassion and indignation, the anxiety and resentment, of his audience. They are pleased in proportion as they are affected, and never so happy as when they employ tears, sobs, and cries to give vent to

\footnotetext{
${ }^{1}$ It is important to note that not all viewers experience such empathy toward the characters in the play. Thomas R. Dash, a reviewer of the play for Women's Wear Daily, writes that "For the cognoscenti and for devotees of O'Neill, these flagellations and psychological penetrations into the pitiful ruins of a family may prove stimulating. But for the neutral and dispassionate observer and for the rank and file of theatregoers, 'A Long Day's Journey into Night' may prove a long night's journey without too much daylight." (Qtd. in Jordan Miller, Playwright's Progress: O'Neill and the Critics, 136). Here it is not necessary for me to defend that all people experience negative emotions with respect to the representation of the Tyrone family; instead, I am attempting to resolve the problem of how anyone may experience a positive response despite - and perhaps because of - the negative emotions she experiences toward the Tyrones and the world of Journey.
} 
their sorrow, and relieve their heart, swollen with the tenderest sympathy and compassion. $^{2}$

In other words, when one observes tragedy in art or literature, often one is most thrilled by the horror it depicts. Why do decent, generally moral people seem to enjoy the representation of human suffering at its most egregious level when it is placed before them in an artistic context? This question transcends mere theatrical tragedy and seems to have far-reaching implications. Much art represents, at least in part, elements of the world that are morally repugnant. If one finds these elements of the world displeasing and seeks to avoid them, why does she seem to enjoy their representation in an aesthetic context?

The paradox Hume believes he has uncovered might be formulated this way:

1.People avoid situations that arouse pain, and pursue situations that arouse pleasure.

2.People experience pain in response to tragedy.

3.People pursue tragedy.

According to most critics, the Humean formation of this paradox (as stated above) relies on a dubious assumption regarding human motivation and action. Alex Neill and Flint Schier point out that for Hume, the "chief spring and actuating principle of the human mind is pleasure and pain."3 On Hume's view, every action that humans take is motivated by a desire to pursue pleasure and avoid pain. It is unremarkable then, that Hume believes he has uncovered a significant problem in the human experience of tragedy. "From such a

\footnotetext{
${ }^{2}$ David Hume, "Of Tragedy," in Hume: Selected Essays, S. Copley and A. Edgar (Eds.), (Oxford: Oxford University Press, 1993), 126.

${ }^{3}$ David Hume, A Treatise of Human Nature, ed. L.A. Shelby-Bigge, $2^{\text {nd }}$ edn. rev. P.H. Nidduch (Oxford:

Clarendon Press, 1978), 574.
} 
perspective, the fact that we keep returning to tragedy, that we value it as highly as we do, can only be explained in terms of its being a source of pleasure for us." ${ }^{4}$

Neill argues that Hume's hedonic assumption is an outdated mode of describing human motivation; there are more sophisticated explanations that describe why humans pursue reward than simple hedonism. If this strong hedonic assumption is removed, the paradox is significantly weakened; however, the problem does not altogether dissolve. Generally, psychologists assume the hedonic principle is a good representation of human motivation, if one broadens her definition of "pain" to include "negative emotions," (fear, anger, and sadness) and expands her definition of "pleasure" to include "positive emotions. ${ }^{, 5}$ All things being equal, people generally pursue experiences which provide positive emotional responses over experiences that elicit negative responses, unless there is some overwhelming reason they should do otherwise. ${ }^{6}$ As this this is the case, the paradox might be better formulated (although weakened) this way:

1.People generally avoid situations that arouse negative emotions, and pursue situations that arouse positive emotions.

2.People have negative emotional responses to tragedy.

3.People pursue tragedy.

Construed for the project at hand, the paradox reads:

1.People generally avoid situations that arose negative emotions, and pursue situations that arouse positive emotions.

2.People have negative emotional responses to performances of Long Day's Journey into Night.

3.People pursue performances of Long Day's Journey into Night.

\footnotetext{
${ }^{4}$ Alex Neill, "Hume's Singular Phenomenon," British Journal of Aesthetics 30 (April 1999), 121.

${ }^{5}$ To be clear, the value judgments "positive" and "negative" refer to the qualia of the experience of these emotional states. Positive emotions are those emotions we claim to "enjoy" in our daily lives, while negative emotions are those we attempt to avoid in daily life, and the latter may even be construed as "painful." From an evolutionary standpoint however, it is likely that all emotions are "positive" in that they have evolved as principles of attraction and repulsion in the context of survival.

${ }^{6}$ Eduardo Andrade and Joel B. Cohen, "On the Consumption of Negative Feelings," Journal of Consumer Research 34: 3 (March 2007), 284.
} 
Both (1) and (3) appear to be uncontroversial. In order to resolve this problem, most philosophers have taken up the task of modifying (2) by offering some caveat to its claim. Ultimately, the question is what motivates audiences to pursue Long Day's Journey into Night?

In order to tease out an acceptable modification to second statement of the paradox, I will examine and eliminate a number of prominent solutions to the paradox. In the first three chapters, I will examine four theories that share a common feature. One strategy that has been employed to undercut (2) is to argue that audiences do not in fact experience significant negative emotions as a result of viewing Long Day's Journey into Night. It does seem, on initial inspection, that the sort of sorrow one might feel when she views Journey is appreciably different than the sort of sorrow she would feel if she encountered similar emotional stimuli in her actual life. There is a family of theories who take this intuition seriously and attempt to deny that tragedy really makes viewers feel all that bad. In Chapter One, I will consider three modifications of (2) along such lines, and I will demonstrate that because of the inadequacies of each approach to account for the experience of "tragic emotions," none of them can get off the ground as a description of an audience's experience of Long Day's Journey. After showing the deficiencies in approaches that deny the existence of significant negative emotions in response to putatively painful art, in chapters Two and Three, I will then explicitly demonstrate, through a detailed analysis of Long Day's Journey into Night, that on the whole, this play is designed to elicit powerful negative emotional states. In so doing, I will refute the theory that on the whole, Journey does not elicit negative emotional states. The method 
that I utilize in these chapters will establish criteria whereby any potential solution to this paradox might be measured.

Chapters four and five mark a disciplinary shift in this project. Any solution to the problem of negative emotions proposed by a specific artifact ought to include a close examination of the artifact itself. Such an analysis is particularly significant in this project because, as I will show, the theme of the play will become a component of the solution to the problem. This theme emerges when one contextualizes Journey as a product of O'Neill's philosophical interests. Eugene O'Neill's affinity for the philosophy of Friedrich Nietzsche has been well-documented, with a number of biographers pointing out that though many O'Neill scholars have noted the influence of Thus Spake Zarathustra in many of O’Neill's plays, I will argue that the paradigm Nietzsche describes in Birth of Tragedy serves as an invaluable interpretive aid for reading the play. One key theme Nietzsche develops is the power of tragedy to enable those who participate in it to find themselves in community with others, and I contend that this is precisely what O'Neill intends to embody onstage. I will show that not only does BoT provide an important reading of Journey, O’Neill also intends to deliver an early Nietzschian message to the audience: a life of positive affirmation of one's suffering can only be achieved in interdependent community with others. The development of this subthesis will allow me to establish a powerful reading of the play in chapter five that illuminates what I believe to be the central theme O’Neill displays to the audience.

In chapter six, I will apply the criteria established in the first five chapters to two potential solutions to the problem of Journey. I will demonstrate that both "rich experience" and "meta-response" theories of tragic pleasure provide the sturdiest 
accounts of the emotions elicited by Journey, and I will argue that there is good reason to prefer a "meta-response" style theory over and above the "rich experience" theory. My ultimate claim is that viewers pursue Long Day's Journey into Night because it provides an occasion whereby viewers experience negative emotional states while being compensated by a positive emotional response directed toward the community created in the event.

There are significant challenges to be faced in constructing a solution to the problem of Long Day's Journey into Night. Though perhaps the most popular solution to the paradox of tragedy in contemporary aesthetics is Alex Neill's "rich experience" theory, no clear consensus has emerged in the discussion as to the best solution to the problem. The paradox of tragedy seems to be an open question. This may be the case for at least two reasons: (a)Most theorists working on the paradox of tragedy assume that there is a single all-encompassing solution to the paradox that explains why people pursue negative emotion in all art. In this case, the "paradox of tragedy" really ought to be referred to as "the paradox of negative emotion in art." A philosopher like Susan Feagin, for example, assumes her solution to the paradox should hold whether the viewer is watching a theatrical tragedy, attending a horror movie, or looking at a particularly violent Caravaggio painting. . She writes, "my remarks do not apply merely to the narrow, Aristotelian sense of tragedy, in which sense there is a question about whether such works as, e.g., Arthur Miller's Death of a Salesman or Eugene O'Neil's A Long Day's Journey into Night are tragedies. I am concerned with, to put it bluntly, the class of works with unhappy endings," a class to which she later adds "works with unpleasant 
subject matter." ${ }^{, 7}$ However, as Alex Neill points out, people are motivated to participate in different genres of art for a variety of reasons. People see plays, for example, for different reasons than they look at sculptures. Therefore it seems easy to provide counterexamples to any grand theory of negative emotion in art by simply analyzing audience response to one or several genres that do not seem compatible with the theory presented. Good responses to the paradox of tragedy ought to be more focused on individual genre; for example, a response to the paradox of tragedy with respect to religious art must consider problems of religious phenomenology and the constraints of religious tradition, while a response to the paradox of tragedy with respect to sculpture must consider problems native to that discipline. It also may be important to examine genres of art and particular work by taking into consideration the cultural and historical moment from which they emerge, instead of opting for more universalized motivational accounts. Largely, these approaches have not been explored. ${ }^{8}$ This dissertation focuses itself one artifact, in the hopes that a localized solution might pave the way for more generalized solutions to the problem.

The second reason there seems to be little consensus on the problem of negative emotion in art is that (b)most philosophers of art are no longer strongly committed to a strong cognitivism of emotion in the current dialogue. Cognitivist understandings of emotions assert that emotions "can be dealt with by a psychology whose main theoretical entities are the beliefs and desires that feature in everyday explanations of people's

\footnotetext{
${ }^{7}$ Susan Feagin, “The Pleasures of Tragedy,” (American Philosophical Quarterly, 20, 1: November 1983), 96.

${ }^{8}$ There does seem to be some progress in this field, however. More focused approaches such as James Harold's "Mixed Feelings: Conflicts in Emotional Responses to Film," (Midwest Studies in Philosophy 34:1, September 2010, 280-294), reflect a much more narrow approach to the problem-in the case of his discussion, the context of cinema.
} 
actions." $"$ Emotions, on this view, should be understood as a kind of thought able to be communicated in strong propositional statements (i.e. "I am jealous of $x$ because he has y.”). On cognitive theories, emotions are strongly intentional — that is, directed toward some object (often referred to as an "intentional object") and occur because of a person's beliefs, judgments, or construals of that object. Additionally, in many cognitivist theories, a high value is placed upon the truth or falsehood of such propositional statements, with many cognitivists asserting that in order to have emotions toward something, a high criterion of belief must be met with respect to the intentional objects of such feelings. In a cognitivist mode, the paradox of tragedy is most sharp, because the problem seems to assert that one can have both a positive and negative feeling (perhaps even simultaneously!) toward a single intentional object—namely, the work of art eliciting such feelings. This is further complicated by the fact that these emotions are aroused by fictional entities and events that are clearly not "real" in the traditional sense.

A cognitivist ought to be very motivated to provide a solution to the paradox, because its implications seem to undermine key features of her theory of emotion. For example, the cognitivist has to make sense of the how seemingly opposite propositional statements might be made about our interaction with tragedy: "I feel fear and pity toward Long Day's Journey into Night," and "I feel pleasure toward Long Day's Journey into Night." If these statements both accurately characterize our experience of tragedy, it appears we have reached a limit with respect to how language can describe emotional content. If emotions are a kind of thought based upon belief, one ought to be able to semantically describe the response to tragedy without having to make two contradictory statements. A cognitivist also has to account for the kind of judgments, beliefs, or

\footnotetext{
${ }^{9}$ Paul E. Griffiths, What Emotions Really Are, (Chicago: Chicago University Press, 1997), 2.
} 
construals about tragedy one must have in order to derive both pleasure and pain from its consumption.

In recent years, however, strong cognitive theories of emotions such as those proposed by Robert Solomon or Martha Nussbaum have fallen out of fashion in favor of "perceptual" or "feeling" theories of emotions. For example, Jesse Prinz, heavily utilizing contemporary methods of experimental philosophy, defends a modified version of the James-Lange theory of emotion that asserts that emotions are "perceptions of bodily change." 10 In other words, emotions ought best be understood as "embodied appraisals," perceptions by the mind that the body has encountered, to borrow James' terminology, something exciting. ${ }^{11}$ Prinz's theory, as well as other feeling theories, denudes the paradox of tragedy by asserting that the problem is largely a conceptual one, brought on by thinking of emotions as first and foremost containing propositional content, instead of initially as perceptions of bodily stimulation that are later evaluated by cognitive processes of the mind. In this description of emotions, the formal object of the emotion (the quality an intentional object must possess in order to elicit such an emotion; for example, an intentional object of fear must possess the formal object "danger"), does not require the cognitivist high standard of belief on the part of the person who is emotionally responding to the intentional object of the emotion. ${ }^{12}$ Given that most solutions of the paradox of tragedy assume at least a moderate cognitivist theory of emotion, it is unsurprising that in recent years, few new theories have been offered. Someone like Prinz, for example, might assert that we feel negative emotions toward

\footnotetext{
${ }^{10}$ For a concise understanding of James' theory, one might refer to his essay "What is an Emotion?" where he famously states "we feel sorry because we cry, angry because we strike, afraid because we tremble, and not that we cry, strike, or tremble because we are sorry, angry, or fearful, as the case may be."

${ }^{11}$ Jesse Prinz, "Embodied Emotions," in Thinking About Feeling: Contemporary Philosophers on Emotion, Ed. Robert Solomon, (Oxford: Oxford University Press, 2002), 55.

${ }^{12}$ Dimasio claims this, but Prinz attempts to retain a high standard for the formal object in his model.
} 
tragedy only incidentally, because we have built an "elicitation file" throughout our lives in response to certain negative stimuli, so that when we encounter a new negative situation in the form of tragedy, we respond to such a situation out of a kind of emotional habituation. Here, two different processes are occurring, a somatic reaction (the initial negative response) and a reaction that can be described semantically (the pleasure we take in the event), therefore the seeming conflict seems to weaken significantly. If "feeling" theories best describe emotions, such solutions, though a bit mundane, are certainly plausible.

Though the challenges described above have led to an interpretative stalemate, the paradox of tragedy is a compelling, and I believe, solvable dilemma. In my survey of the literature on the paradox, I have encountered few lengthy discussions on the subject that take seriously either (a) or (b), and in my dissertation project I intend to utilize a particular artifact, the play Long Day's Journey into Night, as a means to test my own, albeit very limited, solution to the paradox.

Readers unfamiliar with the literature surrounding the paradox of tragedy but loosely familiar with Aristotle's Poetics might notice and complain that I do not discuss Aristotelian catharsis as a potential solution to the problem posed of emotion posed here. After all, does Aristotle not offer a coherent account of tragedy, asserting that its telos is the "purging of the emotions through the arousal of fear and pity?" There are several problems with an assertion of catharsis as a potential solution to the Paradox of tragedy, chief among them is the fact that, as Stephen Halliwell points out, despite what Aristotle provides, it is unclear what catharsis actually is, and there is little interpretive agreement 
in Aristotilean literature about this concept as well. ${ }^{13}$ In contemporary culture, however, the common conception of catharsis is that the term refers to the phenomenon of people reporting feeling better after having a good cry. Unfortunately, there is no empirical evidence to support the claim that such an effect actually exists. ${ }^{14}$ Because the concept of catharsis is so fuzzy, and the empirical evidence from cognitive and behavioral psychology does not seem to support its existence, it seems an insurmountable task to utilize catharsis as a component of a theory of tragic pleasure. Therefore, although Aristotle's understanding of tragic emotion is likely insightful in certain ways, I do not utilize his approach in this essay.

Readers more familiar with the paradox of tragedy will likely notice two more omissions in the discussion that follows, and these omissions might raise questions about my methodology in crafting a solution to the Paradox of Journey. First, one might fairly point out that my discussion does not rely on a specific conception of what constitutes an emotional state. In current philosophical discourse on emotion, there is some controversy about whether emotions should be classified as primarily mental events or physiological responses to stimuli. In chapter two, I will discuss in detail the divide between theories of emotion referred to as cognitivist and those known as "feeling" theories and how these theoretical distinctions might impact an analysis of Long Day's Journey into Night, but here it is unnecessary to stake a claim in this debate, for at least three reasons. Harold points out that those thinking about the problem of negative emotion in art need not make

\footnotetext{
${ }^{13}$ The Poetics of Aristotle, trans. Stephen Halliwell (University of North Carolina Press, 1987), 90.

${ }^{14}$ For more on this, the reader might consult either (or both) Paul Bloom, How Pleasure Works: The New Science of Why we Like What we Like, (New York: W.W. Norton and Company 2010), 192; or Clark McCauley, "When Screen Violence is not Attractive" in Why We Watch: the Attractions of Violent Entertainment, Edited by Jeffrey Goldstein, (New York, Oxford University Press), 1998. 147-149.
} 
a choice between cognitivist and "feeling" (also known as "Jamesian") descriptions of emotions when crafting a solution,

First, for all the differences between the two approaches, there are many similarities. The cognitivists grant that physiological response is an important part of emotional experience, and the Jamesians agree that emotions can and often do lead us to cognize the world differently. They agree that in a wide range of cases, bodily feeling and belief are both very important to emotion. Second, the kinds of emotional conflicts that are of interest here can arise under either theory: for the cognitivists, it arises as a conflict between judgments, and for the Jamesians, it arises as a conflict between bodily feelings that have opposing valences. ${ }^{15}$

In other words, the paradox seems to stand, regardless of one's view on the nature of emotional life.

The final reason one need not commit herself to a particular view of emotion when working on this problem lies in the way in which the paradox has been formulated here. If one were to formulate the paradox of negative emotion and Long Day's Journey into Night as follows, she would likely need to defend a robust depiction of the emotions to craft a solution:

1.People of normal mental constitution do not enjoy experiencing sadness, fear, and disgust.

2.People of normal mental constitution experience sadness, fear, and disgust when they watch Long Day's Journey into Night.

3.People of normal mental constitution enjoy watching performances of Long Day's Journey into Night.

This "hedonic" formulation of the paradox compels a solution that is robust with specific depictions of what emotions really are, but such a formulation is outside the scope of my project. I have formulated this problem in terms of motivation instead of hedonism, and though a solution to the above paradox that relies on precision in emotional vocabulary might help solve the hedonic version of this paradox, I hope to craft a solution that does

\footnotetext{
${ }^{15}$ James Harold, "Mixed Feelings: Conflicts in Emotional Responses to Film," Midwest Studies in Philosophy 34, (September 2010), 281.
} 
not rely on what I believe to be still a burgeoning field where consensus has not yet been reached. I believe that the motivational solution I will ultimately propose will stand regardless of shifts in approaches within emotion theory.

The third major complaint one might have about my approach to solving the paradox of tragedy is that I will not develop a robust explanation for how fictional narratives elicit emotional states sans the requisite beliefs the viewer has about the reality of such events. There is a great deal of literature regarding the so-called "Paradox of Fiction" that could be explicated and utilized on this point, and one might suggest that my solution should refer to these approaches. I deem such discussion, though tangentially relevant to my thesis, as an unnecessary avenue for providing a coherent reformulation of (2) for two reasons: First, the scope of this project focuses, as I have pointed out above, on the motivational component of this problem, and not the hedonic component of the problem. The Paradox of Fiction is primarily concerned with the affective states a work of fiction elicits, and I am primarily concerned with the reasons one would subject herself to such conditions. Secondly_ and relatedly — though there may be little agreement about how this engagement of emotion occurs with respect to fictional narrative, there is little doubt that fiction does elicit emotion. How best to characterize such experiences is a separate (though related) question that is also beyond the bounds of the discussion at hand.

As I have mentioned above, the Paradox of tragedy has fallen out of the mainstream discussion in philosophical aesthetics, and I believe that a dissertation-length inspection of the issue in terms of Long Day's Journey into Night will provide not only a plausible solution to the problem but also a method whereby the problem might be 
examined in other artistic contexts and genres. Not only will this paper be relevant to those with an interest in philosophical aesthetics, it will also interest Theatre Studies scholars and practitioners as well. For those interested in interpreting or presenting the play, I believe the close connection that I make between Journey and Birth of Tragedy provides an important thematic through-line that to my knowledge has not been made explicit in the scholarship surrounding the play. More generally, I believe my solution to the problem of emotion and Long Day's Journey provides a powerful reason audiences should participate in difficult theatre such as Journey: there is a unique positive emotional response one can derive from being a part of a performance of Long Day's Journey into Night, as I will now show. 


\section{CHAPTER ONE TRAGEDY AND THE DENIAL OF NEGATIVE RESPONSE}

\subsection{Introduction}

In the introduction to this essay, I have formulated the paradox presented by the positive reception of Long Day's Journey into Night as follows:

1.People generally avoid situations that arose negative emotions, and pursue situations that arouse positive emotions.

2.People have negative emotional responses to performances of Long Day's Journey into Night.

3.People pursue performances of Long Day's Journey into Night.

One way one might resolve the problem is by denying that people have negative emotional responses to tragedy. Indeed, a question worth asking is whether tragedy really make us feel all that bad? We might cry or feel pity for the fate of a tragic hero or heroine, but can we really feel as badly about the fate of Ophelia or Antigone as we might about a victim of horrible violence in the real world? A family of proposed solutions to the paradox of tragedy suggest that such negative aesthetic experiences are not significantly similar to real-world pain. In the following chapter, I will examine and critique three proposed solutions to the problem of negative emotion and Long Day's Journey into Night drawn from the conventional philosophical discussion of the Paradox of tragedy, and I will conclude that while each approach does have some explanatory scope and power, there is at least one feature of the phenomenon each of these solutions 
fails to sufficiently describe. The common thread that runs through each of the theories that follows is that each of these theories denies that viewers experience significant negative emotional states in response to tragedy generally and can be ruled out as options that apply to viewer's experience of Journey specifically. As each of these explanations fail, their critiques will clarify the criteria a robust solution to the problem of negative emotion and Journey for which it ought to account.

\section{2 "Better You than Me"}

There is a potentially ugly resolution to the problem of negative emotion in art, a resolution is perhaps inspired by ancient Stoic philosophy ${ }^{1}$ and is seemingly verified in the contemporary world on a daily basis. Smuts points to an all-too-familiar phenomenon from daily life, "one of the obvious drawbacks of living in a commuter city is the inevitable traffic jams that result from rubbernecking — drivers slowing down to get a good look at an accident, hoping to catch a glimpse of a gruesome scene." ${ }^{2}$ It is a grim reality that people have strange curiosity about and often seemingly derive pleasure from witnessing the misfortune and suffering of others. Lucretius asserts that people do this "not because it is joy or delight that anyone should be storm-tossed, but because it is a pleasure to observe what troubles you yourself are free."3 Perhaps however, beneath the veneer of culture and compassion, one possible explanation for our enjoyment of others misfortune is that most people are secret sadists who take pleasure in suffering that is not their own. Though this is a sobering thought, such an account provides an explanation for

\footnotetext{
${ }^{1}$ Lucretius, The Hellenistic Philosophers, vol. 1, trans. Anthony Long and David Sedley,(Cambridge: Cambridge University Press, 1987), 120.

2 Aaron Smuts, “Art and Negative Affect," Journal of Aesthetic Education 41:3 (Fall 2007),

${ }^{3}$ Lucretius, The Hellenistic Philosophers, 119-120.
} 
audience's attraction to tragedy: people watch tragedy because they enjoy watching others experience pain.

Such a theory denies that audiences experience any negative emotion as a result of tragedy. When one watches Long Day's Journey into Night, for example, she ultimately does not feel pity or despair for the Tyrone family, but instead experiences pleasure as she watches them suffer, perhaps because she believes that they have each done something to deserve it. This approach to the nature of tragic emotions would require the following re-formulation of (2):

Revised Statement of PoT: Because people enjoy watching the suffering of others, they experience positive emotional states when viewing performances of Long Day's Journey into Night.

If this assessment represents the reality of tragic experience, a consequence of this is that the morality of watching Long Day's Journey into Night would be called into question. Most mainstream ethical theories would correctly criticize a practice that caters to human tendencies to place others in any sort of pain for the gratification of an audience. If this Stoic position best characterizes what happens when an audience pursues tragedy, perhaps performances of Long Day's Journey into Night ought be viewed with the same derision with which most Westerners view cock-fighting. One defending the Stoic position on ethical grounds might assert that viewing Long Day's Journey is a harmless substitute for actually watching others suffer in the real world, however this position seems a difficult one to sustain while holding to most conventional moral frameworks. Most ethical theories would not find simulated cockfighting an acceptable substitute for watching the real thing, so how can one morally justify simulated suffering in the theatre? 
Though this theory has ethical costs, those costs do not rule this theory out as a possible resolution to the paradox of tragedy. However, the "Better You than Me" approach fails because it does not adequately account for the fact that people actually report feeling a great deal of pity and sympathy for those who suffer in an aesthetic tragedy. It would be strange for a viewer to report pleasure when watching Oedipus because Oedipus "got what was coming to him." Instead, the viewer suffers with the tragic hero because he recognizes the disgust and shame Oedipus faces.. A significant feature of tragic power is the capacity of tragedy to elicit pity for and outrage at the fate of those who suffer, whether that suffering is just or unjust. Further, even if the Stoics are correct in assessing the pleasure we take in the suffering of others who are not close to us in the real world (i.e. traffic accidents), it does not follow that we take the same sort of pleasure in aesthetic tragedy.

A study performed at the University of Alberta lends support to the claim that the aesthetic representation of suffering actually heightens a viewer's ability to experience empathy. Participants classified as typically "low empathizers" (young male adults) were presented with several narratives that portrayed melodramatic situations designed to elicit an empathetic response. When these participants were informed the narratives they were reading were reporting actual events, these low empathizers reported very little emotional response to the characters within the stories. When, however, the participants were informed that the events and characters depicted within the narratives were the product of an author's creativity, this group of young men reported significantly higher emotional responses — responses such as sadness and pity_-because they felt freer to do so (likely because of gender stereotypes such as "big boys don't cry") than they would have if they 
were responding to a real-world scenario. ${ }^{4}$ Because of the perceived artificiality of the narrative, men felt stronger feelings of empathy toward the characters portrayed than they would have if they perceived the account as factual. While one study does not provide exhaustive empirical evidence that fictional accounts elicit more empathetic responses than real world situations, this study does suggest that the Stoic intuition about people deriving pleasure from other's pain does not apply to the emotions one experiences when she views tragedy, much less Long Day's Journey into Night, because even if the Stoic assumption is correct about people's experiences in the real world, the aesthetic nature of the emotional encounter one has with the play produces more empathy and pity than real life stimulus.

In order to sustain the Stoic approach as a resolution to the Paradox of tragedy, one would have to deny the reality of pity, empathy, and similar emotions elicited by aesthetic narratives. When a viewer says, "I really felt sorry for Edmund Tyrone," the Stoic reply would be to deny that the viewer is accurately reporting her feelings. This denial flies in the face of the plainest experience of tragedy, and renders such statements about empathetic emotions elicited by tragedy absurd. Since viewers do experience real attachments to the characters who suffer in tragedy (hence the viewer's continued engagement with the narrative), the Stoic position cannot be a viable solution to the problem of negative emotions and Long Day's Journey into Night.

\subsection{Tragic Conversion}

\footnotetext{
${ }^{4}$ Jennifer J. Argo, Riu Zhu, and Darren W. Dahl, "Fact or Fiction: an Investigation of Empathy Differences in Response to Emotional Melodramatic Entertainment," Journal of Consumer Research 34 (February 2008), 614-623.
} 
Another solution that denies audiences experience negative emotion when viewing tragedy is Hume's own, as presented in "Of Tragedy." Hume wonders about the phenomenon of tragic enjoyment. Why is it that in an aesthetic situation, viewers experience pleasure by viewing a tragedy, though they are moved to tears of fear and pity by the portrayal of those horrible events that unfold before them? How can one "enjoy" negative emotions stimulated through theatrical tragedy?

Hume begins by examining a solution to the problem credited to French philosopher Jean-Baptiste Dubos. Dubos, according to Hume, asserts that "nothing is in general so disagreeable to the mind as a languid, listless state of indolence into which it falls upon the removal of all passion and occupation." If this is the case, then any emotional state is more pleasant than dull boredom. If one is moved to tears by the viewing of a dark tragedy, she has found a cure to the malaise of day-to-day life, and the resulting emotion will be welcome to the viewer.

Though Hume thinks that Dubos' theory possesses some explanatory force, ultimately this solution does not provide a robust enough account for his taste. He points out that there is a significant difference between the stimulation one receives from fictional portrayals of negative events and similar negative events experienced in the actual world. No matter how bored one may be, it is unlikely that a normal human being would wish to witness egregious suffering in the real world, no matter how bored she was. No decent person would wish to observe a violent murder, for example, as a cure for boredom. However, such an event portrayed fictionally can bring intense pleasure to the viewer. Dubos' solution does not explain the different responses one might experience given the fictionality or reality of the situation.

\footnotetext{
${ }^{5}$ Ibid., 217.
} 
Laying aside Dubos' proposed solution, Hume next considers the solution offered by Monsieur Fontenelle. Fontenelle's solution resembles contemporary "control" theories. Fontenelle asserts that pleasure and pain do not differ so much in their causes. Pleasure and pain are very closely related, so that "sorrow soft and agreeable" might be called a mild form of pleasure. In the case of theatrical tragedy, though we are moved toward the fate of the tragic hero, we are constantly aware that we are watching a play, and in this context we can experience the enjoyment of watching the play, further heightened by our sorrow for the fate of the tragic hero. This theory might be referred to as a meta-response theory of sorts, as it does suggest the possibility of simultaneous opposing affective states. ${ }^{6}$

Hume critiques this solution because it fails to account for the enjoyment one might take from the description of actual horrific events. As an example of this, Hume discusses Cicero's narrative of the Sicilian captains by the Verres. Apparently, though this account is quite graphic and describes actual events that occurred in the real world, the listener is able to immensely enjoy the retelling of this story. Were Fontenelle correct, the listener could not get pleasure from this retelling, because the listener would realize these grave events actually occurred in real life.

From this objection, Hume is able to draw his own solution to the paradox of tragedy. He writes:

this extraordinary effect proceeds from that very eloquence with which the melancholy scene is represented. The genius required to paint objects in a lively manner, the art employed in collecting all the pathetic circumstances, the judgment displayed in disposing them: the exercise, I say, of these noble talents, together with the force of expression and

\footnotetext{
${ }^{6}$ A more sophisticated meta-response theory proposed by Susan Feagin will be discussed and defended in the conclusion of this essay.
} 
beauty of oratorial numbers ...diffuse the highest satisfaction on the audience, and excite the most delightful movements. ${ }^{7}$

Here, Hume claims that the viewer obtains pleasure not from the negative events that are portrayed on the tragic stage, but that her pleasure comes from the aesthetic quality of the portrayal of such events. It is the eloquence with which the author expresses the painful circumstances of tragic events that pleases the viewer.

Elisa Galgut explains that Hume's theory of tragic conversion relies on his understanding of the emotions as communicated in his analysis of the passions. She writes that "for Hume, an emotion is comprised of three distinct entities: an ideational content (which consists of a propositional attitude directed toward an intentional object), an affect, and a quantity of energy." ${ }^{8}$ To illustrate, Galgut provides a Biblical example. On a Humean account, "Adam feels pleasure of a certain degree in relation to the object of his affection, that is, Eve." ${ }^{\prime 9}$ Adam's propositional attitude toward Eve is love, the affect of this emotion (the phenomenological experience of the emotion) is pleasure, and the quantity of the emotion is the degree of intensity with which he feels this emotion toward her.

The eloquence of a well-written tragedy transforms the subordinate emotion (sorrow or pity) into a predominant experience of joy. The propositional attitude and intentional object of the audience's attention shifts away from the horror of the play to the beauty with which it is written, and the degree of intensity with which one felt the original horror and pity is now redirected powerfully toward this beauty. ${ }^{10}$

\footnotetext{
${ }^{7}$ Ibid., 219-220.

${ }^{8}$ Elisa Galgut, "The Poetry and Pity: Hume's Account of Tragic Pleasure," British Journal of Aesthetics, 41, 4, (October 2001), 413.

${ }^{9}$ Ibid., 414.

${ }^{10}$ This is the dominant interpretation of Hume's theory, but Robert Yanal, in "Hume and Others on the Paradox of tragedy," Journal of Aesthetics and Art Criticism 49:1 (Winter 1991), 75-76, argues against this
} 
Hume provides no description of how this occurs, however, and the narrative here reads more like a supposition than a formula (more will be said on this below). He does offer some evidence that seems to support his claim, however. This support is presented indirectly, in that he provides examples in which passions aroused by lesser emotions rouse the predominant emotions. For example, Hume points out that "novelty" is generally considered an "agreeable" experience, but if one experiences an emotional state brought on by some new negative experience, the pain of that experience is heightened by the newness of it. In this way, the lesser passion is "converted" to the greater passion. Similarly, Hume points out that if a storyteller wishes to increase the dramatic impact of an event, she often can utilize suspense or "delay" to heighten the audience's response to that event. In Othello Act 3. Sceme 3, Othello's jealousy is accentuated by the emotion of impatience. The greater passion (jealousy) is heightened by the lesser one (impatience).

Hume continues to provide examples of the greater passion being somehow supported and transformed by the subordinate. He writes that parents are often most affectionately tied to the child who gives them the most grief. He also notes that there is no single factor that endears one to her friend than that friend's death. Hume then points out that jealousy is an emotion that provides a great deal of support for the dominant emotion love.

\footnotetext{
interpretation. He claims that "Hume's view is rather that our experience of tragedy is made pleasurable overall through the infusion of pleasure from the aesthetic qualities of the work, even though some portions of the overall experience are painful. The sorrow is not made pleasant, though our overall experience of tragedy may be." While Yanal does offer a reasonable argument for this claim, his view is certainly a minority interpretation of Hume and defies the fact that Hume explicitly claims that sorrow is transformed into pleasure. At this point in the essay, I wish to acknowledge this variant interpretation, but I will only directly critique the traditional reading, though this interpretation will emerge again in the chapter that follows.
} 
Hume's final piece of evidence to support the claim that subordinate emotions might be converted into dominant ones is drawn from Pliny the Elder's Natural History, in which Pliny notes that the greatest works of art are often unfinished. If one discovers that a sculptor has died before completing a sculpture, somehow that sculpture is more aesthetically compelling than other works. Pliny writes, "our very grief for that curious hand, which had been stopped by death, is an addition increase (sic) to our pleasure."11 Pliny here seems to validate Hume's assertion; the sorrow one might experience in relation to the loss of the artist somehow brings further delight to her appreciation of the unfinished work.

Hume believes that these examples confirm the essential element of his argument, particularly that subordinate emotions provide additional intensity for the dominant emotional state. He writes,

the force of imagination, the energy of expression, the power of numbers, the charms of imitation; all these are naturally, of themselves, delightful to the mind: and when the object presented lays hold of some affection, the pleasure still rises upon us, by the conversion of the subordinate movement into that which is predominant. The passion, though perhaps, naturally, and when excited by the simple appearance of the real object, it may be painful; yet is so smoothed, softened, and mollified, when raised by the finer arts, that if affords the highest entertainment. ${ }^{12}$

In the case of the paradox of tragedy, though the scenario presented to the viewer outside an aesthetic context might be painful to the viewer, within the realm of theatrical performance, for example, the viewer's dominating pleasure in imitation is reinforced by the intensity of the painful emotions elicited by tragic events unfolding onstage. To support this claim, Hume offers an additional counter-example. He writes of a parent who has lost his child. In this scenario, the parent's dominant emotion is one of pain, and

\footnotetext{
${ }^{11}$ Ibid., 223.

${ }^{12}$ Ibid., 223.
} 
were one to "exaggerate, with all the force of elocution, the irreparable loss,", parent's despair would be significantly heightened by the use of the imagination. In this scenario, the intensity of the subordinate emotion, pleasure in imitation, has added to the intensity of the dominant emotional state, grief.

Certainly something about Hume's argument rings familiar, but does he provide a coherent narrative that explains a viewer's engagement with Long Day's Journey into Night? In order to put his view to the test, one might formulate Hume's revision of (2) as follows:

Revised Statement of PoT: Because of the aesthetic beauty of Long Day's Journey into Night, the energy of people's negative emotional responses to the performances of the play are converted to a powerful positive emotional response to the play.

Though Hume's examples seem to appeal to intuitions about the nature of emotions, ultimately, his version of (2) fails in at least three ways. First of all, Hume fails to provide a satisfying description of the mechanism which makes such a conversion possible. What components are necessary to transform the intensity of a powerful emotion from one valence to another? His claim that "the force of imagination, the energy of expression, the power of numbers, the charms of imitation," somehow cause this transformation is merely an assertion that is inadequately defended. Susan Feagin complains of Hume's theory:

...it is not clear how the 'dominance' of imagination and expression is to be achieved...More puzzling, however, is the process of 'conversion' which imagination performs on the unpleasant feelings (and which those feelings, when dominant perform on the natural pleasantness of the imagination). Pains are not merely mitigated by the pleasure, but converted or transformed into something different. The mechanics of this conversion are never explained. ${ }^{14}$

\footnotetext{
${ }^{13}$ Ibid.

${ }^{14}$ Susan Feagin, “The Pleasures of Tragedy,” American Philosophical Quarterly 20:1 (January 1983), 95.
} 
In order for Hume's theory to rise above an appeal to intuition, he would need to clarify and defend his view of emotion and offer a picture of how the intensity of an emotional state can feed and be transformed into an opposing emotional state.

Hume's idea of tragic conversion might be additionally critiqued by pointing out that rests on a shaky assumption, namely that it is impossible to experience "mixed feelings." Hume's theory seems to assume that one can only meaningfully experience one sort of emotional state at a time, and this is likely not the case. Flint Schier remarks that "Hume was right to suggest that tragedy involves a duplex experience, as of attending to the tragic hero and to how the actor plays him; he was wrong, I think in supposing that these two experiences become fused...in the theatre we simultaneously feel emotions of distinct hedonic change and intensity and there is no need to suppose that these emotions lose their identities in the alchemy of association." ${ }^{15}$ Schier's intuition that one can experience emotional states of opposing valence seems to be confirmed by the findings of experimental psychology. There is a strong empirical case that people have the capacity to feel tangible and conflicting feelings in response to aesthetic stimuli simultaneously. ${ }^{16}$ The idea of mixed feelings is still a somewhat controversial notion in cognitive psychology, but there are several good reasons to accept that people can experience identifiable emotions of opposing valences simultaneously. As cognitive researchers learn more about the brain and its relationship to emotional

\footnotetext{
${ }^{15}$ Flint Schier, “The Claims of Tragedy,” Philosophical Papers 18:1 (1989), 18.

${ }^{16}$ On this point, the reader can consult Jeff T. Larson, et al., "Can People feel Happy and Sad at the Same Time?" Journal of Personality and Social Psychology, 81: 4 (October 2001), 684-696; Ulrich Schimmack, "Pleasure, Displeasure, and Mixed Feelings? Are Semantic Opposites Mutually Exclusive?" Cognition and Emotion, 15:1 (2001), 81-97; David Watson, et al., "Development and Validation of Brief Measures of Positive and Negative Affect: The PANAS scale." Journal of Personality and Social Psychology 54:6 (June 1998), 1063-1070; Patti Williams and Jennifer Aaker, "Can Mixed Emotions Peacefully Co-Exist?" Journal of Consumer Research 28 (March 2002), 636-649.
} 
states, it appears that different areas of the brain are associated with negative and positive emotional states, and there is some evidence that the brain can fire in these areas simultaneously. Joseph LeDoux has concluded that the amygdala is the main cortical center for negative emotional states, ${ }^{17}$ and evidence indicates that happiness typically requires participation of the pre-frontal cortex. ${ }^{18}$ These brain areas can operate in isolation from one another as well as simultaneously, and coupled with evidence drawn from psychological studies, the best explanation is that people can experience such simultaneous states. Using a model for efficiently testing awareness of affective response, Jeff Larsen et al. demonstrated that students placed in emotionally ambiguous experiences were able to report both happy and sad feelings. ${ }^{19}$ Andrade and Cohen confirmed similar findings in their study of emotional responses to horror films. ${ }^{20}$ With the weight of the conceptual and scientific evidence, one ought to conclude that mixed emotional states are not merely a figure of speech, but a reality.

Hume's attempt to consolidate both emotional states into a single, unified, intense feeling of pain-pleasure, fails because it relies on a faulty assumption, that people cannot experience positive and negative emotional states at the same time. However, people frequently are able to experience multiple emotional states which they can readily describe in terms of both affective and propositional difference. As this is the case,

\footnotetext{
${ }^{17}$ Joseph Ledoux, The Emotional Brain: The Mysterious Underpinnings of Emotional Life, (New York: Touchstone, 1996).

${ }^{18}$ Gregory F. Ashby, Alice M. Isen, and U. Turken, “A Neuropsychological Theory of Positive Affect and its Influence on Cognition," Psychological Review 106 (July 1999), 529-550.

${ }^{19}$ Jeff T. Larsen, Catherine J. Norris, and John T. Cacioppo, "The Evaluative Space Grid: A Single-Item Measure of Positive and Negative Evaluative Reactions," working paper, (Department of Psychology, Texas Tech. University, Lubbock), 2005.

${ }^{20}$ Eduardo B. Andrade, and Joel B. Cohen, "On the Consumption of Negative Feelings," Journal of Consumer Research 24 (October 2007), 283-300.
} 
Hume's account becomes superfluous as it adds an unnecessary complexity to a description of tragic emotional experience.

Even if the above objections are ultimately unsuccessful in invalidating Humean conversion theory, one might point out that Hume himself offers a significant caveat that undermines his approach as a whole. He offers an account that describes how disagreeableness of the scenario presented onstage might be so graphic that the pleasure one receives from the tragedy might be overcome by the horror and disgust the viewer experiences in relation to the onstage action. Hume cites Nicholas Rowe's The Ambitious Stepmother as an instance of such a graphic depiction. In the play, a "venerable old man, raised to the height of fury and despair, rushes against a pillar, and striking his head upon it, besmears it all over with mingled brains and gore. ${ }^{21}$ In this case, it would seem that the aesthetic artistry employed by Rowe has taken a back-seat to the crudeness of the event depicted. As a result, the viewer cannot take pleasure in the play, but only be disgusted and horrified by it.

This passage provides an unresolved problem for Hume's theory, given the fact that Rowe's play was enjoyed by many theatregoers of Hume's day. ${ }^{22}$ If Hume intends to provide an account for how one might enjoy negative events in an aesthetic setting, his inclusion of this example is counter-productive. Here, it seems as if his theory is slipping from an explanation of how one enjoys tragedy to how one ought to enjoy tragedy. Hume seems to be saying that there are things that ought to horrify moral people, even presented in an aesthetic context. He does not, however, provide any sort of account for the fact that audiences (though perhaps uneducated in matters of taste) took tremendous

\footnotetext{
${ }^{21}$ Ibid., 224.

${ }^{22}$ Alex Neill, "Hume's 'Singular Phenomenon'," 115.
} 
delight from the besmearing of the venerable old man's head upon the pillar. As the essay concludes it becomes apparent that Hume is not presenting a robust account of tragic pleasure, but instead a limited and perhaps snobbish normative account that saves the "good" tragedies and ignores the bad ones. He seems to intend to use this example as a starting point for a sort of "poetic method" of incorporating negative emotions into artistic works. He concludes the essay by advocating a kind of poetic self-control with the portrayal of objects that might elicit negative response. The responsible tragedian tempers these negative objects with selective detail and artful delivery, so that the primary emotion of pleasure can be heightened by the conversion of the intensity of the painful emotion.

This final point is a serious problem for the theory as Hume presents it, and a contemporary defender of his view would likely have to jettison this value-laden component in order to offer conversion theory as a viable depiction of people's negative emotional response to art. Were she to do this, she still would have to offer a coherent account of how this conversion occurs as well as show that the within the context of tragedy, one experiences only one emotional state as opposed to a "mixed" emotional state, that of a heightened pleasure brought about by way of aesthetic beauty in the context of painful events. For these reasons, Hume's conversion theory fails as a plausible account for what goes on when one views and seems to enjoy Long Day's Journey into Night.

\subsection{The Joy Of Control}


Why is it thrilling to go bungee jumping or ride a particularly terrifying rollercoaster? One feature of such experiences is that while the participant certainly experiences a "rush," she never finds herself in any real danger. If, for example, the bungee cord were to snap and the jumper found herself hurtling uncontrolled toward the earth, the fun of bungee jumping would quickly slip away into terror for the jumper. Likewise, if one rode a roller coaster that flew from the tracks, it is doubtful that she would (provided she survived the event) later describe the ride as "enjoyable" or "exciting." It is more likely that a normal, well-adjusted human being would acknowledge that she was terrified by such an event. The difference in bungee jumping and roller coaster riding and experiences that genuinely cause one to fear for her life seems to be the degree of control she has over the events that she is facing.

This observation about the nature of control and pleasure has inspired a third way of denying the experience of significant pain in response to putatively painful art. Such denial might take the form of a "control" theory in the tradition of those articulated by John Morreall and Marcia Eaton. These theories argue that people pursue tragedy because in an aesthetic context people have more control over these emotions than they do in real life. These responses claim that we do not experience significant negative emotional states in response to tragedy because we have the ability to walk away from the experience at any time. As a result, we only experience as much emotional discomfort as we allow ourselves. This theory differs from the previous too in that it does admit that we might experience some incidental "pain" in our response to tragedy, but this pain is not nearly as palliative as pain felt in non-aesthetic contexts.

Aaron Smuts acknowledges that there is some empirical data that confirms this: 
Recent experiments on pain thresholds seem to support this conjecture. When subjects are able to say when the pressure on their finger should stop, they can take far more pressure and pain than if the experimenter does not give them the option. Subjects also report feeling greater amounts of pain when they are unable to control the experiment. ${ }^{23}$

Furthermore, experiments conducted at the University of California at Berkeley seem to confirm a similar hypothesis - a hypothesis more directly related to aesthetic stimulations of negative emotional states than those Smuts references. Students averse to horror films were asked to watch clips from Salem's Lot and The Exorcist and using computer software based upon the Positive and Negative Affect Schedule, ${ }^{24}$ asked to evaluate their positive and negative emotional responses to the clips. Students who did not enjoy horror films initially reported that they experienced little enjoyment of the clips. These students were then shown clips from a horror film in a window on a computer screen that was framed by information about the film (images and short bios of the actors playing the roles in the given clips as well as other items of trivia regarding the film), and they were asked to report their responses again. In the second experiment, students typically averse to horror films report a marked improvement in their enjoyment and a decline in their displeasure toward the horror films they viewed. It appears that one of the key components of these students positive response to the film was a degree of controlled distance the viewer is able to maintain from the suspenseful and horrific images displayed. The "reference frame" surrounding the clip became a buffer that not only helped the horror-averse student cope with fright and suspense but also improved her

\footnotetext{
23 Aaron Smuts, "The Paradox of Painful Art," Journal of Aesthetic Education 41:3 (Fall 2007), 65.

${ }^{24}$ David Watson, Lee Anna Clark, and Auke Tellegen, "Developments and Validation of Brief Measures of Positive and Negative Affect: the PANAS scale," Journal of Personality and Social Psychology 54 (June 1988), 1063-1070.
} 
enjoyment of the clip. ${ }^{25}$ A control theorist would likely point to such experiments as validation for her claim that people enjoy putatively painful art only when the negative emotional impact can be properly managed and seems appropriately distant as a result.

Morreall offers a compelling control-based resolution of the paradox of painful art in his essay "Enjoying Negative Emotions in Fiction." In his essay, he attempts to show that many real-life emotional experiences can best be understood as manageable based upon a person's level of control of those affective states. With this foundation laid, he claims that the negative emotions generated by tragedy are of little significance compared to the pleasure the viewer takes in her ability to manage her emotional response based upon a set of control criteria.

Morreall begins by asserting that what might be exciting about certain negative emotional states is that they awaken people psychically and offer escape from the doldrums of life. In his analysis of fear, he acknowledges the incredible physiological changes that occur when one finds herself in such a state. He writes that in fear we experience dramatic changes in the nervous and endocrine systems that prepare one to fight or flee for the sake of self preservation, and it may be that, "for someone who leads a relatively dull life, the stimulation provided by fear can be pleasurable by contrast with the ordinary lack of stimulation." ${ }^{26}$ This statement is reminiscent of Dubos description of the pleasures of tragedy in Hume's "Of Tragedy." Fear may be physically enjoyable for the stimulation it provides, however Morreall agrees with Hume that fear is only exciting within limits. If a skydiver's parachute fails to open, for instance, she no longer finds

\footnotetext{
${ }^{25}$ Eduardo Andrade and Joel B. Cohen, "On the Consumption of Negative Feelings," Journal of Consumer Research 34 (October 2007), 283-300.

${ }^{26}$ John Morreall, "Enjoying Negative Emotions in Fiction," Philosophy and Literature 9:1 (April 1985), 96.
} 
herself enjoying the rush of the fall and instead finds herself in a state of terror. Using examples of other "disagreeable" emotional states such as anger and sadness, Morreall argues that "we can enjoy negative emotions only when we retain control of our overall situation. ${ }^{27}$

One might respond by questioning what counts as control in this context. In response to this question, Morreall establishes three criteria for a person's feeling "incontrol." First of all, he claims that "control is usually easiest to maintain when we are merely attending to something which has no practical consequences for us, as when we watch from a distance some event unrelated to us. ${ }^{28}$ For example, one might enjoy watching a YouTube video of a car crash at a race, as she does not know the driver, or even if the event she views actually occurred. In this case, she may be merely enjoying the spectacle of an incredible auto accident. Next, Morreall's analysis reveals that the advantage that this distance offers the viewer is that she has the ability to "stop, start, and direct the experience." If I choose to watch a sad movie on television, for example, I maintain control because I have the capacity to turn the channel, and this ability empowers me to maintain control and enjoy the physical sensations delivered by mild negative emotional states while enjoying myself. Lastly, Morreall argues that in order for control to be maintained, the emotion elicited by the stimulus must not be too strong. In an aesthetic context, he writes, "part of an artist's job is to present that situation in such a way that we can stay in control while feeling negative emotions, so that we can get satisfaction from the experience, rather than being overwhelmed or utterly distressed by

\footnotetext{
${ }^{27}$ Ibid., 97.

${ }^{28}$ Idid.
} 
it. ${ }^{29}$ Here, he agrees with Hume that even in an aesthetic context, it may be possible to elicit emotions that are so strong that the viewer is no longer able to enjoy the experience but is instead overcome by the powerful emotions elicited by a work.

For Morreall, then, these three criteria (distance, the ability to start, stop, and direct, and the emotional stimulation is not too strong) are met in good tragedy, and as a result, the viewer is able to characterize her experience as one of enjoyment and the negative emotions she experiences are ultimately not significantly powerful. If examining this phenomenon as it relates to Long Day's Journey into Night, the control theorist would formulate (2) as follows:

Revised Statement of PoT: Because people are in control of their relationship and emotional response to performances of Long Day's Journey into Night, on the whole, they do not experience significant negative emotional states as a result of viewing the play.

Unfortunately for this approach, it fails upon close scrutiny. First of all,

Morreall's conception of "control" based upon his established criteria is highly dubious. ${ }^{30}$ Robert Yanal points out that there are significant reasons to doubt Morreall's account of control. On Morreall's analysis, in order for the emotion of pleasure to emerge as a result of painful art, that work must hold no "practical consequence" for us, or we must be able to "stop, start, and direct" our attention to it, or if the emotion it inspires is not "too strong," then we will be able to control it. Yanal attacks the first condition by pointing out that there a number of possible real-world instances in which we might observe a situation of no practical consequence to us but still feel powerful negative emotions about

\footnotetext{
${ }^{29}$ Ibid., 101.

${ }^{30}$ Morreall is not the only theorist who proposes a definition for the term control. In her essay, "A Strange Kind of Sadness," Marcia Eaton (Journal of Aesthetics and Art Criticism 41:1, Autumn 1982, 51-63). proposes two criteria for control, and Morreall sees his approach as building upon and improving her criteria to create a more exact and coherent approach. For the purposes of this essay, it is enough to criticize Morreall's conception of control, as objections raised against Morreall's theory apply to Eaton's as well.
} 
or toward those involved. ${ }^{31}$ In no real sense can I intervene at this moment in conditions of starvation in Somalia, nevertheless, I find myself moved by the plight of the children of a country ravaged by famine. One might suggest that in some way, I can help in a way that I cannot with the fate of King Lear, and this is why I am feel real, significant pity for Somalia as opposed to Lear, however it is difficult to see what actions I could take that would directly impact the lives of those involved in Somalia. In other words, there is no appreciable difference in my feelings of pity and sadness toward tragedy and those I experience toward actual conditions in the real world which arouse such emotions. It would seem then, that control is only achieved when one cannot anticipate the possibility of taking action, and that anticipation is grounds for painful experience.

Next, Yanal criticizes Morreall's claim that the ability to stop and start the experience is what allows us to feel in control of the fictional situation, as Morreal is quick to point out that at times we put down a book precisely because it elicits too strong an emotion. How can this be, however, if in this situation, we have been in control the entire time? Morreall's theory cannot account for how this is possible. Additionally, Morreall claims that a third criterion of "weakly felt emotion" is a condition of control, but in order for this to be true it seems to follow that all emotions elicited by tragic art must be weakly felt, and this is plainly false, as powerful emotions can be aroused by fictional tragedy.

Though Morreall's conception of control is fraught with intractable difficulty, it is possible that he and other theorists who defend a control-based framework are generally describing what happens in people's response to negative art. Perhaps all that is needed

\footnotetext{
${ }^{31}$ Robert Yanal, Paradoxes of Emotion and Fiction, (University Park, PA: Penn State University Press, 1999), 147.
} 
is a modification of the existing criteria that supposedly constitute control. After all, as pointed out above, there is some empirical data that supports such the hypothesis that in certain contexts, controlled negative emotional states might be characterized as pleasant. Unfortunately however, regardless of one's conception of control, this family of approaches to the paradox of tragedy ultimately fails in several key respects.

One critique Yanal offers of all control theories is that there often is intense pleasure to be had from losing control of one's emotions. Control is often associated with a kind of miserable restraint. For example, I may have a tremendous problem with my boss, but instead of airing my grievances, I—for the sake of my job—grit my teeth and clench my fists every time he enters the room. It is often very satisfying to lose control and rage unabated or cry without restraint, and perhaps this is what occurs when a person views tragedy. ${ }^{32}$ Control based theories do not have much explanatory power with respect to this phenomenon, as this is the opposite of what they predict.

Aaron Smuts offers a similar critique of control-based theories. He points out that "our emotional responses to fiction are not completely, or even to a high degree, controllable." ${ }^{, 33}$ If one is deeply saddened by her viewing of a play or film, that sadness does not always end at the close of the curtain or as the credits appear on the screen. Often, the most poignant works of art are marked by the emotional power they exercise over people after they are finished, and it is certainly familiar to describe oneself as being "moved for days" by some powerful tragedy. Many empirical studies confirm this claim. Clark McCauley, utilizing the available empirical research on negative emotional states and film, shows that strong negative emotional states elicited by narrative art typically

\footnotetext{
${ }^{32}$ Robert Yanal, Paradoxes of Emotion and Fiction, 148.

${ }^{33}$ Aaron Smuts, "Art and Negative Affect," Philosophy Compass 4:1 (2009), 46.
} 
amplify pre-existing negative emotional states instead of mollifying it. Aggressive young men, for example, who watch a violent film tend to report feeling more aggressive after the film ends. ${ }^{34}$ Though the empirical data cited earlier (Andrade and Cohen) supports the idea that people who are predisposed away from certain negative emotional states gain more enjoyment from negative aesthetic stimuli when that stimuli is presented to them in a controlled frame, it does not falsify the fact that people still feel significant negative emotional states as a result of such stimuli. In light of the abundant evidence McCauley cites, it is wise to conclude that control theories have misrepresented the significance of the negative emotions one experiences in response to "painful" art. Since control theories have little to say about this phenomenon, at best they are incomplete.

A final objection one ought to raise against control-based resolutions of the paradox of tragedy is that they do not answer what Smuts refers to as the "motivational question," namely, what motivates audiences to pursue works of art that elicit negative emotions while they endeavor to avoid such emotions in their daily lives? Even if control theories accurately describe most people's relationship to "painful" art, they still do not provide a reason that people pursue such art. Even if people experience positive emotional states as a result of being able to control their negative affections toward art, why not pursue art designed only to evoke cheerful emotional states? Any satisfactory restatement of (2) ought to at least suggest what motivates audiences to pursue performances of works of art such as Long Day's Journey, but control theories (even if successful) do not provide even a glimpse at why this is the case. On this question, control theories are silent, and for this and the reasons states above, this family of

\footnotetext{
${ }^{34}$ Clark McCauley, "When Screen Violence is not Attractive," in Why We Watch: The Attractions of Violent Entertainment, Edited by Jeffrey Goldstein, (New York: Oxford University Press, 1998), 147-149.
} 
theories fails as a candidate for an explanation of what goes with respect to a viewer's relationship to Long Day's Journey into Night.

\subsection{Conclusion}

In this chapter I have surveyed and critiqued three proposed resolutions the problem of negative emotion and Long Day's Journey into Night. These resolutions attempt to deny that viewers of the play (and tragedy in general) experience significant and powerful negative emotional reactions to the narrative they watch. I have shown that as an overarching theories of negative emotion in relation to art, each theory fails to adequately account for (1)the actual emotional attachments and responses elicited by the tragedy in general and Long Day's Journey particularly, and (2)the "motivational question,"35 an answer to the question of what motivates audiences to participate in such "painful" experiences. As a result, one cannot resort to these explanations to account for the negative emotional address of Long Day's Journey into Night. Given that these theories fail, one will have to turn elsewhere for a robust account of this phenomenon. In the chapter that follows, I will examine a related resolution the problem, using a close, hermeneutical method that will falsify that resolution as well as further validate the claim that audiences experience powerful negative emotions in their relationship to Long Day's Journey into Night.

\footnotetext{
${ }^{35}$ Aaron Smuts, "The Paradox of Painful Art," 60.
} 


\section{CHAPTER TWO PARSING THE NEGATIVE ADDRESS OF LONG DAY'S JOURNEY INTO NIGHT}

\subsection{Introduction}

In the previous chapter, I argued that the family of resolutions to paradox of tragedy that deny the existence of powerful negative emotions elicited by tragedy fail to provide an adequate description of what goes one when one views a play such as Long Day's Journey into Night. In light of this discussion, perhaps the reader has become aware of another related, and intuitively possible, resolution to the paradox. In the chapter that follows, I will examine this possibility, one articulated by Robert Yanal's minority interpretation of Hume's “conversion” theory. According to Yanal, Hume accepts the reality of powerful negative emotional states elicited by tragedy, but he asserts that Hume is merely suggesting that on the whole, people experience more positive emotional states than negative ones in their response to tragedy. ${ }^{1}$ For example, in the case of Hamlet, though audience members are truly and perhaps significantly troubled during the play by the death of Hamlet, in the end, they are more pleased by the fact that justice is carried out and Hamlet's father is avenged than pained by the suffering of the prince. On the whole, then, they can characterize their experience of the play in terms of enjoyment.

\footnotetext{
${ }^{1}$ Robert Yanal, "Hume and Others on the Paradox of tragedy," Journal of Aesthetics and Art Criticism 49:1 (Winter 1991), 75-76.
} 
Were one to adopt such a position, she likely would reformulate step (2) of the Paradox of Negative Emotion and Long Day's Journey into Night as follows:

2.Though audiences do experience powerful negative emotional states as a result of Long Day's Journey into Night, on the whole the play elicits more powerful positive emotional states than negative ones.

This solution has a good deal of potential, as it allows for the possible existence of mixed feelings - emotions of opposing valences that are experienced simultaneously, ${ }^{1}$ which most theories do not admit or account for. Additionally, it provides a good answer to the motivational question, as audiences derive more pleasure than pain from the artifact they view; thus it is reasonable that they pursue Long Day's Journey.

In order to verify or refute this formulation of (2), I will examine the text of Long Day's Journey utilizing an interpretive method proposed by Nöel Carroll. Carroll asserts that it is possible to mine a narrative for its "emotional address" - the sort of emotions the author intends to elicit with the narrative. Using this method, I will demonstrate that the formulation of (2) is not an accurate representation of an audience's experience of Long Day's Journey into Night, because on the whole, audiences do not experience more positive emotional states than negative ones when they watch this particular play. Such an approach will not only falsify (2), it will also provide additional evidence that the category of theories I critiqued in chapter 2 fail as sufficient explanations of the Paradox of Long Day's Journey into Night, as they cannot account for how this play traffics in powerful, negative emotional states.

\subsection{The Emotional Address of Narrative Art}

\footnotetext{
${ }^{1}$ One who does not affirm the reality of simultaneous opposing emotional states could also accept this formulation of 2 .
} 
Nöel Carroll points out that in the study of narrative art such as works of literature, film, and theatre, a great deal of attention has been paid to how one is to read the work. Those who study such works have focused their attention on hermeneutics, analyzing these texts for what "is loosely called the meaning of the work." 2 Though such studies are valuable and important, these approaches have a significant deficiency, in that "what is not studied in any fine-grained way is how works engage the emotion of the audience." ${ }^{3}$ In the essay, “Art, Narrative, and Emotion,” Carroll proposes a research program whereby those who examine works of narrative art might conduct such a research program. Because of advances in philosophy of psychology and emotion contemporary to Carroll's essay, he writes that people interested in emotional responses to narratives have a grounded and practical method whereby they might describe the emotional responses such works elicit.

Carroll anticipates that some might object to his characterization of the state of hermeneutic study. One might point out that critics working in the psychoanalytic tradition seem very concerned with emotional responses to narratives. To such objections, Carroll replies that psychoanalysis is not terribly concerned the workings of "garden variety" emotions such as fear, pity, joy, and the like. Instead, those working under Freudian and Lacanian frameworks are more concerned with emotional disorder like Oedipal anxiety or male castration disorder. Furthermore, if psychoanalysts do utilize terms designated more "typical" emotional states, they are often ambiguous and refer to mental states that philosophers of emotions might refer to in terms of Mood as opposed to emotion.

\footnotetext{
${ }^{2}$ Noel Carroll, "Art, Narrative, and Emotion," in Emotion and the Arts, Edited by Mette Hjort and Sue Laver, (New York: Oxford University Press, 1997), 190.

${ }^{3}$ Ibid.
} 
The mode of analysis Carroll proposes begins with the basic assumption that , "in large measure, what commands and shapes the audience's attention to the artwork, what enables the audience to follow and comprehend the artwork, and what energizes our commitment to seeing the narrative artwork through to its conclusion is the emotional address of the narrative artwork." ${ }^{4} \mathrm{He}$ adds that emotions serve as an adhesive that keeps audiences focused on the events, characters, and objects which make up the narrative. With this assumption in mind, Carroll believes that it might be possible to identify such emotional addresses within the text, asserting that the emotions elicited will likely be "garden-variety emotions," emotions whose qualia are familiar and readily accessible to most people who consume narrative art.

The claim that narrative works of art elicit and even traffic in the arousal of emotions is likely not a controversial one. Carroll points out that this claim is made as early as Plato's Republic, though for Plato this feature of narrative art makes such art unacceptable in the ideal polis. Plato holds that emotions are irrational enemies of a person's capacity for reason. If he is correct in his description of the topography of the mind, then it follows that people dedicated to living rational lives would wish to avoid art which arouses emotions, as emotions serve to blind people from the true nature of reality.

Plato's view of the emotions as somehow at odds with reason seems to have a robust position in contemporary Western thinking. We pejoratively describe others as "blinded by emotion," or as "living based upon gut feelings instead of reason." Mr. Spock, whose alien race has rejected emotion altogether, is regarded as cognitively superior to his Star Trek counterparts precisely because he is able to dispassionately evaluate the world and navigate it based upon pure reason. Eugene O'Neill himself

\footnotetext{
${ }^{4}$ Ibid., 191.
} 
seemed to accept this traditionally strong division between the rational faculties of the mind and its capacity for emotion, though he rejected Plato's veneration of rationality. In an interview with the American Spectator in 1922, he stated that, "Our emotions are a better guide than our thoughts. Our emotions are instinctive. They are the result not only of our individual experiences, but of the experiences of the whole human race through the ages. They are the deep undercurrent, whereas our thoughts are only the small individual surface reactions. Truth usually goes deep, so it reaches you through your emotions." ${ }^{, 5}$ Though in addition to articulating a view on the nature of emotion O'Neill likely is alluding to the Jungian collective unconsciousness here, it is evident that he sees emotion and reason as two psychological forces at odds with one another, and in this way, he is roughly endorsing the Platonic conception of the mind.

Plato's topography of the mind ought to be called into question, however. ${ }^{6}$ Instead of holding a view that strongly distinguishes between the emotive and cognitive capacities of the mind, Carroll writes that contemporary psychologists and analytic philosophers are inclined to "maintain that reason and emotions are not opposed, inasmuch as reason is an ineliminable constituent of the emotions." ${ }^{.7}$ Because emotions can be accounted for in rational terms, in the 1980s and 1990s philosophers began to articulate a "cognitivist" model of emotions. Carroll asserts that there are good reasons to think emotions do not merely consist of feelings of bodily change. Instead, emotions begin with a "cognitive component," a belief, appraisal, judgment or construal initiated

\footnotetext{
${ }^{5}$ Qtd. in. Frederick J. Carpenter, Eugene O'Neill, (New Haven, Conn.: College and University Press, 1964), 175.

${ }^{6}$ Plato himself interrogates this view somewhat critically in the late dialogue Philebus.

${ }^{7}$ Noel Carroll, “Art, Narrative, and Emotion,” 195.
} 
by some perception of the world or oneself, which give rise to a "feeling component," a phenomenological experience and/or bodily change.

Cognitivist philosophers of emotion developed their view in response to the dominant mode of describing the emotions by psychologists and scientists during the mid-20 ${ }^{\text {th }}$ Century, an approach loosely referred to as the Darwinist or evolutionary account of emotion. ${ }^{8}$ This approach was largely held and utilized by psychologists and cognitive researchers, and still has a robust following in the both disciplines. During his lifetime, Charles Darwin became interested in developing an evolutionary account of the emotions after reading Charles Bell's Anatomy and Physiology of Expression, a work of Christian apologetics that argued for the uniqueness of man's emotional experience among the rest of creation. Darwin, sensing that Bell's work would challenge his theory of evolution, developed a theory of the evolutionary necessity of emotion and articulated his view in The Expression of the Emotions in Man and Animals. Darwin examined seemingly purposeless facial expressions and developed an evolutionary account based upon natural selection as to why humans utilized such expressions. This mode of analysis inspires Darwinist researchers of emotion who operate under the theory that an emotion is reducible to "a neurophysiological event whose manifestations typically include the facial and overt bodily movements that are the emotion's true expressions."9 In order to meaningfully talk about and analyze emotions, the Darwinist view holds that one need only examine the bodily—and as far as humans are concerned, facialresponses to stimuli. The bodily response is the emotional response, regardless of and

\footnotetext{
${ }^{8}$ It should be emphasized that these views overlap a great deal, and I have only distinguished them in categorical terms in order to concisely navigate the issues at hand.

9 John Deigh, "Primitive Emotions," in Thinking About Feeling: Contemporary Philosophers on Emotions, Edited by Robert Solomon, (Oxford: Oxford University Press, 2004), 18.
} 
apart from the cognitive directedness the bodily response precedes or accompanies. To determine the emotional state a person is experiencing, Darwinists carefully study the facial responses of that person, and they believe this can yield a definitive description of the emotion that person manifests. ${ }^{10}$

Cognitivist philosophers of emotion find such approaches to the nature of emotions lacking in explanatory scope and power. Some cognitivists grant that evolutionary approaches are adequate explanations for "basic emotions" (rage, disgust, joy, surprise, distress, anger and fear), as these emotions are quick in onset, short in duration, universal to human beings, and innate; ${ }^{11}$ However, John Deigh offers an example that seems to undermine the power of the evolutionary account to explain even these emotions. He points to the phenomenon referred to as Beatlemania. In the 1965 concert at Shea stadium, when the Beatles took the stage, they were greeted (as in many other venues) by the shrieks and cries of thousands of teenage girls. There is clear footage showing that many of these girls break down into tears, "their faces lose all composure and become blubbery and slack."12 If a Darwinist, unfamiliar with the context in which these images were recorded, were to examine this footage, they would undoubtedly describe the emotions these girls were experiencing as anguish, pain, or grief. Yet it is clear that none of the women who responded to the Beatles in this way would characterize their emotional experience of the event in these terms. The missing piece of the Darwinist theory is the cognitive component. The object of the girls' emotional response is the Beatles, and because this approach "excludes considerations of

\footnotetext{
${ }^{10}$ Perhaps the most influential researchers in this area are Stanley Schachter and Jerome Singer. For a detailed example of this theory in action, one might consult "Cognitive, Social, and Physiological Determinants of Emotional State," Psychological Review 69:5, (September 1962), 379-399.

${ }^{11}$ For further elaboration on this claim, one might consult Paul Ekman, "An Argument for Basic Emotions," Cognition and Emotion 6 (1992), 169-200.

12 John Deigh, "Primitive Emotions," 22.
} 
intelligibility from the definitions of the basic categories of emotions, it cannot correctly identify the girls' emotion in this case."13

The picture of the emotions laid out by evolutionary approaches is clearly incomplete, and, if Deigh's example has any force, it cannot even fully account for the simplest emotional responses, much less more complex emotional states like grief, guilt, or pride. In this arena, the cognitivist of emotion attempts to provide a meaningful picture of emotional life that both accounts for the mental events that incite emotions as well as the bodily manifestations of the emotion in question. According to Carroll, one of the key contribution cognitive theories offer to a full picture of affective life is the description of the intentionality of emotions. Cognitivists point out that it is easy to imagine chemically inducing the bodily response in a person that accompany anger, for example; however this seems appreciably different from actually making that person angry. In the chemical induction, "you cannot be said to be in an emotional state of anger unless there is someone who or something that you think has done you or yours some wrong." ${ }^{\prime 14}$ When one is angry, she experiences a state that one can describe in vivid and precise language, developed in this discipline. In a state of anger, that anger is directed at what has come to be called the "intentional object" of that emotion.

Cognitive theories of emotion provide a great deal of information about the nature of intentional emotional states. For instance, if I react in fear to a snake, that snake can be said to be the intentional object of my emotion of fear. It should be pointed out that I only fear the snake because of what I perceive or believe about the snake, that it looks dangerous, or that I know that it is poisonous and able to bite me. I would not have the

\footnotetext{
${ }^{13}$ Ibid., 23.

${ }^{14}$ Noel Carroll, “Art, Narrative, and Emotion,” 195.
} 
same experience of fear if I were at the zoo looking at the snake from behind glass. The state and intensity of my fear is determined by a set of conditions that the snake meets (looking dangerous, being poisonous, and not enclosed), and these conditions are often referred to as the "formal object" of my fear. If these conditions were different, I would undoubtedly find myself in a different emotional state. It is important to note that the cause of the emotion might be different than the intentional object. For example, I might experience the fear of a poisonous snake as described above, but the cause of my fear might not be a snake at all, but someone's telling me that there is a snake at my feet. In the scenario above, cognitive theories of emotion offer clear working categories which allow me to articulate clearly my experience of fear: I am afraid of the (intentional object) poisonous snake, because it possesses the (formal object) quality of being dangerous, though my fear is caused by the practical joke of a friend. If any of these components were altered, it is reasonable to believe that my emotional experience of the poisonous snake would differ from the fear of the snake that I did in fact experience.

Carroll's essay assumes that the cognitivist model of emotions provides a robust picture of emotional life. With this in mind, he argues that not only are emotions governed by reasons (i.e. formal and propositional content), they also contribute to the ways in which a person's mental focus develops in a particular situation. He writes:

Perception and emotion are interrelated in a number of ways. First, it is our attention to certain aspects of a situation - say, the harmful onesthat moves into certain emotional states in the first instance. But the emotions provide feedback to our processes of attention. Once alerted to the harmful aspects of a situation, our fear will impel us to search the situation - to scan the scene-for further evidence of harmfulness. The emotions focus our attention. They make certain features of situations salient, and they cast those features in a special, phenomenological 
light...and then they hold our attention on the relevant features of our situation under the criteria that define the emotional state we are in. ${ }^{15}$

With this in mind, Carroll suggests that a mode of narrative analysis presents itself. If emotions are organizers of "patterns of salience," this might cast a new light upon how narratives engage the viewer's emotions, for in narratives, the author has organized certain details of the narrative, placing characters, objects, and events in deliberate arrangement to direct the reader's focus in particular ways. The author has "foregrounded what features of the event are salient." ${ }^{" 16}$ Carroll asserts that it is possible, then, to examine this arrangement of saliences, and working backward, one might ascertain the kind of emotion the author intends to elicit with the narrative she crafts. Carroll asserts that narrative fictions come to the viewer "criterially prefocused," meaning that narratives typically are arranged in ways that meet the criteria for emotional categorization described above.

Carroll acknowledges that even if texts are criterially prefocused to elicit certain emotions, there is no guarantee that the audience of the narrative will actually experience those emotional states. Distraction or confusion might render such design ineffective. He responds to such a critique, "Nevertheless, I think that it is equally uncontroversial to suppose that narratives do induce readers, listeners, and viewers to preferences about how the story should evolve." ${ }^{17}$ Generally, it is fair to assume that if a reader responds to a narrative emotionally, they will respond in roughly similar modes as those the author intends. Though one might acknowledge that reader response to texts is subjective, using Carroll's method, one can at least determine what the author intends, and in many (if not

\footnotetext{
${ }^{15}$ Ibid., 199.

${ }^{16}$ Ibid., 201.

${ }^{17}$ Ibid., 204.
} 
most cases) can pith the emotions elicited by the text. Carroll writes, "Authors are able, fairly reliably, to induce the emotions they set out to evoke-especially basic emotions (like anger, fear, hatred, and so on)—because of the fact that they share a common background (cultural, but biological as well) with their audiences." ${ }^{18}$ Audiences share not only the physiological capacity for emotion but also the general criteria necessary to cognitively motivate such emotional states. Given that Carroll has appropriately characterized the nature of emotions and how they are aroused in narratives, his method necessarily follows.

\subsection{Challenges to Carroll's Cognitivism}

It must be acknowledged that cognitivist (at least strong cognitivist) theories of emotion have given way to newer developments in philosophy of emotion. The sea change has been largely initiated by a re-examination of "feeling" theories of emotion as initially described by William James in his famous 1884 essay "What is an Emotion?" James' picture of the emotions differs significantly from the cognitivist's conception. James writes famously that,

Our natural way of thinking about these standard emotions is that the mental perception of some fact excites the mental affection called the emotion, and that this later state of mind gives rise to bodily expression. My thesis on the contrary is that the bodily changes follow directly from the PERCEPTION of the exciting fact, and that our feeling of the same changes as they occur IS the emotion ... the more rational statement is that we feel sorry because we cry, angry because we strike, afraid because we tremble, and not that we cry strike or tremble, because we are sorry, angry, or fearful as the case may be. ${ }^{19}$

\footnotetext{
${ }^{18}$ Ibid., 205.

${ }^{19}$ William James, “What is an Emotion?” Mind 9, 34 (April 1884), 189-190.
} 
James conceives of an emotion as a perception of bodily excitement. The important distinction Jamesian approaches to emotion draw from cognitivist conceptions is that the Jamesian believes that the emotion begins in the body as a physiological event, whereas cognitivists assert that the emotion begins in the mind as a belief, construal, judgment, or appraisal. Certainly, one can appreciate how Jamesian conceptions of the emotions have been informed by the Darwinist approach; when cognitivist objections to evolutionary approaches to emotion emerged in the late 1970s and early 1980s, many philosophers of mind seemed to disregard the James-Lange Theory of emotion, as many cognitivist objections apply to Jamesian theories as powerfully as they do to Darwinist theories. ${ }^{20}$ With the publication of works such as Antonio Damasio's Descartes' Error and Jesse Prinz's Gut Reactions, philosophical and psychological approaches to the emotions in the James-Lange tradition have received new attention and acceptance. Prinz's work on the emotions, an interdisciplinary research program which tests philosophical hypothesis against empirical psychological data, has breathed new life into the JamesLange approach, and many (if not most) philosophers of mind are appropriating such a framework into their research on emotions. There are a variety of philosophical theories of emotion that would best be classified as "feeling" theories, however Prinz's "perceptual" theory of emotions is perhaps the most influential and codified; as a result, for the purposes of this discussion, I will focus on some of the key distinctions it draws from cognitivist and psycho-evolutionary models.

\footnotetext{
${ }^{20}$ i.e. Deigh's "Beatlemania" example would apply to James-Lange theories in that James does not have a robust account of how one can display the physical effects of terror and then account for those effects in terms of enjoyment. Phoebe Ellsworth has argued that James even admits that some emotions are caused wholly by thoughts. Her claim is a controversial one, however. For further discussion, the reader might consult "William James and Emotion: Is a Century of Fame Worth a Century of Misunderstanding?" Psychological Review 101: 2, April 1994, and Rainer Reisenzein, Wulf-Uwe Meyer, and Achim Schützwohl, "James and the Physical Basis of Emotion: A Comment on Ellsworth," Psychological Review Vol 102:4, Oct 1995, 757-761.
} 
Prinz sees his iteration of the feeling theory of emotion as a hybrid between Darwinian approaches (approaches which describe emotions as wholly somatic), and cognitive theories (those theories which describe emotions as semantic mental events which evoke somatic response). He defends an approach that defines emotions as "perceptions (conscious or unconscious) of patterned changes in the body (construed inclusively). ${ }^{, 21}$ Prinz agrees with James that the emotions begin in the body and occur as the mind perceives a bodily change, however he improves the James-Lange theory by attempting to show that there is a rationality to emotional elicitation, an idea he borrows, in part, from cognitivist understandings of emotional experience. The evolutionary model asserts that emotions are merely bodily events, and Prinz improves it by attempting to show that they are the mind's perception of those bodily changes.

In light of how much explanatory scope and power the cognitivist model of emotions seems to have, why would Prinz choose to reject it in favor of what seems to be a very counter-intuitive model? Prinz utilizes the empirical data cited by Darwinists regarding the strong link between emotional states and bodily "perturbations." He points out that James himself often cited lengthy passages of Darwin's research on the emotions to establish his claim. A century later, Levenson, Ekman, and Freisen carefully categorized the physiological changes associated with what they call "basic emotions," and "found that each corresponds to unique body pattern." 22 Additionally, Prinz points out that areas of the brain associated with emotional states are all uniquely associated

\footnotetext{
${ }^{21}$ Jesse Prinz, "Embodied Emotions," in Thinking About Feeling: Contemporary Philosophers on the Emotions, Edited by Robert Solomon, (Oxford: Oxford University Press, 2004), 45.

${ }^{22}$ Ibid., 43.
} 
with bodily response, ${ }^{23}$ and he also cites the preponderance of evidence that supports the claim that bodily changes can induce emotional states. If emotions can be incited without appraisal judgments and are instead sometimes merely the byproducts of some physical change, Prinz asserts that the cognitive mode of describing emotions needs to be reexamined because it does not provide an appropriate account of the somatic component of emotional experience. Similarly, he critiques the evolutionary model for failing to account for the fact that the mind is involved (at least in terms of perceptions) in emotional experience.

Another problem with the cognitivist view, according to Prinz, is that it too heavily relies on conceptual analysis and cognitivists take little stock in the empirical data when defining emotional states. Using the example of guilt, Prinz characterizes the method a cognitivist philosopher typically uses as follows:

A philosopher will insist that guilt just cannot occur without thinking about the self and anger cannot occur without judging that someone has delivered an insult. These assertions are based on intuitions. The philosopher will first try to imagine cases of an emotion occurring without a particular concept or propositional attitude. If no one case comes to mind, she will stipulate that the link between the emotion and that concept or propositional attitude is analytic. It is a conceptual truth that guilt involves a concept of the self. ${ }^{24}$

Following the critique of Griffiths, ${ }^{25}$ Prinz complains that this method relies too heavily on a subjective mode of analysis, pointing out that even a philosopher's intuitions are inevitably guided by her theoretical commitments. Perhaps more problematic is the fact that intuitions "derive from reflecting on our concepts, and concepts may contain

\footnotetext{
${ }^{23}$ For more on this, the reader should consult Antonio Damasio, et. al., "Subcortical and Cortical Brain Activity During the Feeling of Self-Generated Emotions," Nat Neurosci 3:10 (Oct. 2000), 1049-1056.

${ }^{24}$ Jesse Prinz, Gut Reactions: A Perceptual Theory of Emotions, (Oxford: Oxford University Press, 2004), 28.

${ }^{25}$ Paul E. Griffiths, What Emotions Really Are, (Chicago: University of Chicago Press, 1997), 21-43.
} 
information that is false or misleading." ${ }^{26}$ For instance, it may well be that though I cannot imagine becoming angry without believing myself insulted, such a state is still possible without such a belief. These worries may pose a significant challenge to those philosophers of emotion who rely on simply thinking hard about what one means when she uses an emotional term. Prinz sees himself as getting to the bottom of the question of the ontology emotions, while most cognitivists simply seem to settle for answers to questions of the epistemology of emotions.

Though Prinz is wary of such modes of argumentation, he does employ some conceptual arguments to reinforce his position as well. For example, to support the idea that bodily changes are necessary to elicit emotional states, he cites the appeals to intuition that James and Lange utilize to support their claims. James and Lange ask their reader to imagine an emotional state stripped of its bodily responses. James writes "What kind of an emotion of fear would be left, if the feelings neither of a quickened heart beat nor of shallow breathing, nor of trembling lips nor of weakened limbs, neither of gooseflesh, nor of visceral stirrings, were present, it is quite impossible to think. ${ }^{27}$ If all the physical responses of fear in this example are stripped away from the emotion, it does not seem apparent that one would describe herself in a state of fear. Yet this is what the cognitivist would have the reader believe, as she believes some mode of thought (appraisal, belief, judgment, construal) is sufficient to account for an emotional state..

While Prinz is rightly suspicious of cognitivist understandings of emotion, he is not ready to fully accept the Darwinist view of emotions either, because such a view offers an inadequate picture for why emotions matter and how they influence our lives

\footnotetext{
${ }^{26}$ Jesse Prinz, Gut Reactions, 29.

${ }^{27}$ Qtd. in Jesse Prinz, "Embodied Emotions," 46.
} 
and decision making, as emotions on this view are merely bodily responses to stimuli.

Prinz argues that there is what might be understood as a cognitive component to emotions. Emotions, as a mode of perception, register bodily changes but represent to the mind certain "core relational themes." This category, first introduced by Richard Lazarus, refers to "a relation that pertains to well-being." ${ }^{28}$ Prinz argues that when the mind perceives a bodily response, that response is represented to the mind in terms of thematic content. For example, when one encounters an apparently dangerous object, the body responds with goose bumps and quickened heart rate and the emotion of fear represents the theme of overwhelming physical danger to the mind. ${ }^{29}$ Because of this cognitive content, emotions do play roles in decision making and value judgments, but they should not be understood as judgments or appraisals in and of themselves. With the above conceptual and empirical evidence, Prinz and other feeling theorists build a cumulative, interdisciplinary case that suggests that emotional states begin in the body and are perceived by the mind, as opposed to cognitivist views which assert that emotions begin in the mind and produce bodily responses.

If Prinz and others of his position are correctly characterizing the nature of emotional life, can one still conduct the sort of analysis of the emotional structure of narrative works Carroll proposes? Carroll's methodology assumes a cognitivist model of emotions, so if the cognitivist model is false, must one give up the ability to pith the emotional address of a narrative as the methodology prescribes? One should consider this

\footnotetext{
${ }^{28}$ Jesse Prinz, Gut Reactions, 15.

${ }^{29}$ It is important to note the distinction Prinz draws from Lazarus in his use of the term "core relational theme." Lazarus uses this term to codify what Kenny refers to as the "formal object" of an emotion, or in other words, the conditional judgments one must make in order for an emotional response to be elicited. Prinz rejects these themes as criteria of judgment, but does adopt this category as what is represented to the mind as it perceives the bodily change elicited by the some perception of the environment.
} 
problem and see if the relevant features of Carroll's method are affected by one's view of the emotions.

One of the most significant problems posed to Carroll's hermeneutic of emotion by the Prinz feeling theory is the problem of intentionality. On this view, it is something of a mistake to assert that emotions have intentional objects (at least as the cognitivist asserts), because emotions are perceptions of the way the body responds to the world. Emotions often accompany the perception of an object by the body, but according to Prinz, it is a bit misguided to assert that an emotion's object is a constituent component of that emotion, even if that "object" is the cause of the emotion. ${ }^{30}$ Cognitivists assert that emotions are a breed of thought, and that thought must contain certain sorts of content (intentional and formal objects), but feeling theorists do not share this commitment. Through careful consideration, one might determine the cause of an emotional response, but this does not mean that somehow that cause is a component of the emotion itself. One might imagine feeling an emotion for which she can identify no object. This is an easy concept to grasp; it is not difficult to imagine being angry, sad, or joyful, for example, without knowing at whom or exactly why one feels this way. ${ }^{31}$ Cognitivists have to do some terminological gerrymandering to deny that such an event is an

\footnotetext{
${ }^{30}$ He explains and illustrates, "While there is a sense in which emotions are directed at particular events, that does not mean that they represent those events, or anything else, for that matter. The events are represented by mental states that combine with emotions. When I am sad about the death of a child, I have one representation of the child's death and I have sadness attached to that representation... The sadness doesn't represent the death. Saying that my sadness is about the death does not mean that my sadness represents the death, rather it means that the death is what has caused me to become sad. I can continue to think about the death after my sadness subsides, and I can continue to be sad after my thoughts of the death subside." Jesse Prinz, Gut Reactions, 62.

${ }^{31}$ Of course, cognitivists of emotions will dismiss such instances as "moods" and not "emotions," but as Whiting points out, "denying these mental states the status of emotion runs the risk of being ad hoc, it's only virtue being that of theory conservation... The emotion theorist does not wish to concede that there can be an objectless emotion; therefore when offered a counter-example he responds by saying that it cannot be an emotion." Demian Whiting, "The Feeling Theory of Emotion and Object-Directed Emotions." European Journal of Philosophy 19:2 (2009), 283.
} 
emotional state because it has no object, but Prinz is under no such burden, because he can simply point to the cause of such an emotional state (some event that elicits a particular somatic response perceived by the mind) as sufficient for that emotion's occurrence.

The reader will recall that one of the central features of Carroll's hermeneutic method is the identification of the objects the author intends to draw into the center of the reader's field of focus. Once the object is identified, the reader can identify how the object is set apart from the rest of the narrative and ascertain the emotional response the author intends. If the feeling theory as articulated by Prinz is correct, and the representation of the object is not part of the emotion but merely attached to it, can the reader really perform emotional "analysis" of a narrative? Perhaps the best one can do is determine the conclusions the author wishes the reader to draw about intended objects of the reader's attention, but how does such an analysis differ from many other hermeneutic methods the reader might consider when she responds to narrative art? If emotions are "perceptions of bodily change," it does not seem that one can be nearly as certain about the emotional address of a narrative as she might if emotions are cognitive judgment, beliefs, or appraisals because an evaluation of the intentional object and the formal conditions established around that object in a narrative are not necessarily components of the emotions elicited by the narrative.

\subsection{Redeeming Carroll's Hermeneutic of Emotion}

There are at least three strategies a philosopher of emotion sympathetic to feeling theories might utilize to avoid this problem. The first and perhaps the simplest way for 
Carroll's methodology to avoid such a threat would be to point out that regardless of the physical and psychological mechanisms involved in the elicitation of emotional states, the claim that narrative art elicits such states is entirely uncontroversial. Whether emotions begin in the mind or in the body, both theories agree that there is cognitive engagement involved in emotional responses, and neither theory is threatened by emotional engagement of an aesthetic nature. ${ }^{32}$ Both theories can even employ intentional and formal objects as part of their terminology, provided that such terminology is properly understood in its respective context. In cognitive theories, these objects are constituents of the emotional state, while in feeling theories, these objects are likely indicators of the causes, conditions, and representations of the elicited emotions in question. In either case, the analytical approach Carroll proposes can yield meaningful emotional analyses of emotion states the author likely intends to elicit. In order to use the methodology, a feeling theorist would have to be prepared to make certain terminological concessions in the interest of preserving the framework, however these concessions would not ultimately undermine feeling theory or the project of pithing the emotional structure of a narrative.

The second strategy one might employ to preserve a hermeneutic of emotion would be to assert that Prinz is correct in his diagnosis of emotions as bodily responses in only the case of "basic emotions"- those emotions specifically identified by Ekman and appropriated for Prinz's argument as having a distinct physiological referent (joy, distress, anger, fear, disgust, and surprise). More complex emotions such as love, guilt, and shame seem to require contextual and cognitive content than do emotions such as

\footnotetext{
${ }^{32}$ Cognitivists are under a greater burden to explain this process, as the voluminous literature on the socalled "Paradox of Fiction" demonstrates.
} 
joy, distress, or anger. Higher cognitive emotions seems to possess a different qualitative character than basic emotions, and one might rightly assert that it is difficult to ascertain the difference (at least on the purest model of feeling theory) between the qualia of jealousy versus that of envy or embarrassment versus shame. One might point to such fine-grained distinctions as inadequately explained on Prinz's view, and she might instead construct a hybrid model that utilizes feeling theory to explain the basic emotions, and a cognitive theory to describe higher cognitive emotions. Since emotions elicited by a narrative typically require complex cognitive evaluations based upon the readers interaction with a text, one who adopts a hybrid view as described above would be well within her rational rights to utilize Carroll's methodology while still holding to a feeling theory of basic emotion.

The final strategy one might employ to justify Carroll's framework while accounting for feeling theory of emotion is by utilizing a feature of the theory unique to Prinz's description of emotions. On Prinz's model of emotions, a feeling theorist is not required to make as large a concession in this area as a traditional Jamesian, as Prinz does allow that some emotions can be elicited by thoughts. Prinz classifies some emotions as "attitudinal emotions," and these emotions are those that consist of some form of thought. Considering the example of anger because of some personal offense, he writes, "when one is angry about an insult, one's thought about that insult is not merely the cause of one's anger, it is part of one's anger." ${ }^{33}$ Such emotions differ from what Prinz defines as "state emotions," which fire upon environmental stimulation..$^{34}$ Attitudinal emotions

\footnotetext{
${ }^{33}$ Jesse Prinz, Gut Reactions, 181.

${ }^{34}$ The existence of such emotions is an open question for Prinz, as he writes that there is not enough empirical data available to address this question. Of the binding of the cognition to the affective state, he writes, "Perhaps emotions are bound to representations of their particular objects via neural mechanisms
} 
require complex situational and relational cues without which they would not exist. One who is interested in preserving Carroll's interpretive approach while maintaining a feeling theory of emotion might insist that emotions elicited by a narrative are "attitudinal" in that they are not initiated accidentally; instead they involve a person's consideration of a deliberately construed aesthetic work. Such a work is designed—at least in part - to elicit such emotional states. If attitudinal emotions exist, then describing them in terms of their relation to objects is a consistent and coherent practice, and a hermeneutic of emotion remains viable. This strategy allows one to utilize Carroll's method consistently without compromising her commitment to the nature of emotional life.

\subsection{Conclusion}

By utilizing one of the routes described above, a feeling theorist of emotion might consistently utilize Carroll's methodology without significantly compromising her position on the question of the nature of affective states. For the purposes of this argument, it is unnecessary to defend one of these positions over and above the other two; instead, I have presented these options to demonstrate that the hermeneutic of emotion proposed here stands whether one is a cognitivist or a feeling theorist. Both approaches agree that emotion and perception are linked, and both allow that emotions are intentional, at least to a degree; therefore the research program Carroll proposes seems a

like those that bind together components of a complex precept...In the case of attitudinal emotions, the proposal would be that the neural representation of an emotional body state fires at the same time as the neural representation of its particular object... When the attitudinal emotion arises, this embodied appraisal must be caused by the representation of the particular object and, once caused, must be linked with that representation, so that the two persist simultaneously." (Ibid.). 
fruitful analytic endeavor. It is to such a process that I will now subject Long Day's Journey into Night. 


\section{CHAPTER THREE \\ AN EMOTIONAL ANALYSIS OF LONG DAY'S JOURNEY INTO NIGHT}

\subsection{Introduction}

According to Harold Bloom, there is a vexing puzzle posed by Long Day's Journey into Night. O'Neill, on Bloom's view, is America's greatest playwright, and Journey is obviously O'Neill's masterpiece. It stands to reason, then, that Long Day's Journey into Night should be read in the company of The Scarlett Letter, Huckleberry Finn, and As I Lay Dying, but when one reads the text of O'Neill's play, she finds that "perhaps no major dramatist has been so lacking in rhetorical exuberance." O’Neill, according to Bloom, is incredibly limited in his ability to construct powerful dramatic language, and he adds that,

it is embarrassing when O'Neill exegetes attempt to expound his ideas whether about his country, his own work, or the human condition. When one of them speaks of 'two kinds of nonverbal, tangential poetry in Long Day's Journey into Night,' as the characters' longing for 'a mystical union of sorts,' and the influence of the setting, I am compelled to reflect that insofar as O'Neill's art is nonverbal, it must also be nonexistent. ${ }^{1}$

If Long Day's Journey into Night is mediocre, why is it highly esteemed as the greatest tragedy the United States has ever produced? ${ }^{2}$

\footnotetext{
${ }^{1}$ Harold Bloom, Introduction to Eugene O'Neill's Long Day's Journey into Night, (New York: Bloom's Literary Criticism, 2009), 1-2.

${ }^{2}$ As in any value judgment about the significance of a particular literary work, there is some dispute over claims of Journey's mediocrity and/or its greatness. For a survey of such criticism, the reader might consult Michael Wikander, "Eugene O'Neill and the Cult of Sincerity" in The Cambridge Companion to Eugene O'Neill, (Cambridge: Cambridge University Press,1998), 217-235.
} 
Bloom concludes that the power of Long Day's Journey is not contained in the force of the language O'Neill employs in dialogue, but instead this power comes from a "drive-toward-staging he learned from Strindberg." When Bloom reflects upon performances of the play that have significantly moved him, he does not recall Mary's "petulant outbursts" or the languid speeches of Edmund about the sea; instead, what Bloom finds moving are the powerful stage pictures O'Neill creates through meticulous stage directions. Of the closing of act one when Edmund pleads with his mother not to return to morphine, Bloom writes, "That grim ballet of looks, followed by the terrible, compulsive drumming of her long fingers, has a lyric force that only the verse quotations from Baudelaire, Swinburne, and others in O'Neill's text are able to match."2 According to Bloom, then, it is clear that the emotional force of the play is largely derived from the staging of the action, more so than the eloquence of dialogue he has written.

Because of the care with which O'Neill describes the scenes and character interactions within Journey, such an analysis can be especially revelatory. In the following analysis, I intend to focus almost exclusively upon the images O'Neill crafts in his stage directions, as I believe these images function primarily to provide the criteria necessary to focus the audience's emotional attention along certain lines. Using the hermeneutic of emotion Carroll describes, I will examine these stage pictures to determine in a "fine-grained" way what emotions O'Neill intends to elicit. On the whole, the reader will discover that O'Neill does in fact intend to elicit forceful negative emotional states. This analysis will heighten the problem posed by the paradox of tragedy and allow me to suggest a solution in the conclusion of this essay.

\footnotetext{
${ }^{1}$ Harold Bloom, Introduction to Eugene O'Neill's Long Day's Journey into Night, 2.

${ }^{2}$ Ibid., 5 .
} 
To conduct this analysis, I will pay special attention to each stage picture explicitly called for in the text in concert with the dialogue of the play to determine, based upon O'Neill's stage directions, where he intends the audience to focus their attention. I will refer to this object of the audience's attention as the intentional object of the emotion in question. Next, I will examine under what conditions that object is displayed, which will allow me to establish the formal object of the emotion in question, or the conditions under which the object of the emotion are presented to the reader, and this will reveal the dominant emotion O'Neill intends to elicit with that particular stage picture. Based upon the conditions met by the formal object of the emotion, I will be able to classify the relevant intended emotional state roughly based upon the following list of "core relational themes" first constructed by Richard Lazarus in Emotion and Adaptation: ${ }^{3}$

\begin{tabular}{ll}
\hline Emotion & Core Relational Theme \\
\hline Anger & A demeaning offense against me and mine \\
Anxiety & Facing uncertain, existential threat \\
Fright & Facing an immediate, concrete, and overwhelming physical danger \\
Guilt & Having transgressed a moral imperative \\
Shame & Having failed to live up to an ego-ideal \\
Sadness & Having experienced and irrevocable loss \\
Envy & Wanting what someone else has \\
Jealousy & Resenting a third party for loss or threat to another's affection \\
Disgust & Taking in or being too close to an indigestible object or idea \\
& (metaphorically speaking) \\
Happiness & Making reasonable progress toward the realization of a goal \\
Pride & Enhancement of one's ego-identity by taking credit for a valued object or \\
& $\begin{array}{l}\text { achievement, either one's own or that of some group with whom we } \\
\text { identify. }\end{array}$ \\
Relief & A distressing goal-incongruent condition that has changed for the better or \\
& gone away. \\
Hope & Fearing the worst but yearning for better \\
Love & Desiring or participating in affection, usually but not necessarily \\
& reciprocated \\
Compassion & Being moved by another's suffering and wanting to help.
\end{tabular}

${ }^{3}$ Richard Lazarus, Emotion and Adaption, (Oxford: Oxford University Press, 1991), 122. 
It is important to note, that for Lazarus, these themes represent how the mind interprets emotional states, so he is not, in constructing this list, exhaustively establishing necessary and sufficient conditions required for a formal object of each emotion in question. Nevertheless, I find that the criteria he establishes as relational themes sufficiently describe the conditions generally necessary to count for instances of each emotional state possibly elicited by a text. As a result, these themes will be used to help characterize the emotional state the text addresses.

After the object of the audience's attention is identified and the conditions under which that object is presented is analyzed, the reader should be in good position to identify the emotional state O'Neill intends to elicit in each of the stage pictures he creates throughout the play. Once this analysis is conducted, the reader will conclude that on the whole, Long Day's Journey into Night elicits negative emotional states that are not mitigated or controlled by positive emotional states. Given the likelihood of these intended states actually being elicited by the faithful reproduction of the stage pictures O’Neill prescribes in conjunction with the spoken dialogue of the play, the reader will conclude that more often than not, if Long Day's Journey into Night is presented in a manner faithful to the text, the audience's emotional experience on the whole should be negatively characterized.

\subsection{The Emotional Structure Of Long Day's Journey into Night}

As the play opens, O'Neill describes in exhaustive detail the precise appearance of the set. In the later thematic analysis of the play, a great deal of space will be devoted to the 
appearance of the stage as the curtain rises. The scene depicted is the Tyrone drawing room and perhaps the most notable feature for this analysis is the presence of the morning sunshine coming in through the stage right windows. It is fair to assume that O'Neill is likely attempting to elicit a feeling of repose, a calm that will be broken by the rising conflict of the Tyrones. This repose is not directed at a clearly discernible object, therefore cognitivists might describe this moment in terms of setting a mood.

In Act I, there are basically three distinct scenes marked by a steady decline in the positive emotional states O'Neill intends the viewer experience. The first of these scenes begins as the play opens in the morning just after breakfast. Mary and James enter from the dining room, his arm around her waist. As they enter he gives her a hug and praises her for her recent weight gain. As Mary and James are the only characters in the room, illuminated by the morning sun, and jovially joking with one another, it is probable that the emotional response O'Neill intends to evoke is at least a mild form of happiness. It is clear based upon his careful descriptions of both Mary and James in the stage directions that he intends the viewers find Mary and James initially attractive, even if they have aged beyond their best years. Of Mary, O’Neill writes that, she "must have once been extremely pretty, and is still striking,"4 while James, though sixty-five, "looks ten years younger...His face has begun to break down but he is still remarkably good looking-a big, finely shaped head, a handsome profile, deep set, light-brown eyes.", Mary and James close connection and love for one another is demonstrated to the audience both by their proximity to one another as well as their playful — though noticeably contrarydialogue with one another. Mary teases James about his overeating as well as his real

\footnotetext{
${ }^{4}$ Eugene O'Neill, Long Day's Journey into Night, 12.

${ }^{5}$ Ibid., 13.
} 
estate speculating, and though James clearly takes offense, he does not respond with the venom that will later mark his interactions with his family.

There are brief but mild shifts away from this overall tone of happiness crafted by O'Neill, but these are momentary. For example, Edmund and Jamie can be heard joking in the dining room, and this is interrupted by the sound of Edmund's consumptive coughing. At this point, there is a marked shift in the tone of James' and Mary's dialogue. Mary marks this shift by nervously drumming her fingers on the drawing room table. Here O'Neill is attempting to elicit mild anxiety from the audience. Though James attempts to reassure his wife that her concerns are unwarranted, it is clear to the audience that there is an undercurrent of truth to the worries Mary is experiencing, and when Mary and James change the subject to the sound of the foghorn keeping them awake, once again adopting a teasing tone with one another, this momentary anxiety undoubtedly pulls against the feeling of happiness and repose O'Neill has set out to establish in the play's opening.

The Tyrone sons enter joking and laughing with one another, which likely further relieves the anxiety of the previous moment. Mary continues to tease James about his snoring and invites her eldest son to join her, but he responds by staring at her strangely with an "uneasy, probing look," which prompts her to begin fussing with her hair to avoid his glance. This moment compels the audience to focus on Mary again as the object of their attention, and her attempt to avoid her son's suspicious gaze at least evokes curiosity, and worst evokes a kind of dread about what is to come between them. It is clear that Jamie is not interested in pursuing the conflict his stare might provoke, and to avoid this conflict he praises his mother for how well she has looked lately.

${ }^{6}$ Ibid., 20. 
Throughout the play this is a method the Tyrone men use to alleviate Mary's anxiety, as will become apparent throughout Act 1.

The mood of the scene is further lightened by Edmund's retelling of the Shaughnessy-Harker incident, and it is clear O’Neill intends to evoke happiness directed toward this story, and though James reacts grouchily to what he perceives as Marxist overtones in Edmund's stories, generally the emotion of the narrative is not interrupted by another emotional elicitation until Tyrone becomes enraged at Jamie's needling. Edmund heads upstairs to avoid further conflict, and the audience is focused, in a likely disgusted manner, at the inappropriate rage James has displayed toward his sons.

As Edmund leaves the room, the emotional address of the narrative is directed toward Edmund's illness, evoked by the sounds of his coughing from upstairs. Mary expresses her worry, and Jamie and James attempt to persuade her that Edmund's illness is nothing she should be concerned about. Based upon Mary's return to her anxious adjustment of her hair, it is clear to the audience that she is not comforted, as O'Neill is attempting once again evoke anxiety from the viewer.

This anxious tension is momentarily broken as James kisses his wife and tells her that her eyes are beautiful. Mary forgets her anxiety for a moment and "her face lights up with a charming, sly embarrassment. Suddenly and startlingly one sees in her face the girl she had once been, not the ghost of the dead, but still a living part of her."7 This moment of tenderness between this pair that has been married for so many years undoubtedly elicits a moment's compassion for both Mary and James, and though the audience does not yet realize the depth of Mary's psychic trouble and addiction, the audience is once again drawn to she and her husband in compassionate terms.

\footnotetext{
${ }^{7}$ Ibid., 28
} 
This moment of compassion is broken as Mary leaves the room, when she turns in the doorway and asks her husband not to require Edmund to work with his brother trimming the hedges. The audience is focused on Mary, as she is likely the only character standing, and her dramatic turn and shift from girlish tone to that of motherly concern initiates the anxiety that the audience will experience throughout the conversation between Jamie and his father after Mary leaves the room.

With Mary and Edmund offstage, the second major scene marked by a particular emotional address begins - this scene much darker than the first. Because the emotionally weak Mary has left the room, the elder Tyrone and his son begin a strident argument that marks a turn toward emotionally addressing anxiety, disgust, and perhaps anger from the audience. As Mary leaves, James turns to his son "condemningly" and berates him for suggesting to his mother that Edmund's condition might be more serious than a summer cold. Throughout the ensuing dialogue of attack and retreat between James and Jamie, an intensifying anxiety is evoked by the dialogue.

Initially, Edmund's condition is the subject of this anxiety. James reveals to his son that Doc Hardy believes that Edmund has tuberculosis, and immediately, Jamie attacks his father because of his cheapness. Because Tyrone does not deny the charge, the audience recognizes that Jamie is speaking the truth about his father, which likely arouses the emotion of disgust directed toward the father. This emotion of disgust is likely also conferred upon Jamie as the dialogue unfolds, as his father reveals that Jamie is a "lazy lunk and sponge" who spends all his money on whiskey and whores and who only remains employed because of his father's influence and good graces. Again, Jamie

\footnotetext{
${ }^{8}$ Ibid., 29.

${ }^{9}$ Ibid., 32.
} 
does not object to his father's characterization of him, which reinforces and validates the feeling of disgust the audience is intended to experience in response to him.

The overwhelming sense of anxiety marked in this section of Act 1 is interrupted by a few moments designed to mitigate some of the disgust the audience likely feels toward these two privileged white men whose pain is largely brought on by their own actions. For example, when James scolds Jamie for introducing Edmund to the "worldly wisdom" of barrooms and whore houses, accusing his son of wishing to destroy his brother, Jamie replies, "that's a rotten accusation, Papa. You know how much the kid means to me — and how close we've always been—not like the usual brothers! I'd do anything for him."10 James is moved and retreats by saying, "I know you thought it was for the best, Jamie. I didn't say you did it deliberately to harm him." ${ }^{\text {11 }}$ Moments such as these are peppered throughout this scene, interrupting the worsening conflict, and they are constructed to elicit compassion for these Tyrone men, though their personalities and dialogue are strident and full of ego.

The conflict between James and his son turns from the subject of Edmund's tuberculosis to that of Mary's addiction. This moment is meant to reveal important exposition to the audience, but it also increases the anxiety of the scene. When Jamie reveals his suspicion that Mary has returned to morphine and authentically expresses his concern for her recovery, James attacks him "with a burst of resentful anger" by saying "by God, how you can live with a mind that sees nothing but the worst motives behind everything is beyond me!"12 Though Tyrone is attempting to change the subject, for the audience member, it appears that he is abusing his son who has momentarily opened up

\footnotetext{
${ }^{10}$ Ibid., 35.

${ }^{11}$ Ibid.

${ }^{12}$ Ibid., 38.
} 
to him with genuine concern for Mary. Undoubtedly, such behavior toward James would arouse feelings of disgust toward the father and sympathy toward James.

As the argument between Tyrone and his son reaches its zenith, Mary enters the room and interrupts, which marks a third downward emotional shift in the texture of Act I. Mary again returns to the room, this time with a strange manner of movement and tone of voice that provokes both Tyrone men to stare at her "with a growing dread."13 She holds up her hands and complains of how ugly they have become, to which Tyrone responds by gently pushing them and reassuring her that her hands "are the sweetest hands in the world." ${ }^{14}$ Again, this stage picture likely evokes compassion for the elderly couple, and Mary responds to James' kindness by kissing her husband.

As James exist, Jamie momentarily encourages his mother not to worry about Edmund, and he walks out onto the front porch. Mary's inner conflict becomes evident to the audience as she is momentarily alone onstage.

She waits rigidly until he (Jamie) disappears down the steps. Then she sinks down in the chair he had occupied, her face betraying a frightened, furtive desperation, her hands roving over the table top, aimlessly moving objects around. She hears Edmund descending the stairs in the front hall. As he nears the bottom he has a fit of coughing. She springs to her feet, as if she wanted to run from the sound, and goes quickly to the windows at right. She is looking out, apparently calm, as he enters from the front parlor, a book in one hand. She turns to him, her lips in a welcoming, motherly smile. ${ }^{15}$

This moment, of course, is likely meant to elicit several emotions, but chief among them is likely the feeling of anxiety. The audience is, for the first time in the play, witnessed the frantic inner-turmoil that Mary is facing, and though she manages to regain control of herself by the time Edmund enters, it is clear that she will not be able to maintain this control throughout the play. The audience likely wonders when she will lose control of

\footnotetext{
${ }^{13}$ Ibid., 41.

${ }^{14}$ Ibid.

${ }^{15}$ Ibid., 42. (Parenthesis mine).
} 
herself and what will be the cause of this loss of control, and this will provoke an unsettled, anxious feeling directed toward Mary, a feeling which is heightened by her other-worldly tone of voice and mannerisms.

Throughout this final sequence of Act I, Mary's demeanor has clearly been altered by the presence of the narcotic, and her clearly detached manner inevitably heightens the anxiety level O'Neill intends to craft in this scene. In addition to this anxiety toward Mary, O'Neill is clearly establishing a pattern of salience in order to elicit compassion for Edmund. Mary remarks that he has grown too thin, and he weakly sits down in rocking chair. She kisses him, and he looks at her earnestly and urges her "Never mind me. Take care of yourself. That's all that counts." Again, it is fair to characterize this moment as displaying something of Edmund's nobility in spite of his consumption, and this heightens the audience's sympathetic compassion toward him, especially as this is contrasted by Mary's punctuated detachment toward him.

Mary, clearly under the influence of the narcotic, complains about her husband's pride, his cheapness, her lack of friends, and the moral depravity of her sons, all while Edmund rests, wearily, in the rocking chair. Her behavior in the face of her stricken youngest son likely further strengthens the audience's sympathy toward him as well as their disgust for her. Edmund gently encourages his mother to stay strong in her resistance to the addictive power of morphine, to which Mary replies by accusing him of being overly suspicious and somehow in league with his father. These accusations intensify when Edmund reveals that he had heard his mother in the spare room the night before. "Her hands flutter up to pat her hair in their aimless, distracted way. Suddenly a

\footnotetext{
${ }^{16}$ Ibid., 43.
} 
strange undercurrent of revengefulness comes into her voice." ${ }^{17}$ Of Edmund's suspicions that Mary is returning to morphine, she blurts out "It would serve you right if it were true!”"18 Edmund is clearly hurt by this attack, and it is clear the audience would be disgusted by her attack on a weak, ailing, and loving son.

Mary realizes that she has gone too far, and she puts her arms around her son, hugging him "with a frightened and protected tenderness." ${ }^{\text {"19 }}$ She attempts to soothe her son for a moment but quickly slips back into her detached and strange tone of voice. She eerily informs him that she is going upstairs to take a nap, and he responds with a look of suspicion, then "ashamed of himself, looks away." ${ }^{20}$ Edmund goes to the screen door and attempts to make a joke at which Mary forces a laugh. He exits and she is left alone on the stage, the sole object of the audience's focus:

Her first reaction is one of relief. She appears to relax. She sinks down in one of the wicker armchairs at rear of the table and leans her head back, closing her eyes. But suddenly she grows terribly tense again. Her eyes open and she strains forward, seized by a fit of nervous panic. She begins a desperate battle with herself. Her long fingers, warped and knotted by rheumatism, drum on the arms of her chair, driven by an insistent life of their own, without her consent. ${ }^{21}$

This last moment of the act reinforces the general anxiety O'Neill has crafted in the final scene of the act. As the curtain falls, undoubtedly the audience member is left with uncertainty about Mary's conflict within herself, and the strange physical manifestation of this inner conflict leaves is constructed to leave the audience member ill-at-ease with respect to how the upcoming acts will unfold.

\footnotetext{
${ }^{17}$ Ibid., 47.

${ }^{18}$ Ibid.

${ }^{19}$ Ibid., 48.

${ }^{20}$ Ibid., 49.

${ }^{21}$ Ibid.
} 
When one evaluates the emotional address of the first act, she finds that while the play begins by eliciting positive emotional responses (happiness in the scene just after breakfast), and momentary positive emotions are elicited throughout (compassion toward Mary, James, and Edmund), by the conclusion of the first act negative emotions (largely disgust and anxiety) dominate. On the whole, then, it is unlikely that an audience member would characterize her emotional experience of the first act positively. The anxious discomfort she is intended to feel is likely to increase as the following acts develop the plot and deepen the onstage conflicts within the Tyrone family.

As the curtain rises on the second act, the audience discovers Edmund sitting in the armchair, reading a book. The stage directions point out that sunlight no longer comes into the room now, and "outside the day is still fine but increasingly sultry, with a faint haziness in the air which softens the glare of the sun."22 Edmund appears nervous and unsettled, undoubtedly worried about his mother. Additionally, he looks "more sickly than in the previous act." These features of the scene likely recall the anxiety of the first act, although since Edmund finds himself alone onstage, this anxiety is significantly weakened.

Cathleen appears with the tray of whiskey, and her appearance continues the move away from the anxious tone set by the appearance of Edmund. Because she is obviously flirting with Edmund during her dialogue with him, and the brash, uncouth manner with which she shouts for the other Tyrone men to come to lunch, she provides a comic relief that may well evoke laughter from the audience, and one might describe the tone of this first scene as eliciting a mild happiness. Before Jamie enters, Edmund sneaks a drink and returns to his chair quickly, but as he enters, Jamie looks knowingly at the

\footnotetext{
${ }^{22}$ Ibid., 51.
} 
bottle and teasingly chides his brother's sneakiness. This moment further lightens the tone of the scene, increasing the comic happiness O'Neill intends, likely as a break from the intense emotional anxiety that ended the preceding act. Jamie takes a drink for himself and then fills the bottle up to the level he has taken with water, and this act continues the comic tone of the scene, further easing the previously felt anxiety and strengthening a feeling of happiness.

The happiness elicited by the comedic moments at the beginning of the first act is abruptly interrupted when Jamie inquires as to the whereabouts of Mary, and Edmund informs him that she has been upstairs throughout the morning. Immediately Jamie's demeanor changes, and he attacks his brother for allowing her to go upstairs by himself. Edmund attempts to weakly defend himself, and then the brothers both acknowledge their awareness that Mary had been in the spare room the night before. The stage directions prescribe a pause, during which "the brothers avoid looking at each other." ${ }^{, 23}$ This pause once again elicits anxiety directed toward Mary's condition.

Edmund attempts to deny that his mother has returned to her drugs, but Jamie attacks him for it. Jamie "bursts out" saying "you're a damned fool! Why did you leave her alone here so long? Why didn't you stick around?"24 The focus of the audience's attention moves here from Mary's suspected relapse to the conflict between the brothers, and during this dialogue, O’Neill intends to create sympathy for the sickly Edmund. Edmund defensively replies, "Because she accused me—and you and Papa—of spying on her all the time and not trusting her. She made me feel ashamed. I know how rotten it

\footnotetext{
${ }^{23}$ Ibid., 56.

${ }^{24}$ Ibid., 57
} 
must be for her." ${ }^{, 25}$ Jamie himself seems to be moved with compassion for his brother's predicament. He empathizes with Edmund and explains that Edmund does not appreciate the signs of Mary's relapse. This moment, though likely colored by the anxiety elicited by the impending revelation of Mary's addiction, establishes a connection between the brothers that compels compassion from the audience. This moment is very brief however, as Mary re-enters the room.

As Mary enters, Edmund coughs nervously and this initiates a "real fit of coughing." ${ }^{26}$ This coughing directs the audience's attention back to the ominousness of Edmund's condition, and it is accompanied by Mary's otherworldly presence in the parlor. She is clearly under the influence of the drugs now, and this is made clear to the audience, as they become aware "that her eyes are brighter, and there is a peculiar detachment in her voice and manner, as if she were a little withdrawn from her words and actions. ${ }^{27}$ She gently and eerily scolds Edmund for his heavy coughing, kissing him, and Edmund does not initially suspect that anything is wrong with her. Jamie, on the other hand, "knows after one probing look at her that his suspicions are justified. His eyes fall to stare at the floor, his sets in an expression of embittered, defensive cynicism. ${ }^{28}$ Mary sits behind Edmund, so that he cannot see in her eyes, and this arrangement of the characters, coupled with Mary's inebriated tone of speaking, is constructed to once again evoke and strengthen the feeling of anxiety evoked so powerfully at the end of the first act.

\footnotetext{
${ }^{25}$ Ibid.

${ }^{26}$ Ibid., 58.

${ }^{27}$ Ibid.,

${ }^{28}$ Ibid., 58 .
} 
Mary asks why Jamie is so "down in the dumps," concluding that his demeanor is the result of his having had to work outside on the hedges. Jamie glumly replies, "If you want to think so Mama." ${ }^{29}$ She asks where James is, which provokes one of Jamie's criticisms of his father as an old blow-hard. This criticism draws a fierce attack from Mary, and she hits him where it hurts, "Everyone else admires him, and you should be the last one to sneer-you, who thanks to him, have never had to work hard in your life!"30 The stage directions describe Jamie as "stung" by this attack, and he appears for a moment in a sympathetic light, compelling a feeling of compassion from the audience.

Despite her brief attack on Jamie, Mary returns to her strange tone of speaking, and "Edmund is made apprehensive by her strangeness. He tries to look up at her eyes but she keeps them averted. Jamie turns to her-then looks quickly out of the window again." This tableau, Edmund's searching look, and Jamie's deliberate avoidance of eye contact with Mary, and Mary's unwillingness to look at her sons, again evokes a pronounced anxiety. Jamie's deliberate refusal to look at his mother portends a later conflict that the audience realizes will erupt in the near future. He attempts to change the subject, stating that he is hungry and he wishes his father would return to the house for lunch. His comment ultimately his ineffective, as Mary continues to deliver a long speech in the same eerie, detached tone as before.

Cathleen enters and informs the trio that James is too busy talking with the neighbor to come in for lunch, and Edmund takes this opportunity to leave the awkwardness of the parlor, asserting that he will hurry his father along. Jamie and Mary are left alone onstage, and this moment will mark an intensification of the tension and

\footnotetext{
${ }^{29}$ Ibid., 59.

${ }^{30}$ Ibid.
} 
anxiety already elicited earlier. When left alone with her eldest son, Mary "has risen from the arm of the chair. Her hands play restlessly over the table top. She does not look at Jamie but she feels the cynically appraising glance he gives her face and hands. ${ }^{31}$ She asks why he is staring at her, and Jamie says "you know," and turns back toward the window. ${ }^{32}$ Instead of taking the opportunity to avoid the conflict, Mary protests that she does not know what he is talking about, and Jamie angrily tells her to examine her eyes in the mirror. It is clear, based upon her eyes, that she is under the influence of the narcotic. Edmund re-enters from the porch, looks around, and senses the tension between his mother and Jamie. Mary appeals to Edmund for help from Jamie's attack, and Edmund takes "a threatening step toward him. Jamie turns his back with a shrug and looks out the window." ${ }^{33}$ The anxiety created by the eerie tone of Mary's speech and the unwillingness of Jamie to engage her has been amplified by his direct accusation of her and Edmund's confrontation of him, but again, instead of following the conflict where it will lead, Jamie avoids the situation, further prompting anxiety by keeping the threat of the impending argument alive. The audience knows that this fight is coming, and they will remain anxious until this conflict is resolved.

James enters from outside, oblivious to what has transpired while he has been gone, and his entrance provides a moment of emotional relief as he calls attention to the earlier moment of comedy in which Jamie filled the whiskey with water up to the level of liquor he had taken. James "comes to the table with a quick measuring look at the bottle of whiskey." ${ }^{34}$ He cheerfully offers his sons a drink, though he cautions Edmund about

\footnotetext{
${ }^{31}$ Ibid., 61-62.

${ }^{32}$ Ibid., 62.

${ }^{33}$ Ibid., 64 .

${ }^{34}$ Ibid., 65.
} 
taking liquor given the younger Tyrone's illness. Edmund gets up and pours himself a big drink immediately after his father advises him to observe moderation given his condition. He then looks at Jamie and remarks, "I suppose it'd be a waste of breath mentioning moderation to you. ${ }^{35}$ Though there is darkness to this humor, it is fair to characterize this moment as eliciting mild happiness through levity, especially compared to the moment of intensity that has just occurred among Jamie, Mary, and Edmund.

Tyrone's momentary levity is undercut as Mary returns to the scene. Mary returns to the room, and it is clear to James, based upon her excited behavior and uninhibited speech that she is once again under the influence of narcotics. She flies into a tirade about James' pretense that this is a home, and implicitly accuses him of causing her addiction, and "they stare at her. Tyrone knows no. He suddenly looks a tired, bitterly sad old man. Edmund glances at his father and sees that he knows, but he still cannot help trying to warn his mother." ${ }^{36}$ Though Edmund attempts to get his mother to stop talking, James already understands what has happened, and his appearance as a "bitterly sad old man," compels sympathy from the audience in the face of their disgust for Mary's behavior. This moment is further heightened when she notices that Edmund has taken a drink despite his illness. She violently attacks her husband for allowing this behavior, and then eerily and checks herself, asserting in an eerily distant tone of voice, "But, of course, there's no comparison at all. ${ }^{, 37}$ Again, Mary has suggested a point of conflict that she will only later address, promoting a feeling of unresolved anxiety. As the family leaves the room for dinner, Mary begs James' forgiveness, and she cries "James! I tried so hard! I tried so hard! Please believe.” For a moment, it is clear that O'Neill intends the

\footnotetext{
${ }^{35}$ Ibid.

${ }^{36}$ Ibid., 67

${ }^{37}$ Ibid., 68.
} 
audience have compassion for Mary, as her husband momentarily does, but when Mary once again denies that she knows what James is talking about, the feeling of anxiety returns, and as the lights dim to close the first scene of the second act, the audience is undoubtedly left with anxiety directed toward the conflict that has yet to be fully explored.

The second scene of Act Two begins as the Tyrone's re-enter the parlor after lunch. The stage directions describe their entrance:

Mary is the first to enter from the back parlor. Her husband follows. He is not with her as he was in the similar entrance after breakfast at the opening of Act One. He avoids touching he or looking at her. There is condemnation on his fact, mingled now with the beginning of an old weary, helpless resignation. Jamie and Edmund follow their father. Jamie's face is hard with defensive cynicism. Edmund tries to copy this defense but without success. He plainly shows that he is heartsick as well as physically ill.

Mary is terribly nervous again, as if the strain of sitting through lunch with them had been too much for her. Yet at the same time, in contrast to this, her expression shows more of that strange aloofness which seems to stand apart from her nerves and the anxieties which harry them. ${ }^{38}$

Based upon the way the family enters the room after their meal, especially contrasted with the way they entered after breakfast, the audience immediately recalls the anxiety they had experienced as the last scene closed.

This anxiety is likely interrupted as Mary informs the family that she will return upstairs. As she leaves the room, presumably to administer more morphine, Jamie cynically remarks, "Another shot in the arm!"39 This bitterly blunt remark is intended to evoke a mild disgust that will be evoked much more strongly in Act IV when Jamie remarks that his mother is like Ophelia in Hamlet. Immediately, James and Edmund attack Jamie for his frank and disrespectful lack of pity, and Jamie's response compels

\footnotetext{
${ }^{38}$ Ibid., 71.

${ }^{39}$ Ibid., 75.
} 
sympathy for the young loafer. As a spasm of pain crosses is face, he asks, "No pity? I have all the pity in the world for her. I understand what a hard game to beat she's up against—which is more than you ever have! My lingo didn't mean I have no feeling. I was merely putting bluntly what we all know, and have to live with now, again. ${ }^{, 40}$ At least momentarily, the audience comes to understand that Jamie sees himself in the same situation as his mother, and that his criticism of her is an indictment of his own weakness. Because of this understanding, it is likely the viewer is sympathetic to Jamie's plight and the attack on him by the other Tyrone men has elicited this compassion.

The pattern of disgust mitigated by sympathy occurs throughout the conclusion of Act Two. For instance, James rebukes his sons for their pessimistic nihilism in lifestyle and philosophy, asserting that if the sons have "flouted the faith you were brought up in - the one true faith of the Catholic church—and your denial has brought nothing but self-destruction!" ${ }^{41}$ Jamie and Edmund immediately ridicule their father's appeal to Catholicism, and the fact that he has used the Church as a weapon to demean his sons likely makes his faith unappealing to the audience. When Jamie and Edmund expose their father's hypocrisy he almost immediately becomes a target of the viewer's sympathy as James reveals that he prays daily for his wife. James admits that he has lost hope that Mary will triumph over her addiction, and this admission likely heightens the viewer's sympathy toward him.

This pattern is repeated with more intensity in James' conversation with his intoxicated wife. Mary inquires as to why Jamie seems to be in such a bad mood, and she concludes that it is James' fault, ultimately because "If he'd been brought up in a real

\footnotetext{
${ }^{40}$ Ibid., 76.

${ }^{41}$ Ibid., 77.
} 
home, I'm sure he would have been different." ${ }^{42}$ She continues her assault on James by attacking his alcoholism, to which he replies bitterly, "If I did get drunk it is not you who should blame me. No man has ever had better reason." lonely, and James encourages her to take a trip into town in the car, pointing out that she never uses the car though he bought it for her. He accuses her for this, bitterly asserting that the purchase was "Waste! The same old waste that will land me in the poorhouse in my old age! What good did it do you? I might as well have thrown the money out the window." ${ }^{44}$ Mary evades this attack by criticizing James' cheapness in the purchase of the car and the hiring of a second-rate driver. During this dialogue, Mary's tone is eerily calm as James' becomes more and more strident, but their argument does not compel the viewer's sympathy; instead, watching an old married couple attack each other as directly and brutally as they can imagine likely compels disgust for both of them.

Again the tension builds to a breaking point, and instead of further attacking his wife, James begs Mary to stop for his sake and the sake of their sons. This request moves Mary, and though she denies that she knows what he is talking about, she begs him to remember "We've loved each other! We always will! Let's remember only that, and try not to understand what we cannot understand, or help things that cannot be helped — the things that life has done to us we cannot excuse or explain." As she utters these words, she puts her arms around her husband, and these sentiments, coupled with the stage picture of deep love serve to momentarily break the disgusted anxiety created by James and Mary and once again initiate compassion for the patriarch and matriarch of the Tyrone family.

\footnotetext{
${ }^{42}$ Ibid., 91.

${ }^{43}$ Ibid., 83.

${ }^{44}$ Ibid., 84.
} 
As Edmund leaves to see Doctor Hardy, there is a unique moment between him and his father that possibly calls for a unique emotional response from the viewer. Edmund confesses to James that he is broke and needs cab fare, and instead of lecturing his son about the value of a dollar, the old miser generously gives his son ten dollars and praises him for the hard work he has been doing at the local paper. Edmund is “embarrassed by his generosity," 45 and reacts by sarcastically asking if Doc Hardy had told James that he was going to die. As Edmund genuinely thanks his father for the gesture, the viewer is compelled to experience hope. It seems as if something has changed in Edmund and his father's relationship, and James' unexpected generosity might be evidence that the cycle of Tyrone family conflict may end.

The hope generated by this moment of tenderness is abruptly interrupted by another Mary's outbursts. Latching onto Edmund's joke about dying, she "suddenly turns to them in a confused panic of frightened anger," stomps her foot, and cries, "I won't have it!...Do you hear, Edmund! Such morbid nonsense!...You're not really sick at all!" The tender moment between James and Edmund is shattered, and though Mary quickly changes her mode of address, "instantly changing to a detached tone," teasingly scolding her son for his morbid humor, the familiar anxiety is raised, potentially erasing the feeling of hope created a moment earlier. Mary can only sustain the detached tone for a moment, and she puts her arm around her youngest son, "hiding her face in his shoulder, sobbing. Edmund is moved in spite of himself. He pats her shoulder with an awkward

\footnotetext{
${ }^{45}$ Ibid., 89.

${ }^{46}$ Ibid., 90.
} 
tenderness. ${ }^{\circ 7}$ Mary once again appears a sympathetic and tragic victim, her image compelling compassion and anxiety.

Act II ends with an emotionally harrowing conversation between Edmund and Mary. Upon James' prompting, Edmund pleads with his mother to stop taking morphine. Predictably, Mary denies she knows what he is talking about. When this strategy fails to satisfy Edmund's efforts, Mary changes the subject to James' cheapness, Doctor Hardy's ineptitude, and the loss of her Catholic virtue and soul. Her monologue is delivered in the same strange, intoxicated tone that has marked much of her speech throughout the act, and this tone, coupled with her unwillingness to engage Edmund's pleading, contribute once again to the ever growing anxiety directed toward her.

As Edmund leaves the stage, Mary is left alone to deliver a soliloquy in which she reveals, as her "face hardens with bitter contempt," that she is glad to be rid of her family members for the afternoon, for "their contempt and disgust aren't pleasant company." As the curtain closes, however, she asks of herself, "then Mother of God, why do I feel so lonely?"48 This admission may address the audience emotionally in two ways: 1)the eeriness of Mary's tone, and her bitter attitude toward her family promote and heighten the anxiety that is already present as part of the scene, and 2)her final admission of loneliness again calls for compassion.

The emotional contours of Act II frenetically modulate, but the reader would be hard pressed to deny that the overwhelming emotional tone of the act is negative. There are several moments of levity that produce a mild happiness, particularly Cathleen's boorishness as well as the stage business with the whiskey bottle, but overall the scene is

\footnotetext{
${ }^{47}$ Ibid., 91.

${ }^{48}$ Ibid., 95.
} 
marked by anxiety and disgust. There is one unique moment of hope directed toward James and Edmund's relational attitudes toward one another, but this moment is quickly subverted by Mary's caustic attacks and otherworldly tone. On the whole, the audience member would likely characterize this act as arousing more negative emotional states than the first.

The third act occurs just before dinner. Mary and Cathleen have returned from the pharmacy, where Cathleen has filled more of Mary's prescriptions for morphine. As a reward, Mary has treated Cathleen to some bourbon, and the servant girl is noticeably intoxicated as the scene opens. The stage directions describe Mary's appearance:

Mary is paler than before and her eyes shine with unnatural brilliance. The strange detachment in her manner has intensified. She has hidden deeper in within herself and found refuge and release in a dream...There is at times an uncanny gay, free youthfulness in her manner, as if in spirit she were released to become again, simply and without selfconsciousness, the naïve, happy, chattering schoolgirl of her convent days....as the curtain rises, she is standing at the screen door, looking out. ${ }^{49}$

Seen in the light of the current analysis, this section of the Act presents an interesting variation on the theme O'Neill has crafted in Acts 1 and 2. As each of these acts began, O'Neill uses levity, the hijinks the whiskey bottle, and Cathleen's boorish behavior serve to contrast the emotional load that is levied upon the audience as each respective act develops. There is a comical element present as Act 3 begins as well, as Cathleen's obvious drunkenness heightens her boorishness, and Mary and Cathleen attempt to fill the whiskey bottle with water to supplement what they have taken (as the Tyrone sons have done in the previous act). The emotional tone set in at the beginning of this act, however, is not happy, because of the eerie manner of speech and intoxicated behavior of

\footnotetext{
${ }^{49}$ Ibid., 97-98.
} 
Mary (accompanied with the absence of sun and drone of the foghorn) that dominates this sequence. As Mary and Cathleen reminisce about Mary's past, the anxiety familiar to the audience at this point in the play returns and intensifies until the re-entrance of the Tyrone men.

Throughout Mary and Cathleen's conversation, O’Neill works to arouse sympathy for both of the women. Cathleen complains of Smyth's inappropriate sexual advances, including "pinching me on the leg and the you-know-where," her complaints, lost in her own dream-like self-centeredness. Mary’s callous lack of regard for Cathleen's sexual safety calls for compassion directed toward the simple servant girl. Likewise, compassion is momentarily elicited for Mary when Cathleen attempts to leave to go to the kitchen, and "with a flash of approbation," Mary says, "No, don't go, Cathleen. I don't want to be alone, yet."51 Though Cathleen stays, it is clear that she does not comprehend the depth of Mrs. Tyrone's admission, as she continues to make small talk, oblivious to the severity of her mistress's condition. Cathleen's lack of appreciation of the suffering of the tormented woman of the house likely directs additional compassion toward Mary.

Though several additional moments of Mary's reflection of the past likely elicit mild compassion for her, these lines are supposed to be delivered in such a distracted and distant tone that it is unlikely the audience would receive much relief from anxiety they feel directed toward Mary's impending demise. However, there is one significant moment that likely arouses a great deal of compassion for Mary. After Cathleen returns to the kitchen, Mary is alone in the parlor, where she delivers a powerful soliloquy after

\footnotetext{
${ }^{50}$ Ibid., 98.

${ }^{51}$ Ibid., 99.
} 
suddenly relinquishing "all the girlish quality" and appears "an aging, cynically sad, embittered woman." She bemoans the loss of her faith and recites the Hail Mary "in a flat, empty tone," 52 and then reminds herself that the Virgin sees not only what she does, but who she is within her heart. Mary decides that she has not had enough of the drug and resolves to go upstairs to administer more, when she recognizes that James and Edmund have returned home. "Suddenly, her whole manner changes. She becomes pathetically relieved and eager," ${ }^{, 53}$ claiming that she is glad they have returned. This war within herself likely elicits strong sympathetic compassion for the suffering woman.

It might be fair to claim that this compassion directed toward Mary lingers as James and Edmund return to the scene. She is genuinely glad that they have returned, and attempts to pour them a drink and make them comfortable, but they respond to her with "condemning eyes," compassion falls away as she begins to criticize Jamie and compares Edmund's colicky behavior as a child to her "angel" Eugene, who died in infancy. This diversionary tactic arouses disgust directed toward her, as Edmund is clearly not to blame for his behavior as a baby, and the audience likely senses how cruel she I being to her consumptive son.

As earlier in the play, O'Neill interrupts this moment of disgust with a moment of genuine tenderness that recalls the earlier compassion the audience likely felt toward James and Mary. After delivering a long, critical speech of James, Jamie, and Edmund, Mary apologizes and in a changed tone, justifies her behavior by saying, "it's very dreary and sad to be he alone in the fog with the night falling." 55 This statement moves James to

\footnotetext{
${ }^{52}$ Ibid., 107.

${ }^{53}$ Ibid., 108 .

${ }^{54}$ Ibid., 108.

${ }^{55}$ Ibid., 112.
} 
compassion, and he assures her that, "I'm glad I came, Mary, when you act like your real self." 56 For a moment, they reminisce about how they met, and James tone of voice becomes husky. Edmund turns away as his parent share a brief moment of romance, and this moment allows the audience to once again feel compassion for the tortured lovers. However, as before, this compassion falls away as Mary's reminiscences turn away from the happy times she and her husband have shared and toward James' continual drunkenness. She recalls a night on her honeymoon, when James had gotten so drunk in a bar that he had to be carried back to the hotel room where she had waited for him for hours. Mary's retelling of this story, as well as her return to her impersonal, distant tone of speaking called for in the stage directions, once again elicits anxiety and disgust directed toward both the elder Tyrones.

Throughout the final, lengthy conversations that Mary has with her husband and son, the overwhelming emotion that is addressed is anxiety, made more acute than in previous acts as the family reveals more details of the past they have only hinted at before. One example of such a revelation is when Mary bluntly blames Edmund for her addiction. When Edmund rebukes her for taking Cathleen to fill her prescription, Mary attacks him in the worst way she can conceive. She turns to Edmund, in a fit of "almost revengeful enmity," and exclaims, "I never knew what rheumatism was before you were born! Ask your father!" Immediately, the stage directions call for Edmund to look away, "shrinking into himself." Edmund's physical action reveals how hurt he has been by his mother's blame, and the audience feels incredible sympathy for him as well as disgust for what Mary has become. Overall, because of this blunt attack, the audience would likely characterize their response to this moment in terms of anxiety, and perhaps even anger.

\footnotetext{
${ }^{56}$ Ibid.
} 
The emotional climax of the third act occurs just before the act closes. Edmund has had enough of his mother's inebriated attacks and he abruptly exits. The stage directions indicate that "He hurries away through the front parlor. She keeps staring out the window until she hears the front door close behind him. Then she comes back and sits in the chair, the same blank look on her face." ${ }^{, 57}$ James re-enters the parlor after visiting the cellar for another bottle of whiskey and discovers that Edmund has gone. Of her youngest son's decision to miss dinner, she says, "He doesn't seem to have any appetite these days." Then, seeming to reassure herself, she says, "But it's just a summer cold." James looks at her blankly as he has another drink, and "suddenly it is too much for her and she breaks down in sobs.” Mary throws her arms around her husband and cries, “Oh, James! I'm so frightened!...I know he's going to die!” Tyrone attempts to reassure Mary, but she accuses him of acting. The image of Mary falling sorrowfully into her husband's arms calls for a sympathetic response from the audience, and though this moment is hastily interrupted by the arrival of the drunken Cathleen announcing dinner, it is likely this image looms largest in the audience's mind as the act ends.

When one attempts to inventory on a large scale the sorts of feelings she experiences throughout the third act, the overwhelming emotional contour can only be characterized negatively. Though there are a few comical elements present in the act, these elements are not powerful enough to mitigate the overwhelming anxiety, disgust, and compassion incited in the action and dialogue propelling the plot. Any trace of hope that Edmund or Mary might recover is almost immediately squashed by the return of anxiety produced through continual conflict and accusation. The third act continues the

\footnotetext{
${ }^{57}$ Ibid., 121.
} 
long emotional slide toward negative emotional states as onstage the day dwindles into a fog-ridden and dark night.

The opening of Act Four is remarkable in that when one attempts to isolate and examine the emotional address of this act's first ten pages, she finds herself at something of a loss Edmund has returned from a walk in the fog down by the beach, and though he and his father have several superficial conflicts over whether or not to burn the lights, which poets are best, and other such superficial topics, the viewer is not directly presented with a clear emotional object whereby she may organize her perceptions of James and his youngest son. Though the dialogue does not provide a clear emotional focus, it is fair to acknowledge that O'Neill is crafting a general mood of (at least mild) anxiety as he paints a picture of the stage in his directions. He writes:

It is around midnight. The lamp in the front hall has been turned out, so that now no light shines through the front parlor. In the living room only the reading lamp on the table is lighted. Outside the windows the wall of fog appears denser than ever. As the curtain rises, the foghorn is heard, followed by the ships' bells from the harbor. ${ }^{58}$

Because of the lack of stage lighting as well as the appearance of fog outside the windows, the room appears much smaller, and as the curtain rises, James sits alone in the room, drunkenly playing cards. Mary is absent, and it is likely the viewer will recall that she has gone upstairs to take more morphine. For these reasons, it is fair to claim that though Edmund and James' conversation does not elicit a clearly discernible emotional response, most of their conversation is colored by anxiety, given the circumstances surrounding their conversation as well as the appearance of the room that they inhabit. Edmund and his father play a game of Casino at the parlor table, and as they do, they provide a good deal of exposition that further acquaints the viewer with the

\footnotetext{
${ }^{58}$ Ibid., 125.
} 
relationship between Mary and her husband. The first poignant conflict arises when Edmund blames his father for Mary's addiction. When James reminds Edmund that Mary has returned to morphine because of her anxiety about his condition, Edmund angrily retorts,

It should never have gotten hold of her! I know damned well she's not to blame! And I know who is! You are! Your damned stinginess! If you'd spent money for a decent doctor when she was so sick after I was born, she'd never have known morphine existed! Instead, you put her in the hands of a hotel quack who wouldn't admit his ignorance and took the easiest way out, not giving a damn what happened to her afterwards! All because his fee was cheap! Another one of your bargains!",59

Edmund's attack on his father does not evoke compassion for his father, as similar remarks have through the course of the play, because instead of being stung by his son's words, James defies his son's estimation of events, first angrily retorting, "How dare you talk of something you know nothing about!" and secondly by entreating his son to appreciate his side of the story. ${ }^{60}$ James dismissal of his son's accusation likely makes Edmund appear insolent in this instance, which calls for disgust on the part of the audience. Edmund amplifies his accusation instead of relenting in the face of his father's defense, ending a violent speech by angrily shouting, "Christ, is it any wonder she didn't want to be cured. Jesus, when I think of it I hate your guts!" 61 This disrespect toward James likely increases the disgust the viewer feels, and James' line "how dare you talk to your father like that, you insolent young cub!",62 clearly articulates the grounds for such feeling.

\footnotetext{
${ }^{59}$ Ibid., 140.

${ }^{60}$ Ibid.

${ }^{61}$ Ibid., 141.

${ }^{62}$ Ibid.
} 
It is unclear at first exactly why Edmund is so angry at his father. After all, Mary has been suffering this addiction for many years. Why is Edmund's ire toward James' miserliness os intense? This confusion is quickly alleviated as the scene progresses, as the audience member comes to understand that because of James' unwillingness to pay for a private institution, Edmund is to be sent to a "state farm" to recover from his tuberculosis. As this point is raised, the audience's attention is justifiably focused the damage that James' cheapness has done and is currently doing to those who he claims to love. Under these circumstances, it is likely that the disgusted feeling the viewer might experience with respect to Edmund's insolence is redirected toward the father. Edmund points out that with James' attitude toward tuberculosis as a death sentence, it would be unreasonable to expect him to spend his money on a private hospital for his son, and though Tyrone denies this accusation, it is clear based upon the "bitter confusion" called for in the stage directions that Edmund's comment reflects reality, again legitimating the disgust one feels toward Tyrone.

Edmund delivers an impassioned speech about "making allowances" for everyone in the Tyrone family, but he states that he will no longer do so with respect to his father's cheapness. "Bursting with rage," Edmund cries, “And don't think I'll let you get away with it! I won't go to any state farm just to save you a few lousy dollars to buy more damned property with!"63 As he delivers these lines, his rage provokes a fit of severe, consumptive coughing. This moment evokes compassion toward Edmund by both the viewer and James as well. Instead of defending his selection of the state sanitarium for Edmund, James relents. He tells his son, “ As he delivers these lines, his rage provokes a fit of severe, consumptive coughing. This moment evokes compassion toward Edmund

\footnotetext{
${ }^{63}$ Ibid., 145.
} 
by both the viewer and James as well. Instead of defending his selection of the state sanitarium for Edmund, James relents. He tells his son, "You've got yourself worked up over nothing. Who said you had to go to this Hilltown place? You can go anywhere you like. I don't give a damn what it costs." ${ }^{\prime 44}$ This moment is designed to elicit the emotion of hope. The viewer once again becomes hopeful that Edmund and James' relationship can be restored as she hoped when James had given Edmund the extra money for the cab fare in act three. This hope is soon squashed however, as Tyrone quickly recovers his persona and states, "you can choose any place you like! Never mind what it costs! Any place I can afford! Any place you like—within reason." ${ }^{65}$ Here, the audience comes to realize that it is unlikely that anything will ever change in the relationship between Edmund and his father, and this realization compels profound sadness.

Quickly this hopelessness is replaced with compassion for James in spite of his consuming concern for preserving his material wealth, as James next delivers a lengthy speech about his acting career, where he reveals that he feels a great deal of remorse for not staying true to his promise as a great Shakespearean actor. He blames his impoverished upbringing for this failure in his life, an upbringing which made him jump at the chance to play the same role through his entire career for a profit of "thirty-five or forty thousand a season." ${ }^{, 66}$ Tyrone confesses that he had realized too late that he had become so closely associated with that role that he could never be cast in other plays and that he had wasted his acting talents "through years of easy repetition." confession arouses sympathy from Edmund, who is moved and "stares at his father with

\footnotetext{
${ }^{64}$ Ibid., 146.

${ }^{65}$ Ibid., 148.

${ }^{66}$ Ibid., 150 .

${ }^{67}$ Ibid.
} 
understanding." ${ }^{68}$ Edmund feels compassion and sympathy for his father's condition, and the audience shares his feeling toward James.

Jamie's return from town marks a shift in the emotional tone of the act, as he is "as drunk as a fiddler's bitch," and as a result initially brings some levity to the scene by tripping over the front stairs and turning on every light in the house in part to annoy his father, who has stepped out on the porch to avoid any potential conflict. The amusement that Jamie provides relieves the feeling of compassion that was incited in the previous moment, but quickly Jamie becomes a mean drunk and begins to criticize James for his cheapness and pretension. Edmund weakly berates his brother for such attacks, clearly still moved by what he has learned about James moments earlier, and this interaction calls for more anxiety as conflict is impending between the brothers.

It is likely that in addition to anxiety, the viewer would experience disgust directed toward Jamie for at least two reasons. First of all, Jamie is nearly out of his mind with inebriation, and he staggers around the stage, slurring his speech and insulting both his brother and his father. Secondly, Jamie tells the story of visiting the whorehouse and sleeping with Fat Violet, the overweight prostitute who plays the piano for Mamie Burns. Jamie's interaction with low-end prostitutes, who he later reveals are actually "poor, stupid, diseased slobs,"

The audience's disgust toward Jamie is further reinforced and intensified (perhaps to its most powerful point in the play thus far) when Jamie, "in a cruel, sneering tone with hatred in it," asks, "Where's the hophead? Gone to sleep?"70 Upon hearing such a statement of disrespect directed toward his mother, Edmund jumps up and punches his

\footnotetext{
${ }^{68}$ Ibid., 151.

${ }^{69}$ Ibid., 165.

${ }^{70}$ Ibid., 161.
} 
brother. This rapid movement and physical confrontation again validates the audiences' sense of disgust toward the eldest Tyrone son. Despite the fact that Jamie has incited rage and disgust from his brother and those who observe his interaction with his brother, Jamie's response to Edmund's attack immediately undermines that emotional response. According to the stage directions, "For a second Jamie reacts pugnaciously and half rises from his chair to do battle, but suddenly he seems to sober up to a shocked realization of what he has said and he sinks back limply." Jamie immediately apologizes, thanking his brother for hitting him, recognizing that he "had that coming." "71 Jamie explains why he is feeling so negatively toward his mother, explaining that he had hoped that if "she'd beaten the game, I could too." 72 Upon admitting this disappointment, Jamie breaks into tears, "and the horrible part of his weeping is that it appears sober, not the maudlin tears of drunkenness." ${ }^{, 73}$ This revelation is provided to the audience so that they might cease feeling disgusted toward Jamie and begin to feel compassion for him again, as they undoubtedly realize the toll Mary's addiction has taken on even him.

O'Neill does not seem content to allow the audience to dwell upon compassionate feelings they may have toward Jamie, however. In a moment of frankness, Jamie reveals to Edmund that he has been a "rotten bad influence." Not only this, Jamie claims that he has done so on purpose in a harrowing and drunken speech:

No, Kid! You listen! Did it on purpose to make a bum of you. Or part of me did. A big part. That part that's been dead so long. That hates life. My putting you wise so you'd learn from my mistakes. Believed myself at times, but it's a fake. Made my mistakes look good. Made getting drunk romantic. Made whores fascinating vampires, instead of poor, stupid, diseased slobs they really are. Made fun of work as a sucker's game. Never wanted you succeed and make me look even worse

\footnotetext{
${ }^{71}$ Ibid., 162.

${ }^{72}$ Ibid.

${ }^{73}$ Ibid.,
} 
by comparison. Wanted you to fail. Always jealous of you. Mama's baby, Papa's pet!...And it was your being born that started Mama on dope. I know that's not your fault, but all the same, God damn you, I can't help hating your guts- $!^{74}$

For audience members sympathetic to the suffering Edmund, this speech likely incites anger, especially as Jamie is explicitly blaming his brother for the worst part of the Tyrone family's lives. However, this moment is complicated by the fact that Jamie is - at least in his opinion-honestly warning his brother about the harm he intends to cause him. At first Edmund dismisses Jamie's statements as drunken babbling, to which Jamie replies,

Think it over and you'll see I'm right. Think it over when you're away from me in the sanitorium. Make up your mind you've got to tie a can to me - get me out of your life — think of me as dead-tell people, "I had a brother, but he's dead." And when you come back, look out for me. I'll be waiting to welcome you with that "my old pal" stuff, and give you the glad hand, and at the first good chance I will stab you in the back. ${ }^{75}$

Based upon this duplex display of brotherly affection and revelation of brotherly hatred, it is very unclear how the viewer is to feel toward Jamie, and perhaps this lack of clarity is designed to escalate the anxiety that will lead to the emotional climax of the act - and of the play_namely, Mary's only appearance in the final act.

Jamie passes out on the couch from the effects of too much alcohol and James returns to the parlor, admonishing Edmund not to put too much stock in what Jamie says when he is drunk. James stares down at his son, pours himself a drink, and then says, "A waste! A wreck, a drunken hulk, done with and finished!" 76 This statement is ironically accompanied by the image of James having another drink. Here the audience sees the generational curse of alcoholism passed from Tyrone to his namesake. Though the

\footnotetext{
${ }^{74}$ Ibid., 165.

${ }^{75}$ Ibid., 166.

${ }^{76}$ Ibid., 168.
} 
emotional address of this moment might be difficult to pin down in conventional

emotional terms, it is likely that this stage picture is intended to evoke sadness.

After Jamie wakes and chides his father about the "art of acting," the three men sit dozing at the table, waiting for Mary to go to bed so that they might too go to bed without seeing her because by now she would undoubtedly be completely under the control of the morphine. O'Neill then prescribes how Mary appears for the first time in the act. In the stage directions, O’Neill indicates:

Edmund sits tensely. He hears something and jerks nervously forward in his chair, staring through the front parlor into the hall. He jumps up with a hunted, distracted expression. It seems for a second he is going to hide in the back parlor. Then he sits down again and waits, his eyes averted, his hands gripping the arms of the chair. Suddenly, all five bulbs of the chandelier in the front parlor are turned on from a wall switch, ad a moment later someone starts playing a piano in there - the opening of one of Chopin's simpler waltzes, done with a forgetful, stiff-fingered groping, as if an awkward schoolgirl were practicing it for the first time. Tyrone starts to wide-awakeness and sober dread, and Jamie's head jerks back and his eyes open. For a moment they listen frozenly. The playing stops as abruptly as it began, and Mary appears in the doorway. She wears a sky-blue dressing gown over her nightdress, dainty slippers with pompons on her bare feet. Her face is paler than ever. Her eyes look enormous. They glisten like black polished jewels...Her white hair is braided in two pigtails which hang over her breast. Over one arm, carried neglectfully, trailing on the floor, as if she had forgotten she held it, is an old-fashioned white satin wedding gown, trimmed with duchesse lace...They stare at her. She seems aware of them merely as she is aware of other objects in the room, the furniture, the windows, familiar things she accepts automatically as naturally belonging there but which she is too preoccupied to notice. ${ }^{77}$

The sudden illumination of the stage prescribed by the stage directions, coupled with Mary's pale appearance and strange, girlish attire, is likely intended to evoke a great deal of anxiety from those watching the action on the stage. As Mary plays this piano, the strange, halting lilt of a poorly performed Chopin piano piece heightens that anxiety.

\footnotetext{
${ }^{77}$ Ibid., 170.
} 
Mary's arrival and behavior elicit a sharp response from the three Tyrone men, and Jamie arouses disgust by his disrespectful reference to Hamlet. After Mary finishes playing, he "breaks the cracking silence-Bitterly, self-defensively sardonic," and proclaims, "The Mad Scene. Enter Ophelia!",78 This statement and the tone with which it is delivered, provokes a reaction of disgust from James and Edmund, and Edmund "slaps Jamie across the mouth with the back of his hand."79 Jamie does not retaliate, admitting once again that he "had that coming," and he buries his face in his hands and begins to weep ${ }^{80}$ Here, the audience sees the toll Mary's addiction has taken on Jamie, and in this moment, perhaps feels compassion directed toward him, if not outright sadness. Jamie's weeping dampens his father's anger toward him, and he turns to his son "and shakes his shoulder, pleading, ${ }^{, 81}$ that Jamie stop crying, strengthening the compassion one feels toward Jamie.

This moment is interrupted, for "then Mary speaks, and they freeze into silence again, staring at her. She has paid no attention whatever to the incident. It is simply a part of the familiar atmosphere of the room." 82 Again, the audience's anxiety is raised, given the fact that she is behaving as if she were still a girl in the convent. As she speaks, the audience learns that she is carrying her wedding gown, which likely intensifies the anxiety they direct toward her.

As the act and the play draw to a close, O'Neill crafts deliberate moments to arouse compassion directed toward each of the Tyrone men. The first of these moments occurs when James realizes that Mary is carrying her wedding gown. He begins to scold

\footnotetext{
${ }^{78}$ Ibid., 170.

${ }^{79}$ Ibid.,

${ }^{80}$ Ibid., 171

${ }^{81}$ Ibid.,

${ }^{82}$ Ibid.
} 
her for what she is doing, but adopts a different tack, and offers to take it from her, saying “you'll only step on it and tear it and get it dirty dragging it on the floor. Then you'll be sorry afterwards." 83 He then takes the dress and sits back at the table, "holding the wedding gown in his arms with an unconscious clumsy, protective gentleness." ${ }^{84}$ The image of Tyrone holding the wedding dress coupled with his weak pleading with Mary to come to her senses, likely casts the glow of compassion on him for the audience. It is likely that they see him as a devoted husband who has come to the end of his rope and is deserving of pity.

Jamie next compels the audience's compassion, and his brother elicits similar feelings. He tells James that it is no use to try to appeal to Mary, but it seems as though he cannot resist making an attempt of his own to draw her back from the dream-world she inhabits. He "turns to look up into her face — and cannot help appealing pleadingly in his turn." He simply says, "Mama," but she does not respond, and "he looks away hopelessly." ${ }^{85}$ Jamie's attempt to reach his mother has proven as futile as his father's, and Mary's rejection of the pleas of her firstborn directs the viewer's compassion toward Jamie. As Mary babbles about the looking for something she lost, Edmund abruptly turns to Mary, takes her by the arm and tries to tell her that her suspicions have been confirmed - that he has consumption. Momentarily, Mary is jarred from her dream, but she immediately retreats to the world of the convent, saying, "You must not try to touch me. You must not try to hold me. It isn't right, when I'm hoping to be a nun." ${ }^{86}$ Edmund

\footnotetext{
${ }^{83}$ Ibid., 172.

${ }^{84}$ Ibid.

${ }^{85}$ Ibid., 173.

${ }^{86}$ Ibid., 174.
} 
immediately releases his mother in defeat. Mary's inability to comfort her son in his most vulnerable moment shifts the focus of the audience's compassion to Edmund.

As Mary delivers her final monologue that will close the play, James and his sons pour themselves more whiskey, and while he holds his wife's wedding dress, "Tyrone lifts his glass and his sons follow suit mechanically, but before they can drink Mary speaks and they slowly lower their drinks to the table, forgetting them." ${ }^{„ 87}$ This simultaneous movement demonstrates to the audience that the men are not able to ignore the words of the Tyrone patriarch, and this is likely intended to draw the audience's attention to Mary, presumably heightening the impact of her final speech.

The emotional address of Mary's final monologue is ambiguous. She speaks as if she is a young girl, and the stage directions call for her to deliver her lines "with a girlish pique. ${ }^{\prime 88}$ She reflects upon her experience in the convent, claiming that she had always wished to be a nun and recalling how the Reverend Mother had recommended she not pursue such a profession. The Reverend Mother, according to Mary, had told her to return home and take a year or two to decide whether or not she was serious about her commitment to a life of chastity in service to the church. After recounting this event, the stage directions indicate that Mary "pauses and a look of growing uneasiness comes over her face. She passes a hand over her forehead as if brushing cobwebs from her brain." ${ }^{89}$ Mary's illusion of girlhood is gone as she delivers her final lines, "That was in the winter of senior year. Then in the spring something happened to me. Yes, I remember. I fell in love with James Tyrone and was so happy for a time." ${ }^{90}$ After she finishes delivering the

\footnotetext{
${ }^{87}$ Ibid., 175.

${ }^{88}$ Ibid., 175.

${ }^{89}$ Ibid., 176.

${ }^{90}$ Ibid.
} 
final line of the play, the stage directions indicate that James shifts in his seat, and Edmund and Jamie sit motionless. What is not present in Mary's speech and the accompanying stage picture prescribed in the directions is any sense of conclusion. The viewer can have no confidence that things will improve for the Tyrones, and it is likely that the feelings one is left with as the curtain closes can only be characterized as anxiety, sadness, or compassion.

Overall the final act is easily the darkest of the four acts of the play, and when one examines the emotions elicited by this act, she can only characterize those emotional states as negative, as there are minimal mitigating positive emotional states. The appraisals the audience makes of the three Tyrone men oscillate from compassion to disgust, and Mary's appearance is so otherworldly and strange she likely elicits anxiety

more than any other emotional response. In emotional terms, the play ends more gloomily than it began.

\subsection{Conclusion}

In the above analysis, I have carefully evaluated the emotional address of each act, and I have provided good reason to reject the formulation of (2) proposed in the previous chapter. In terms of the emotions elicited in response to the events and characters Long Day's Journey into Night, it seems absurd to suggest that on the whole people experience more positive emotional states than negative ones. Though there are moments of levity throughout the play, these moments do not mitigate the overwhelming feelings of compassion, anxiety, and sadness elicited by Journey. 
Should the reader conclude, then, that it is nonsense for an audience member to claim to “enjoy” a performance of Long Day's Journey into Night? Though the preceding analysis seems to render such a statement incoherent, in the following chapters I will present an approach to this problem that attempts to salvage the concept of tragic enjoyment while recognizing the powerful negative emotional address of the play. I will argue that it is possible to enjoy Long Day's Journey into Night for a unique opportunity it affords the viewer, although this enjoyment is not derived from the events depicted in the play. In order to build this approach, one must turn to a significant voice in O'Neill's creative process and personal philosophy, the voice of the revolutionary Friedrich Nietzsche. 


\section{CHAPTER FOUR TRAGEDY AND THE AFFIRMATION OF LIFE}

\subsection{Introduction}

In his 1936 Nobel Prize acceptance speech, Eugene O’Neill calls the Swedish playwright August Strindberg, "the master, more modern than any us, still our leader." Egil Törnqvist remarks that this statement should be not at all surprising, as O’Neill's dramatic works owe a great deal to the creative genius of the playwright; additionally, in this speech he was addressing the Swedish Academy and the Swedish people. ${ }^{2}$ It is only natural that O’Neill would praise Strindberg in this way. However, the praise O'Neill confers upon the Swede is not a solitary honor; in the same sentence, the American playwright bestows the same accolades upon German philosopher and modernist visionary Friedrich Nietzsche.

The connection between Nietzschian philosophy and O'Neill's plays has been well-documented, and no other literary/philosophical influence can be as transparently detected throughout the playwright's work. In a letter to close friend Benjamin de Casseres, O’Neill explicitly confesses his indebtedness to Nietzsche's work. He writes:

What you say of "Lazarus Laughed" deeply pleases me - particularly that you found something like "Zarathustra" in it. "Zarathustra," although my work may appear like a pitiable contradiction to this statement and my life add an exclamation point to this contradiction, has influenced me more than any other book I've ever read. I ran into it, through the

\footnotetext{
${ }^{1}$ Qtd. in Arthur and Barbara Gelb, O’Neill (New York, 1962), 814.

2 Egil Törnqvist, "Nietzsche and O’Neill: A Study in Affinity," Orbis Literatum, 23: 2, (June 1968), 97.
} 
bookshop of Benjamin Tucker, the old philosophical anarchist, when I was eighteen, and I've always possessed a copy and every year or so I reread it and am never disappointed, which is more than I can say of almost any other book. (That is, never disappointed in it as a work of art. Spots of its teaching I no longer concede. $)^{1}$

This passage has proven to be a powerful starting point for those studying the philosophical and literary influences present in O'Neill's plays, and many Nietzschian analyses of O'Neill's plays have been performed, beginning in earnest with an extensive, unpublished 1956 dissertation by Esther J. Olsen and continuing to this day in the work of Egil Törnqvist, Albert A. Kalson, and Lisa M. Schwerdt, among many others.

Bearing in mind the abundance of Nietzschian analysis available for all of O'Neill's work, the reader might wonder what another such analysis might contribute to a discussion of tragic emotion and Long Day's Journey into Night. On this objection, I should like to point out that the majority of analyses performed on Journey based in Nietzschian philosophy fail to adequately account for O'Neill's parenthetical statement to Casserres as presented above. O’Neill claims, as early as June of 1922, that there were spots of Zarathustra's teaching "that I no longer concede." The vast majority of Nietzschian approaches to Long Day's Journey into Night consider almost exclusively how mid- and late-Nietzschian themes (such as those represented in Thus Spake Zarathustra, The Gay Science, and The Geneology of Morals) manifest themselves in the playwright's work. To my knowledge, no critic or commentator looking at Journey has noticed that the play seems to reflect a much earlier Nietzchian sensibility, a sensibility obscurely but powerfully communicated in the philologist's first work, The Birth of Tragedy.

\footnotetext{
${ }^{1}$ Qtd. in Ibid., 97-98.
} 
In the following chapter, I intend to construct an interpretive framework utilizing Birth of Tragedy that reveals a key thematic message O'Neill intends his audience receive when viewing the play: a life well-lived (which is constituted of a positive attitude toward one's suffering) cannot be achieved in isolation; this life can be obtained only in interdependent relationship with others. In order to substantiate this claim, I will first describe O’Neill's understanding of and relationship to Nietzsche, making reference to how this understanding informs some of O'Neill's most important work. Next, I will explicate some important themes of The Birth of Tragedy and construct a method whereby one might analyze Long Day's Journey using those themes. With this interpretive frame established, in the next chapter I will perform a close reading of Journey that will demonstrate the validity of my thematic reading.

\section{2 "More Modern than any of Us"}

In order to grasp what O'Neill meant in his Nobel Prize acceptance speech, it may be necessary to roughly contextualize O'Neill's experience of Modernity, particularly as this experience was manifested in his experience of the theatre. Since O'Neill was raised in the home of James O’Neill, one of the most eminent American actors of his day, much of Eugene's experience of the advent of the Modern age develops along Nietzschian lines. Growing up in the world of the theatre, O’Neill sensed the aesthetic crisis that Nietzsche describes in Birth of Tragedy firsthand, and Nietzsche's hope for tragic redemption perhaps provided an impetus for O’Neill's own work.

O'Neill's father made his name and fortune in what had become an almost entirely commercialistic theatrical industry in the United States. In the decades before the 
Civil War, nearly every major American city had at least one resident stock company, ${ }^{2}$ but by the end of the 1800s, that system had largely eroded, so that most playhouses in the United States hosted traveling shows. These "combinations," traveling companies organized around one or more "stars," had access to towns and cities across the country because 130,000 new miles of track had been added by expanding railroad companies. ${ }^{3}$ This system is what allowed James O'Neill, the star of the colossally successful theatrical adaptation of The Count of Monte Cristo, to make a small fortune by performing in only one production throughout most of his career. This system was funded by large monopolies of theatre owners and producers, and "plays that appealed to conventional tastes and were likely to be profitable took precedence over innovation, experimentation, and literary merit."4 Eugene was born in a New York hotel in 1888, during one of James' touring seasons, and before he was sent to boarding school, he traveled extensively with his mother and father as James performed the lead role in Count.

By the time O'Neill began writing plays, the American theatrical scene was almost entirely relegated to New York. Daniel Watermeier remarks, "Indeed, 'Broadway' and 'American theatre' had become synonymous terms." Because of rising production costs and other factors, the "star" model of touring shows diminished, and most theatre of significance appeared on Broadway. Though the touring had largely ceased, the lion's share of the successful productions that appeared on Broadway during this time were still funded by large, monopolistic groups much more concerned about profit than artistic integrity. As a result, plays such as Peg O' My Heart, Abie's Irish

\footnotetext{
${ }^{2}$ A company of local performers presenting standard repertory from the English/American canon.

${ }^{3}$ Daniel Watermeier, "O'Neill and the Theatre of his Time," in The Cambridge Companion to Eugene O’Neill, (Cambridge: Cambridge University Press, 1998), 34.

${ }^{4}$ Ibid., 35.

${ }^{5}$ Ibid., 33.
} 
Rose, and The Count of Monte Cristo dominated the Broadway theatrical scene, making investors a great deal of profit and providing audiences exciting but rarely challenging theatrical experiences. The plays performed were familiar, thrilling, and entirely conventional, and audiences consumed such experiences in great numbers.

There were serious actors, critics, and playwrights working against this cultural trend toward commercial, "popular" entertainment to the detriment of "legitimate" theatrical production, but their voices were largely stymied by the power of the monopolies. William Winter, perhaps the most prominent American theatre critic, mourned that theatre had moved away "from the hands either of Actors who love and honor their art or of men endowed with the temperament of the Actor and acquainted with the art and its needs." ${ }^{\prime 6}$ 'Neill would sympathize with such a critique, and throughout his career he would refer to Broadway as the "Great Trite Way.",

The crisis the theatre faced in the United States mirrored the crisis Freidrich Nietzsche describes in his first—perhaps greatest—book The Birth of Tragedy. In a letter to Wagner that accompanied a manuscript of the book, Nietzsche points out what he believes to be the reason Germany finds itself ensconced in the Franco-Prussian war of 1870:

...if this act of self-collection were to prompt anyone to think of patriotic excitement and aesthetic self-indulgence, or courageous seriousness and serene play as opposites, they would be wrong; indeed, if such people really read the work they might realize, to their astonishment, that the matter with which we are concerned is a grave problem for Germany, a problem which we now place, as vortex and turning point, into the very midst of German hopes. Perhaps, however, these people will take offence at such serious consideration being given to any aesthetic problem at all, particularly if they are incapable of thinking of art as anything more than an amusing sideshow, a readily dispensable jingling

\footnotetext{
${ }^{6}$ Qtd. in “American Stage in Danger, says William Winter," in The Theatre Magazine 7:71, (1907), 268.

${ }^{7}$ Qtd. in Egil Törnqvist , "Nietzsche and O'Neill: A Study in Affinity," 102.
} 
of fool's bells in the face of the 'gravity of existence'...Let these serious people take note: my conviction that art is the highest task and the true metaphysical activity of this life is based on an understanding which I share with the man and fighter whose sublime lead I follow and to whom I now wish to dedicate this work. ${ }^{8}$

According to Nietzsche, Germany's conflict stems from a crisis of art. Art in Nietzsche's age has become largely "an amusing sideshow," a mere distraction from the problems of life, instead of a "metaphysical activity" of life. In plain terms, one of Nietzsche's aims in The Birth of Tragedy is to call the reader to art that draws the reader deep into lifeincluding, and perhaps primarily, the horror of life - instead of distracting her from it. In Nietzsche's account, such art had last manifested itself in Greek (particularly Aeschylian and Sophoclean) tragedy. Almost as quickly as it had emerged, this "tragic spirit," was killed by the father of Western knowledge, Socrates, who introduced the methodology of abstraction and cause and effect to ancient Greek thought. On Nietzsche's understanding, Socrates' deductive method of inquiry built a veneer over the horror of reality that produced an unfounded optimism, as Törnqvist describes it, "that despicable heritage which enslaves modern man." 9 Socratic philosophy attempts to make the world intelligible, but according to Nietzsche, the world is too horrible for human rationality too behold. On Nietzsche's view, Socrates gives people hope that they may overcome the world, and this hope is delusional. This optimism assures those who use the Socratic method they will be able to accurately apprehend and ultimately overcome the ways of the world, when in reality, the world is cruel and incoherent for human comprehension and too powerful an adversary to be dominated. Nietzsche will, upon later reflection, conclude that the problem he has uncovered is larger than the German inability to

\footnotetext{
${ }^{8}$ Friedrich Nietzsche. "Forward to Richard Wagner," in The Birth of Tragedy and Other Writings, Edited by Raymond Guess and Ronald Spiers, (Cambridge: Cambridge University Press, 2010), 13-14.

${ }^{9}$ Egil Törnqvist, "Nietzsche and O’Neill: A Study in Affinity," 101.
} 
appreciate significant tragic art; instead, the problem is "the problem of science itself, science grasped for the first time as something problematic and questionable." ${ }^{10}$ The translation of this line into English does not reveal entirely what Nietzsche is driving at here. The German term he uses here is Wissenschaft, which refers to any endeavor of study. The "science" of history, for example, might be referred to in German as Geschictswissenschaft. When Nietzsche refers then to a problem of "science," he is referring to a problem in the fundamental mode of knowledge humans in the West have trusted for two millennia. Nietzsche is not merely questioning the answers Westerners have developed to important life questions; he is questioning the method whereby the entire project of finding such answers has been undertaken.

When O'Neill refers to Nietzsche as "more modern than any of us," he is acknowledging Nietzsche's unflinching awareness of the crisis of Modernity. The very foundations of the world Westerners had trusted had rightly been called into question; as a result of this process much of the cultural heritage of the West had been wrecked. O'Neill saw himself as part of Nietzsche's lineage, an artist who is tasked with rebuilding authentic culture on the rubble of collapsed Socratic civilization. The rise and popularity of Apollonian, "plastic" theatre reflected a society that was fundamentally sick, and O'Neill believed, as did Nietzsche, that an authentic "tragic" theatre could provide the remedy for the cultural malaise infesting the United States.

Though both O'Neill and Nietzsche held critical views of the culture they inhabited, they both shared the conviction that a pre-Socratic, authentic mode of encountering reality could be actualized in their respective historical moments. This

\footnotetext{
${ }^{10}$ Friedrich Nietzsche, "An Attempt at Self-Criticism," in The Birth of Tragedy, Edited by Raymond Guess and Ronald Spiers (Oxford: Oxford University Press, 2010), 4.
} 
redemption would come through a return to tragic art. Nietzsche believed this rebirth to be embodied in Wagnerian opera, and he cheerfully writes that, "...we appear to be moving back from the Alexandrian age and towards the period of tragedy. At the same time we feel that the birth of a tragic age means the return of the German spirit to itself, a blissful reunion with its own being after the German spirit, which had been living in hopeless formal barbarism, had been tyrannized for too long by forms introduced from outside by a vast, invading force (BT 19)." O’Neill, similarly, believed that America was "in the throes of a spiritual awakening," soul from its Socratic bonds toward authentic existence.

Before one might ask how tragedy, on O'Neill's view, delivers its viewers from Socratic optimism to a "pessimism of strength," as Nietzsche calls it (in other words, an authentic attitude toward life) one must have an understanding of what Nietzsche refers to as the life well-lived, an authentic existence. In order to explicate such a concept, it is helpful to turn to O'Neill's favorite Nietzschian work, Thus Spake Zarathustra. O'Neill was captivated by this work from the time he discovered it in 1908, and he even translated it from the original German, despite having only a rudimentary knowledge of the language, aided by "a German grammar and a dictionary."12

Thus Spake Zarathustra is a perplexing work of literature, and though Nietzsche claimed it was his most important work, many in the philosophical and literary community often disregard it. However, during the Modern era, it appears that Zarathustra was Nietzsche's most popular book. ${ }^{13}$ This seems a strange puzzle for a

\footnotetext{
${ }^{11}$ Arthur and Barbara Gelb, O'Neill, (New York: Harper and Rowe, 1962), 487.

${ }^{12}$ Barrett H. Clark, Eugene O'Neill: the Man and His Plays, (Dover: New York, 1947), 25.

${ }^{13}$ Robert Pippin, Introduction to Thus Spake Zarathustra, Edited by Adrian Del Cairo and Robert Pippin, (Cambridge: Cambridge University Press, 2006). x.
} 
work so apparently haphazard, unusual, and possibly philosophically confused. Even more puzzling is exactly what to make of the work. How should one interpret Nietzsche's central theme in Zarathustra $?^{14}$

Nietzsche claimed, upon reflection, that the fundamental "idea of the work," is "the Eternal Recurrence, the highest formula of a life affirmation that can ever be attained (EH III:Z1)." The notion of eternal recurrence appears throughout Zarathustra, but the clearest and earliest explication of this doctrine appears in aphorism 341 of The Gay Science. In this aphorism, entitled "The Heaviest Weight," Nietzsche prompts the reader to consider what she might do if,

in some day or night, a demon were to steal into your loneliest loneliness and say to you: "This life as you now live it and have lived it you will have to live once again and innumerable times again; and there will be nothing new in it, but every pain and every thought and every joy and every though and sigh and everything unspeakably small or great in your life must return to you, all in the same succession and sequence - even this spider and this moonlight between the trees, and even this moment and I myself. The eternal hourglass of existence is turned over again and again, and you with it, speck of dust!"

Nietzsche provides the reader with two options at such a moment: either she throws herself down and gnashes her teeth, cursing the demon, or she proclaims that the demon is a god, imparting divine beauty upon her life. Nietzsche continues by asking the reader "how well disposed would you have to become to yourself to your life to long for nothing more fervently that to this ultimate confirmation and seal?" In Zarathustra, Nietzsche reiterates the doctrine of the eternal return:

"Now I die and disappear," you would say, "and in an instant I will be nothing. Souls are as mortal as bodies.

But the knot of causes in which I am entangled recurs - it will create me again! I myself belong to the causes of eternal recurrence.

\footnotetext{
${ }^{14}$ To make matters worse, Nietzsche even subtitles the book "A Book for All and None," perhaps acknowledging that even if the reader grasps the central theme of the work, she will likely reject it!
} 
I will return, with this sun, with this earth, with this eagle, with this snake - not to a new life, or a better life, or a similar life:

-I will return to this same and selfsame life, in what is greatest as well as in what is smallest, to once again teach the eternal recurrence of all things (Z III:13).

Though Nietzsche claims this to be the central teaching of Zarathustra, and perhaps the most important philosophical concept he has developed, it is unclear exactly what the "doctrine" here is. What central teaching is Nietzsche communicating here? That the universe is fixed as an eternal, repetitive cycle? That one ought to be ready to give an account of her life? That one ought to accept or reject her fate in a never-ending feedback loop?

Before I endeavor to provide an answer to these questions from an O'Neillian point of view, I should point out the significance of Eternal Return in some of O'Neill's most importatnt plays. Perhaps the earliest reference one might draw from O'Neill's plays to this teaching appears in Anna Christie (1920), when after a mystical cleansing by the sea, the title character claims, "It all seems like I'd been here before, lots of times on boats - in this same fog (AC II)." In the Emperor Jones (1920), Brutus Jones expresses a similar sentiment, “Seems like I know dat tree - an’ dem stones - an’ de river. I remember - seems like I been heah befo' ( $E J$ vii)." Upon initial reading, these statements seem to reference the Nietzschian Eternal Return, however Egil Törnqvist cautions those who adopt such an interpretation. He acknowledgesa that O'Neill might be drawing from a different intellectual tradition, that of psychoanalyst Carl Jung. ${ }^{15}$ Here he refers the reader Doris Falk's Eugene O'Neill and the Tragic Tension, as in the case of Anna Christie, Falk provides a convincing argument that Anna's déjà vu refers to "Jungian race memory or collective unconscious," by pointing out that Jung refers to the

\footnotetext{
${ }^{15}$ Egil Törnqvist, "Nietzsche and O’Neill: A Study in Affinity," 106.
} 
sea as a symbol of such mental phenomena. ${ }^{16}$ The entire play Emperor Jones, seems best understood through a Jungian hermeneutic, as through the plot of the play, Brutus Jones strips away layers of masks, "until at the end, he must confront his destiny - himself - in nakedness." ${ }^{\prime 17}$ If Falk is correct, O’Neill is likely only superficially invoking the doctrine of Eternal Recurrence while more directly referring to Jungian categories of mental experience.

It is easier to see references to the eternal return in O'Neill's characters that are forward looking. For example, Martha Jayson of The First Man (1921) proclaims: "Yes, it's been a wonderful, glorious life. I'd live it over again if I could, every single second of it - even the terrible suffering (TFM II)!" Martha not only wishes to relive the good parts of her life, she expresses what Nietzsche refers to as amor fati, a love of fate. Were the demon to appear to her at some time in the day or night and tell her that she would have to do it all over again, she would praise the demon as a god. At the moment of death, Ponce de Leon in O'Neill's The Fountain (1922) recognizes that his soul will be poured out into the "Fountain of Eternity," and that it will eternally return as part of the fountain. Törnqvist points out that these final lines of the play mirror Zarathustra's speech in Part Four of Thus Spake Zarathustra. ${ }^{18}$ Zarathustra asks of eternity, "When will you drink my soul back into yourself (Z IV: 10)?”

Many of O'Neill's middle plays represent the eternal return through cyclical repetition. Great God Brown and Ah, Wilderness! "both evoke seasonal recurrence at the

\footnotetext{
${ }^{16}$ Doris Falk, Eugene O'Neill and the Tragic Tension. (New Brunswick, NJ: Rutgers University Press, 1958), 51.

${ }^{17}$ Ibid., 67.

${ }^{18}$ Egil Törnqvist, "Nietzsche and O’Neill: A Study in Affinity,” 107.
} 
end of each." ${ }^{19}$ The most obviously Nietzschian play O'Neill wrote is Lazarus Laughed, which tells of the "ministry" of Lazarus after Jesus raised him from the dead. The Lazarus of O'Neill's play frequently resembles Zarathustra in his cheerful acceptance of life's fullness, including his eventual execution at the hands of the Roman government. Throughout the play, there is a constant refrain of "Death is dead!" aesthetically underscoring the theme of eternal recurrence through cycles of repetition. ${ }^{20}$

With the strong connection between O'Neill's plays and the doctrine of Eternal Recurrence established, I will now turn my attention to why this teaching mattered so much to O'Neill and how the reader ought to understand it. Though some evidence suggests that Nietzsche believed that Eternal Return was an actual description of the temporality of human existence ${ }^{21}$ - that each of us would continually live and relive our lives throughout eternity — the reader need not commit to its reality to appreciate the significance of this teaching as a kind of moral or psychological litmus test. Whether or not Eternal Recurrence is true, the reader might ask, "if this were true, how would I react?" Törnqvist reads Nietzsche's doctrine of the Eternal Return as endowing a great deal of meaning to every event of life. He writes, "the moral consequence of this is

\footnotetext{
${ }^{19}$ Zander Brietzke, The Aesthetics of Failure: Dynamic Structure in the Plays of Eugene O'Neill, (Jefferson, NC: Macfarland and Company, 2001), 130.

${ }^{20}$ Brietzke classifies the cyclical repetition within O'Neill's plays as repetition of seasons, generation, and struggle. He provides a number of examples not discussed here in his chapter entitled "Plays Without End" in The Aesthetics of Failure: Dynamic Structure in the Plays of Eugene O'Neill (Jefferson, NC: McFarland and Company, 2001), 126-164.

${ }^{21}$ The evidence does seem to support the claim that Nietzsche thought more of the doctrine than a mere thought-experiment. It seems that he believes that he has described a feature of reality in this teaching. In an 1881 note in which Nietzsche chides political systems who only think of addressing individual wellbeing in this moment, he writes, "My doctrine says; the task is to live in such a way that you must wish to live again - you will anyway! To whom striving is the highest feeling, let him strive; to whom rest gives the highest feeling, let him rest; to whom ordering, following, obedience give the highest feeling, let him obey. May he only become aware of what gives him the highest feeling and spare no means! Eternity is at stake!" (qtd. in Paul S. Loeb, "Identity and Eternal Recurrence," 179).
} 
obvious. It makes every moment of life important. ${ }^{, 22}$ It should be noted that the moral consequence of this is not nearly as "obvious" as Törnqvist asserts. A number of Nietzsche's critics have asserted the exact opposite. Martin Heidegger, for example, writes that "if everything recurs all decision and every effort and will to make things better is a matter of of indifference; that if everything turns in a circle, nothing is worth the trouble." ${ }^{23}$ For many, Heidegger's critique is sound and renders Nietzsche's central doctrine unpalatable. In fairness, such an objection is not easily answered; fortunately such an answer is beyond the scope of this work, for the evidence suggests that O'Neill interpreted the doctrine much more charitably.

One might read the doctrine of eternal return as an exhortation to live one's life in such a way that when the demon appears one is able to praise the demon because she will have the opportunity to live this fully through all eternity. On this line of interpretation, Nietzsche is providing the reader a motivational account, a reason she should live in a certain way. Unfortunately, this reading does not account for the fact that Nietzsche is very suspicious of the notion of "freedom of the will;" an important theme in Genealogy of Morals is that this concept is largely illusory and a product of the misguided approach of Western philosophy. ${ }^{24}$ What we think of as free moral choices, Nietzsche describes as the products of the evolution of civilization. If freedom of the will is illusory, it is unlikely that Nietzsche is suggesting that a meeting with the demon might change the way that the reader would behave. O'Neill seems to share Nietzsche's worry on this point, as in particularly The Iceman Cometh and Long Day's Journey into Night he crafts

\footnotetext{
${ }^{22}$ Egil Törnqvist , "Nietzsche and O’Neill: A Study in Affinity," 106.

${ }^{23}$ Martin Heidegger, Nietzsche Volume 2: The Eternal Recurrence of the Same. Translated by Farell Krell, (New York: Harper and Rowe, 1984), 65.

${ }^{24}$ For the most specific development of this claim, the reader might consult GM II:7.
} 
worlds in which the characters are ultimately powerless to stand against the whims of the universe.

If Nietzsche is not providing a motivational account, as he likely believes that human action and will is largely determined, what good is the thought experiment he presents to the reader? I believe the best way to read the doctrine of Eternal Recurrence is as a psychological test. The demon's statement allows the reader to evaluate her attitude toward her life. Is she able to affirm her life, even the darkest, most tedious, treacherous parts, or does the knowledge that life will repeat eternally banish her to a kind of mental Sisyphean hell? Ultimately, this is a test that determines what kind of person the reader is by determining her psychological response to her life's infinite return. Can the reader affirm her suffering? Is she positively disposed to the darkest moments of her life? Nietzsche might regard such a person as an Overman, a being able to overcome herself.

O’Neill seemed to view his writing of Long Day's Journey as evidence of such a self-overcoming. In his famous dedication letter, published in the 1956 edition of the play, he writes to his third wife Carlotta that "I give you the original script of this play of old sorrow, written in tears and blood...But you will understand, I mean it as a tribute to your love and tenderness which gave me the faith in love that enabled me to face my dead at last and write this play_—write it with deep pity and understanding and forgiveness for all the four haunted Tyrones." 25 Though here it seems O’Neill is adding his own caveat to the Nietzschian doctrine (a caveat I will discuss further in this chapter), the sentiment he expresses resonates with Zarathustrian life-affirmation. The act of

\footnotetext{
${ }^{25}$ Eugene O'Neill, Dedication of Long Day's Journey into Night, (New Haven: Yale University Press, 1956).
} 
writing an honest and painfully autobiographical play was, for O'Neill, a demonstration that he had the capacity to grasp, embrace, and affirm his own past personal grief.

\section{3 "Spots Of Its Teaching I No Longer Concede"}

In writing his most significant and final plays, The Iceman Cometh, Long Day's Journey into Night, and A Moon for the Misbegotten, O'Neill abandoned most of the theatrical experimentation that had marked much of his career. Sophoclean choruses, masks, and cyclical repetition have been left behind in favor of serious, albeit more theatrically conventional, dialogue and action. No longer is O'Neill attempting to pair Greek tragedy with American modernity as he did in plays such as Morning Becomes Electra. Travis Bogard describes Long Day's Journey into Night as "a return he to four boards and a passion - to in other words, a confident reliance on his actors." ${ }^{26}$ The form of the play is, as Edmund Tyrone might describe it, "a faithful realism."27 Given this turn in O'Neill's writing, one might naturally assume he has set aside his hopes for remaking society through theatrical tragedy as Nietzsche describes in his early work, and such assumptions are well-founded. By the time O’Neill writes Long Day's Journey, the experimental, Modernist mode of theatre he and the Provincetown Players endeavored to produce had largely fallen out of fashion in the United States, and perhaps it was clear to O'Neill that tragedy, on the whole, might not provoke the great "spiritual awakening" he had envisioned early in his career. Most critics analyzing Long Day's Journey from a Nietzschian point of view make this assumption regarding the play and focus their attention on certain themes within the play that seem sympathetic with Nietzsche's later

\footnotetext{
${ }^{26}$ Travis Bogard, “The Door and the Mirror," in Eugene O'Neill's Long Day's Journey into Night, (New York: Chelsea House Publishers, 1987), 62.

${ }^{27}$ Eugene O’Neill, Long Day's Journey into Night, (New Haven, CT: Yale University Press), 154.
} 
work, themes such as the death of God, inauthentic vs. authentic living, and dreary nihilism in the face of the horror of existence. What I propose however, is that Birth of Tragedy's presence looms large in Journey, and a close reading of the play reveals how much Nietzsche's first work informed O'Neill in the writing of his most important play. In order to argue for the significance of Birth of Tragedy within Long Day's Journey so that I may use it as an interpretive tool, I must first explicate some key themes of Birth of Tragedy. ${ }^{28}$ I will pay particular attention to the spirits of Apollo and Dionysus - the most significant figures throughout the book-using Nietzsche's text to construct a methodology whereby each of these concepts may be appropriated in order to analyze Long Day's Journey into Night.

While lecturing on pre-Socratic philosophy in 1870-71, Nietzsche became interested in what he began to refer to as the "Dionysian world-view." As a philologist by training, Nietzsche was disciplined in the art of "reading well." According to Pearson, philology is an art which "consists of reading slowly and deeply, and with which one looks and sees in a certain and specific manner." 29 This training allowed him to uncover what he believed to be the powerful driving force behind the pre-Socratic, Greek Spirit. He begins his analysis in Birth of Tragedy by examining Athenian tragedy before

\footnotetext{
${ }^{28}$ I should note that in addition to explicating Birth of Tragedy, I will draw from some of Nietzsche's later interpretations of BoT as well as some elements from his middle works, though I recognize that such an approach assumes that Nieztsche's work can be harmonized. There is a philosophical tradition of attempting to unify Nietzsche's ideas into a coherent system, and I find this tradition somewhat problematic, as the later Nietzsche will assert ideas that stand in fairly strong opposition to views the younger Nietzsche seemed to hold. For example, in "The Dionysiac World View," written roughly two years before The Birth of Tragedy, Nietzsche asserts that Dionysus and Apollo represent stylistic opposites, while in $B o T$, he is very clear to avoid describing these deities in dialectic terms. Here one sees an example of the maturation of Nietzsche's thought over a very short period of time, and he even acknowledges changes in his ideas about tragedy, Kant and Schopenhauer in "An Attempt at Self-Criticism."

Nevertheless, there are general constants in Nietzsche's thought, and I believe my approach relies most heavily on such constants.

${ }^{29}$ Keith Ansell Pearson, "Friedrich Nietzsche: An Introduction to his Thought, Life, and Work," in A

Companion to Nietzsche, Edited by Keith Ansell Pearson, (Boston: Blackwell Publishing, 2006), 2.
} 
Euripides. In Athenian tragedy, Nietzsche detects and identifies two primordial, psychological urges that the Greeks named for two of their most significant deities, Apollo and Dionysus. In art, Apollo is manifested in the "art of the image maker or sculptor," while Dionysus produces "the imageless art of music (BT §1)." Though these impulses make themselves most obvious in art, the Apollonian and Dionysiac spirits are fundamental features of the natural world. These powers "erupt from nature itself, without the mediation of any human artist, and in which nature's drives attain their first, immediate satisfaction $(B T$ §).”

These fundamental elements appeared to Attic Greeks in tragic art, and they are best understood, according the Nietzsche, in terms of analogy. Apollo reveals itself to the mind most readily in the "art-world" of a dream. In a dream, "every human being is fully an artist...and the lovely semblance of dream is the precondition of all the arts of image-making, including, as we shall see, an important half of poetry (BT §1).” Dionysus, however, is best understood in terms of intoxication. When intoxicated, the Dionysiac spirit causes "complete subjectivity to vanish to the point of complete selfforgetting." In this moment of drunkenness, those under the influence of this spirit "awaken either under the influence of narcotic drink, of which all human beings and peoples who are close the origin of things speak in their hymns, or in the approach of spring when the whole of nature is pervaded by a lust for life (BT §1)."

In order to appreciate the power of these images for Nietzsche, it may be helpful to consider the philosophical tradition which weighs heavily upon his interpretation of tragedy. Nietzsche is drawing here upon the work of the German nihilistic philosopher 
Arthur Schopenhauer. ${ }^{30}$ According to Schopenhauer's metaphysics, the world can be divided into two primary spheres: will and representation. Pearson explains that Schopenhauer,

borrows the expression principium individuationis (principle of individuation) from scholastic thinking and uses it to denote the phenomenal world of time and space as that which gives us a plurality of coexistent ad successive things...by contrast, the will is the thing-in-itself and outside the order of time and space. ${ }^{31}$

In Birth of Tragedy, Nietzsche appropriates this metaphysical dualism and, although he will attempt to improve on Schopenhauer's theory, roughly the forces manifested in Apollo and Dionysus reflect representation and the will, respectively.

The Apollonian spirit, conceived as a manifestation of principium individuationis, cultivated in representation, directly manifests itself in works people recognize as illusion. In a dream, for example, one may be drawn powerfully toward some image or conclusion, yet she still "nevertheless retains the sense that it is semblance $(B T \S 1)$." Representational art relies on the spirit of Apollo; artists and poets attempt to mirror the "real" world. People enjoy such representations, and part of this enjoyment is derived from the fact that they are somehow being willingly deceived about the nature of the object before them. In pairing Apollo with Schopenhauer's force of representation, Nietzsche is asserting that the Apollonian spirit reflects a fundamental fact of reality, that though people may conceive of themselves as individuals unique and apart from the world, in truth, they are willingly (and necessarily) deluding themselves, as the will underlies and unifies all things. While Nietzsche will be critical at times of the

\footnotetext{
${ }^{30}$ Nietzsche will break from Schopenhaurian metaphysics later in his career, and even in BoT he sees himself improving on his predecessor's theory. For a fuller discussion of this improvement, as well as Nietzsche's account of the individual and individuation, the reader might consult a very original interpretation in Nuno Nabais, "The Individual and Individuality in Nietzsche," in A Companion to Nietzsche, Edited by Keith Ansell Pearson, (Boston: Blackwell Publishing, 2006). 76-94.

${ }^{31}$ Keith Ansell Pearson, 5.
} 
Apollonian impulse, he does acknowledge its necessity in the lives of those who choose to go on living despite the horror of existence (BT §1).

Nietzsche points out that Apollo was also the god of prophecy, and this feature of the Apollonian urge will be especially relevant to his later critique of the Socratic Method. This Apollonian prophet might be best conceived of in terms of abstraction and pattern recognition, much like the philosophical and scientific tradition that followed Socrates. A prophet recognizes what he believes to be consistent, repeated features of the world (on Nietzsche's view, such features are Apollonian illusions), and he is able to abstract from these features to make predictions about future events as a result. It is important to bear in mind, however, that the features of the world the Apollonian prophet relies on are ultimately illusory, and though the prophet's predictions seem to reflect truth, these truths do not reflect the true nature of the world.

The phenomenal character of the Apollonian spirit might best be understood as one of repose. Of the image of Apollo, Nietzsche writes that it "should include that measured limitation, that freedom from wider impulses, that wise calm of the imagemaking $\operatorname{god}(B T \S 1)$." Apollo represents for humans the capacity to comprehend and control the world, and a human who possesses such an Apollonian spirit will meet the world with a kind of calm confidence, knowing that she will not be overcome by it. $\mathrm{He}$ invokes an image from Schopenhauer's World as Will and Representation to communicate this sense of calm:

Just as the boatman sits in his small boat, trusting his frail craft in a stormy sea that is boundless in every direction, rising and falling with the howling, mountainous waves, so in the midst of the world full of suffering and misery the individual man calmly sits, supported by and trusting in the principium individuationis (qtd. in $B T$ § 1).” 
The Apollonian spirit not only allows one to see herself as an individual, but it also endows her with the ability to traverse the horrors of the world without descending into terror.

The other deity manifesting itself in tragic art, the god of wine and fertility Dionysus, defies the principium individuationis. It is best understood in terms of intoxicated ecstasy, because in moments of group hysteria brought on by strong drink, one loses a sense of herself as unique, and experiences the feeling which "arises from the innermost ground of man, indeed of nature itself." When one is under the influence of the Dionysiac spirit, "he feels himself to be not simply united, reconciled, or merged with his neighbor, but quite literally one with him, as if the veil of maya had been torn apart, so that mere shreds of it flutter before the mysterious, primordial unity $(B T \S 1)$."

The knowledge one gains when experiencing Dionysiac ecstasy roughly correlates to the knowledge of the Schopenhaurian will. Those in such a state recognize they are one with all things, and for a moment, they are able to forget themselves and experience a basic unity with all existence, unmediated through language or other forms of mental abstraction. In effect, the spirit of wine and fertility endows his followers with the opportunity to appreciate reality at its fundamental level.

Nietzsche writes that in tragedy, the feelings aroused by the Dionysiac spirit are experienced as "Titanic" and "barbaric." Attic Greeks, participating in the festival of Dionysus, felt themselves connected to the greatness of their forbearers. The tragic hero that these Greeks venerated endures bleak and seemingly endless suffering. "Excess revealed itself as the truth; contradiction, bliss born of pain, spoke of itself from out of the heart of nature $(B T \S 4) . "$ The Dionysiac spirit unifies all beneath a singular banner of 
suffering. The unity that one derives from Dionysus is in part a recognition of the horror of life; all that exists does so through pain.

As I have suggested earlier in this chapter, though Nietzsche is analyzing the forces present in Attic tragedy, for him, this is not merely a historical or hermeneutical exercise. Instead, Nietzsche believes himself to be articulating a new, non-religious “justification for existence." By “justification of existence," Nietzsche seems to refer to two unique, but related concepts. The first of these concepts seems to be roughly ontological. He intends to offer the reader an occasion to view the world and her place in it through eyes untarnished by the Socratic — and what would later become the Christian - tradition. If one strips away the optimism produced through the Socratic tradition, she is able to appreciate the world as Dionysus describes it to Silenus. The king asks his companion "what is the best and most excellent thing for human beings?" The god replies,

"Wretched, ephemeral race, children of chance and tribulation, why do you force me to tell you the very thing which it would be most profitable for you not to hear? The very best thing is utterly beyond your reach not to have been born, not to be, to be nothing. However, the second best thing for you is: to die soon $(B T \S 3)$."

This passage is one Nietzsche's earliest suggestions of what will become a significant theme throughout his philosophical work: the horror of existence. At the heart of the existence is the truth that life is full of suffering, but this reality is not what is ultimately most horrifying. Kahn points out that "human beings can live with suffering. What they cannot live with is meaningless suffering — suffering for no reason at all. ${ }^{32}$ Yet this is precisely the reality that human beings inhabit. The world is not merely indifferent to

\footnotetext{
${ }^{32}$ Philip J. Kahn, "Horror, Eternal Recurrence, and the Horror of Existence," Journal of Nietzsche Studies 33 (2007), 49.
} 
human beings, "it is not designed for human beings at all...the cosmos is horrible, terrifying, and we will never surmount this fact. It is a place where human beings suffer for no reason at all. ${ }^{33}$

Given that such a world exists, what is one to do? Since Socrates, Westerners have ignored this reality and created a "scientific," Apollonian illusion to obscure the horror of existence, but Nietzsche suggests that Greeks before Socrates adopted a different strategy to "justify existence." Here, the justification of existence refers to a method whereby one might live a flourishing life in the context of a horrific universe. Even as early as The Birth of Tragedy, Nietzsche believes such a justification is possible, as he is already dissatisfied with Schopenhauer's nihilism. He writes,

For what must be clear to us above all, both to our humiliation and our elevation, is that the whole comedy of art is certainly not performed for us, neither for our edification or our education, just as we are far from truly being the creators of the world of art; conversely, however, we may very well assume we are already images and artistic projections for the true creator of art, and that our highest dignity lies in our significance as works of art - for only as an aesthetic phenomenon is existence and the world eternally justified (BT 5).

To navigate and embrace the horror of existence, one must adopt an attitude drawn from the experience of tragic art. In tragedy, the horror of existence is displayed through the mimetic representation of Apollo, and instead of being defeated, it is celebrated in the revelry of Dionysus. Though this concept is primitively communicated in Birth of Tragedy, Nietzsche is essentially making the same claim he will more fully develop in Zarathustra, a flourishing life can be achieved if one is able to unflinchingly gaze upon and celebrate her suffering.

\footnotetext{
${ }^{33}$ Ibid., 50.
} 
While what counts as an abundant life stays essentially the same throughout the development of Nietzsche's thought, there does seem to be a shift in how a positive disposition toward the horror of existence might be achieved - if such a disposition is even possible for most people. This shift seems to occur in reference to the role of the individual in a community. The later Nietzsche as represented in Zarathustra suggests on many occasions that an overflowing life - a life positively disposed toward the horror of existence - cannot be achieved in community with others. In "On the Love of the Neighbor," Zarathustra claims that the affirmation of others prohibits most people from becoming the Overman. He states, "you invite a witness when you want someone to speak well of you; and when you have seduced him into thinking well of you, you think well of yourselves $(Z 1 ; 16)$." The affirmation of others leads one away from her true nature, the "farthest," as Zarathustra describes it in this passage. He writes that one's love of her neighbor is her "bad love" for herself. He echoes such a sentiment in his discussion on marriage and procreation, pointing out that most people procreate as a distraction from themselves, thus failing to live up to their true natures $(Z 1 ; 20)$.

At the end of the first part of Thus Spake Zarathustra, the prophet leaves his disciples, advising them to go into the world alone as well, because he recognizes that even his companionship inhibits them from actualizing themselves in the way that he has been describing. In what amounts to a loose parody of Christ's warning to Peter that he would deny Him three times, Zarathustra commands his followers, “Indeed, I counsel you to go away from me and guard yourselves against Zarathustra! And even better: be ashamed of him. Perhaps he deceived you $(Z 1 ; 24,3)$." This dramatic moment underscores the individual's need to stand alone and affirm her life by her own strength. 
In point of fact, Zarathustra claims that even his influence may be inhibiting his followers from achieving such a goal.

Perhaps this feature of Nietzsche's philosophy expressed in Zarathustra is what O'Neill refers to in his letter to de Cacerres as a point he can no longer concede. This seems a fair assumption in light of O'Neill's dedication letter to Carlotta published in Long Day's Journey into Night. O'Neill sees the writing of the play as a way of facing and affirming his suffering as embodied in the dead members of his family, but he found himself only emboldened to do so through her "love and tenderness." This act of selfovercoming was assiduously difficult for O'Neill, as his wife Carlotta reports in her diary. He was, according to her account, "being tortured every day by his own writing. He would come out of his study at the end of the day gaunt and sometimes weeping. His eyes would be all red and he looked ten years older than when he went in in the morning." ${ }^{34}$ Yet O’Neill saw himself as one who courageously faced his suffering and captured it aesthetically, a course of action Nietzsche would applaud. However, he does not face this suffering alone. Self-overcoming, on Nietzsche's developed view, can only be achieved in isolation, but O'Neill believes differently; he attributes his ability to overcome himself to courage derived from a faithful, loving relationship with another.

There was a Nietzschian option amenable to such a view, however, and this option is described in Birth of Tragedy. Here, O'Neill might have considered more thoroughly the mode of life affirmation described by Nietzsche in Birth of Tragedy, and he may have discovered that Nietzsche had, in his first work, articulated a claim sympathetic to O'Neill's beliefs about life-affirmation. Greek tragedy was produced in

\footnotetext{
${ }^{34}$ Qtd. in Travis Bogard, “The Door and the Window," in Eugene O'Neill's Long Day's Journey into Night, Edited by Harold Bloom, (New York: Chelsea House Publishers, 1984), 62.
} 
context of community. The festivals of Dionysus were a collective event, and it is this context which produces the union of the Apollonian and Dionysiac powers. Hellenic tragedy, according to Nietzsche, provides an occasion during which the Greeks gazed upon and celebrated their common identity, an identity fundamentally unified by the fact that all living things suffer. The individual has an opportunity to approve of her suffering because of her collaboration with the community of sufferers in which she finds herself. Unlike Zarathustra, who urges his disciples to go out into the world and actualize themselves alone, the early Nietzsche believes such an existence can be attained through interaction with an event that requires the willing — and authentic — contributions of others. $^{35}$ This theme seems to resonate as a key element of Long Day's Journey, and with Birth of Tragedy in mind, paired with the life-affirming elements of Nietzsche's developed philosophy, supports such a reading of the play

\footnotetext{
${ }^{35}$ Interestingly enough, Zarathustra even directly criticizes such events, claiming "Nor do I love your festivals: too many actors I found there, and even the spectators behaved often as actors $(Z 1 ; 16)$." This illustrates the significant evolution of Neitzsche's thought on this point. In BoT, Nietzsche had offered many words of praise for such festivals, believing Wagnerian drama to be a modern incarnation of them, however, after his split from Wagner, he finds such events to be counter-productive to the task of becoming the Overman. In light of "The Attempt at Self-Criticism," perhaps this position should be nuanced somewhat, but it is consistent to point out in this introduction at no point does Nietzsche offer praise of tragedy per se, instead praising BoT for the modern problems that it raised, which he believes himself to be exploring in his later work.
} 


\section{CHAPTER FIVE \\ A NIETZSCHIAN READING OF LONG DAY'S JOURNEY INTO NIGHT}

\subsection{Introduction}

With the key principles of Birth of Tragedy explicated, I am now in a position to apply these principles to a reading of Long Day's Journey into Night. It is highly unlikely that in Birth of Tragedy Nietzsche is proposing anything resembling a hermeneutic method one might use to read a work of literature, however, the above explication has revealed rough categories to do such a reading. In what follows, I will describe these categories, drawing from the above explication and distilling the conceptual content I intend to use to interpret the play:

1.The Horror of Existence-As described above, this concept is represented in Dionysus' answer to Silennus' question: “The very best thing is utterly beyond your reach not to have been born, not to be, to be nothing. However, the second best thing for you is: to die soon." This interpretive category will be used to describe moments of the play which depict the "horrific universe," a universe not only indifferent to human existence, but in fact hostile to life. Additionally, this category will describe depictions of what amounts to meaningless suffering within the play.

2.Affirmation of Life - This concept refers to an individual's capacity to embrace life "as it is," which means not only accepting the hardships and suffering inherent in 
existence, but embracing and even celebrating such hardships. A person with such a disposition toward her own suffering can be described as having overcome herself. This does not refer to a "grin-and-bear-it" sort of attitude, which relies on an understanding that at some point suffering will end. Instead, this is a grim "pessimism of strength," that affirms unending (and perhaps eternally recurring!) difficulty.

3.The Dionysiac - Arises in moments of intoxicated ecstasy, when individuality is lost. The Dionysiac feeling is a primitive, titanic, experience, marked with excess and indulgence. Individuals under the influence of Dionysus recognize themselves as one with all living things. It is a "bliss borne of pain," therefore one should not construe the intoxication of the Dionysiac spirit as an escape from life's suffering, but as an spirit which empowers those under its influence to deeply appreciate such suffering. Under possession of Dionysus, self-deception is stripped away, along with individuality, and this enables those in such a state to glimpse the world for what it is and who they are within it. In this sense, the Dionysiac refers to unflinching awareness of the truth, especially those truths that are so horrible most people wish to remain unaware of them.

4.The Apollonian-The Apollonian manifests itself, not merely in mimetic art, but in the human propensity to abstract illusion from reality. Under the Apollonian influence, people cultivate a sense that the world can be overcome and predictable outcomes can emerge from past events. The emotional state produced by Apollo might best be described as calm, however it is important to point out that this calm feeling is based upon the dubious belief in man's ability to defeat the destructive forces of the world. Informed by Apollo's spirit, people believe themselves to be unique individuals, able to 
guide their own destinies. While this may be a necessary self-deception for many, such a belief inhibits people from attaining their highest nature.

If one reads Long Day's Journey into Night with these categories in mind, I believe she will come to two important conclusions: 1)In the writing of O'Neill's greatest play, the playwright is heavily informed, not just be a general Nietzschian philosophy, but specifically by a Nietzschian philosophy drawn from Birth of Tragedy, and 2)With Journey, O’Neill intends his audience understand that a positive attitude toward life as Nietzsche describes cannot be achieved in isolation; instead, such a disposition can only be obtained in concert with others. In what follows, I will conduct a close analysis of the play that should validate both (1) and (2).

\subsection{A Nietzschian Reading of Long Day's Journey into Night}

As Long Day’s Journey into Night opens, O’Neill carefully and "novelistically" prescribes the setting and stage layout. The play is set in August of 1912, and the events of the play unfold over a single day in the parlor of Tyrone home. In O'Neill's initial description of the layout of the stage, the careful reader already begins to sense the Apollonian/Dionysiac tension that will play itself out on this day in the Tyrone home. On stage right, between two entrances O’Neill describes,

a small bookcase, with a picture of Shakespeare above it, containing novels by Balzac, Zola, Stendhal, philosophical and sociological works by Schopenhauer, Nietzsche, Marx, Engels, Kropotkin, Max Sterner, plays by Ibsen, Shaw, Strindberg, poetry of Swinburne, Rosetti, Wilde, Ernest Dowson, Kipling etc... Farther back is a large, glassed-in bookcase with sets of Dumas, Victor Hugo, Charles Lever, three sets of Shakespeare, The World's Best Literature in fifty large volumes, Hume's History of England, Thiers' History of the Consulate and Empire, Smollett's history of England, Gibbon's Roman Empire and miscellaneous volumes of old plays, poetry, and several histories of 
Ireland. The astonishing thing is that all the volumes have the look of having been read and reread. ${ }^{1}$

As the audience member gazes for the first time at the set, she - provided she had the ability to read the titles of the books on each shelf ${ }^{2}$ - immediately is able to sense the tension between the Dionysiac and Apollonian. Beneath a looming image of Shakespeare, the viewer discovers what is undoubtedly Edmund's library. These works certainly reflect O'Neill's autobiographical impulse, representing the philosophy and literature he was reading in 1912 before entering a tuberculosis sanitarium, however from a Nietzschian vantage point, perhaps such works represent a mode of knowing the world that might be loosely characterized as Dionysian. The thinkers listed represent radical lines of divergence — not simply in content, but in epistemological method—from those represented in the glassed-in bookshelf farther back, presumably the library of James Tyrone. On the one hand, Edmund is absorbed in the work of egoists, nihilists, radicals, and anarchists, while James reads and rereads received historical accounts detailing the standard story of Western evolution. Hume and Gibbon's empirical approaches to past events stand in stark contrast to the assertions found in Nietzsche, Marx, and Engels that Western culture is fundamentally warped and has to be remade.

The creative and dramatic literature represented on each of these bookcases represents a similar divergence. The works of Dumas, Hugo, and Lever typically portray heroic figures that, despite intense struggle, rise above their world and conquer their opposition. Such works clearly represent a "Socratic optimism" about man's ability to

\footnotetext{
${ }^{1}$ Eugene O'Neill, Long Day's Journey into Night, (New Haven: Yale University Press, 1956), 11.

${ }^{2}$ I admit that it is unlikely the audience member would be aware of the titles of the texts on the shelves. However, throughout the play, O'Neill heavily prescribes such details about the way the set should look, lighting and sound cues, and even how lines are to be delivered by the actors. Though some of these features may go unappreciated by the audience, it does seem clear that O'Neill places such "Easter eggs" within the text to create an atmosphere where his thematic message might be made evident.
} 
overcome the universe in the face of hardship. The Apollonian character of such works informs James' illusion of the world, and in the final act of the play, he will acknowledge how his adherence to creating such an illusion in the form of a single, Romantic theatrical role has robbed him of the ability to personify his true talent as an actor. By contrast, the novels of the Balzac, Zola, and Stendhal appearing on Edmund's shelves contain naturalistic and often bleak portrayals of the world. These French writers embody an unflinching look at reality, regardless of the loss of the centeredness or optimism that might result from such an act. Paired with these naturalists, it seems hardly a stretch to suggest that the decadent, self-indulgent poetry of Swinburne and Wilde, full of reckless sexual experimentation, are included to refer to Dionysian revelry which is certainly Nietzschian in spirit. These books, embedded, practically invisibly within the set, are a literary manifestation of the contest which will take place on this day- the contest between Apollonian illusion and Dionysiac intoxication.

The play opens just after breakfast, and the morning sunshine illuminates the stage from the windows at the right of the stage. Mary and James Tyrone enter the room, playfully discussing Mary's recent weight gain and healthy appetite. Mary points out, by contrast, that Edmund had no appetite for breakfast whatsoever, foreshadowing the later revelation that he has contracted tuberculosis. As she does, the viewer discovers that she has become agitated and nervous, her hands frantically fidgeting. This moment is the first indication that Mary has resumed her use of morphine, an addiction she with which has been struggling since the birth of Edmund. Since Edmund has returned home for the summer, and Mary has begun to suspect that he is consumptive, the stress has driven her back to her addiction, from which she had been previously in recovery for three months. 
Early on in this act, a major motif is introduced as Mary and James discuss the fog of the previous night. Mary complains that the sound of the foghorn kept her awake throughout the night, and James empathizes, though it is fairly clear that he slept soundly through the noise. The fog is clearly symbolic throughout the play, although many critics differ on what exactly the fog represents. On the surface, the fog, steadily increasing throughout the day, frames the descent into intoxication which will occur as the day progresses. Beneath the surface, Falk claims that the fog 'O'Neill's first and last symbol of man's inability to know himself."3 Here she is undoubtedly referring in part to one of O’Neill's earliest (and perhaps worst!) one-act plays The Fog. From Falk's Jungian point of view, this interpretation has considerable merit, however I intend to argue throughout this reading of the play, that the fog-akin to the intoxication it portends - is a Dionysiac symbol which points to man's ability to see through the "veil of maya," and recognize himself as one with all that exists. In contrast to Falk, throughout my analysis, I will defend the claim that the fog symbolizes man's ability to know himself, as Nietzsche would likely argue, beyond the illusion created by Apollonian individuation. Instead of drawing one away from reality, throughout the play, the fog draws members of the Tyrone family deeply into reality at its most fundamental level.

As the Tyrone sons Edmund and Jamie enter the room, the mood continues to be light and jovial, however it is clear that much of this joviality is feigned. First of all, Jamie - perhaps the character in the play most sensitive to the signs of his mother's addiction — notices that Mary is acting a bit too happy this morning. His stare during her quips about James' snoring, immediately provokes a guilty reaction from Mary, and she

\footnotetext{
${ }^{3}$ Doris Falk, “Long Day's Journey,” in Eugene O'Neill's Long Day's Journey into Night, (New York: Chelsea House Publishers, 1987), 11.
} 
begins nervously fussing with her hair. When Jamie attempts to change the subject by sharing in Mary's joke about the volume of James' snoring, the elder Tyrone immediately attacks Jamie's frivolous gambling and aimless lifestyle. Upon Mary's admonition, James changes the subject and resumes the ruse of family serenity by asking the sons what they had been joking about in the dining room.

Edmund relates a story he had been told the night before in a bar by Shaughnessy, a poor Irish farmer who is renting land from Tyrone. The land that Shaughnessy rents borders the land of Harker, an oil millionaire who is friends with Tyrone. Edmund relates the story Shaughnessy had shared with him:

Well, you remember, Papa, the ice pond on Harker's estate is right next to the farm, and you remember Shaughnessy keeps pigs. Well it seems there's a break in the fence and the pigs have been bathing in the millionaire's ice pond, and Harker's foreman told him he was sure Shaughnessy had broken the fence on purpose to give his pigs a free wallow.

So, Edmund continues, when Harker confronts Shaughnessy with his foreman's

accusation, the Irish farmer,

accused Harker of making his foreman break down the fence to entice the pigs into the ice pond in order to destroy them. The poor pigs, Shaughnessy yelled, had caught their death of cold. Many of them were dying of pneumonia, and sever others had been taken down with cholera from drinking the poisoned water. He told Harker he was hiring a lawyer to sue him for damages. And he wound up by saying that he had to put up with the poison ivy, ticks, potato bugs, snakes, and skunks on his farm, but he was an honest man who drew the line somewhere, and he'd be damned if he'd stand for a Standard Oil thief trespassing. So would Harker kindly remove his feet from the premises before he sicked the dog on him. And Harker did! ${ }^{4}$

Of this passage, Törnqvist remarks that "O'Neill has inserted what to a casual observer may seem a digression out of tune with the serious mood of the play and

\footnotetext{
${ }^{4}$ Long Day's Journey into Night, 24-25.
} 
completely unrelated to it." However, he contends that this passage is significant not only because it serves as an episodic starting point for O'Neill's later Moon for the Misbegotten, but that it "obviously helps to characterize the Tyrones in the sense that their reactions to it reveal something about their natures." ${ }^{\prime 6}$ Törnqvist argues that this story is a microcosm of the family's story, and that the fate of pigs eerily resembles the fate of each member of the Tyrone family. He points out that James' reaction to the retelling of the story is quite telling. Initially, James responds with admiration for Shaughnessy's boldness, laughing as he proclaims the Irishman, "the damned old scoundrel! By God, you can't beat him!" However, as James reflects for a moment on the situation, he quickly changes his mind, telling Edmund, "That dirty blackguard! He'll get me in serious trouble yet. I hope you told him I'd be mad as hell." ${ }^{7}$ Edmund points out that his father is secretly "tickled to death by the great Irish victory," 8 and his observation makes the conflict within James' response to the incident clear. On one hand, James feels a great sense of connectedness with his Irish tenant because he too had risen from abject Irish poverty, and this incident represents a victory for a "wily Shanty Mick." 9 On the other hand, however, as an immensely successful matinee actor and incredibly wealthy member of the upper class aristocracy, he believes himself responsible to his station in the world. Tyrone's feigned offense at the effrontery of Shaughnessy, which the whole family — as well as the audience — clearly sees through, might be read as an attempt by Tyrone to maintain an Apollonian lie with respect to his own life. Tyrone claims to be worried about a potential lawsuit filed against him, but what he really

\footnotetext{
${ }^{5}$ Egil Törnqvist, "Life in Terms of Lives," in Eugene O'Neill's Long Day's Journey into Night, (New York: Chelsea House Publishers, 1984), 54.

${ }^{6}$ Ibid., 55.

${ }^{7}$ Long Day's Journey into Night, 25.

${ }^{8}$ Ibid.

${ }^{9}$ Ibid., 22.
} 
worries about is his standing with people like Harker, who live in a social class to which he does not rightfully belong. Jamie seems to relish his father's unveiling before Harker, as he maliciously quips, "I'll be the next time you see Harker at the Club and give him the old respectful bow, he won't see you," to which Edmund adds, "Yes, Harker will think you're no gentleman for harboring a tenant who isn't humble in the presence of a king of America."

As Tyrone's tone escalates, Edmund decides to leave the go upstairs to read in order to avoid more conflict. When he is gone, Jamie worries aloud that Edmund is suffering from something worse than a "summer cold," and it is clear he believes Edmund to be consumptive. Mary's demeanor immediately changes upon the mention that Edmund might be really ill. Once again, she begins to nervously adjust her hair in the mirror, and she remarks how it had once been a beautiful, "rare shade of reddish brown."11 She complains that she cannot see clearly in the mirror because she does not have her glasses. To perceptive readers this is yet another sign that she has resumed her use of morphine, as this act is an attempt to maintain the appearance of self-control, though her ability to do so is quickly slipping away. Throughout the first two acts of the play, each time Mary gazes at herself in the mirror, the reader might infer, through eyes informed by Nietzsche, that Mary is desperately attempting to reclaim an Apollonian illusion of herself. Throughout her life, she has defined herself in terms of the praise of others, as is evidenced by her asking Tyrone, "but I truly did have beautiful hair once, didn't I, James?" Here one might recall the words of Zarathustra, "you invite a witness when you want someone to speak well of you; and when you have seduced him into

\footnotetext{
${ }^{10}$ Ibid., 23.

${ }^{11}$ Ibid., 28.
} 
thinking well of you, you think well of yourselves $(Z 1 ; 16)$." As the features that she was once praised for have faded due to old age, she tries in vain to maintain the illusion by constantly adjusting and primping in the mirror, but the approval she had received was superficial and transitory, like the images of Apollo. It is only later in the play, when Mary is in the euphoria of a morphine high, where the audience will actually be able to glimpse — and appreciate her—for who she really is behind the illusion.

After Mary leaves the room to make dinner arrangements with the cook, Jamie reveals himself to be the most Dionysian character in the play. In the ensuing quarrel with his father, this is suggested in two ways: First of all, and most obviously, the audience learns that Jamie is a "no-good" carouser, a frequenter of whore houses, who squanders his genetic ability to be a fine actor. Instead of living up to his reputation as a Tyrone, Jamie opts for more immediate and primal gratification. Secondly, Jamie perpetually implores his family to see the world for what it is, making no accommodation for personal fear. When Tyrone tells him that he should not worry his mother about Edmund's condition, Jamie shrugs and says, “All right, have it your way. I think it's wrong to let Mama go on kidding herself. It will only make the shock worse when she has to face it." 12 He criticizes Doc Hardy for "pulling punches" with Edmund's diagnosis, and he directly points out that his father is a miser, even when it comes to paying for his son's care. From Edmund's youth, Jamie had taught his younger brother how to navigate barrooms and whore houses; he had "put Edmund wise to a few things," teaching him "that if you can't be good, at least you can be careful."13 Jamie is not afraid to face the horror of existence, and his drinking and "irresponsible" lifestyle are not

\footnotetext{
${ }^{12}$ Ibid., 29.

${ }^{13}$ Ibid., 34-35.
} 
attempts to escape reality, but to live fully. Tyrone points out that Jamie is able to live this way because he has his inherited his father's strong constitution. In contrast to Edmund, Jamie is a "healthy hulk," and this characteristic rings as a characteristic of Nietzsche's Overman. Jamie's reckless living, propensity for truth-telling, and physical and mental power to withstand the horror of existence can be best accounted for as Dionysian characteristics.

During Tyrone and Jamie's emsuing argument, the audience also learns that Edmund has recently returned home from a voyage as a merchant sailor, and that since the suspicion of his consumption has been raised, both Jamie and Tyrone have begun to worry that Mary will succumb to worry and return to her addiction. Jamie's suspicions have been raised because he observed his mother in the spare bedroom instead of sleeping with her husband the night before. It is implied that she has used the spare bedroom as a location to administer morphine, and Jamie recognizes that Mary, because of her fear that Edmund has tuberculosis, is on the verge of relapse. Upon Jamie's mention that Mary had been in the spare room, Tyrone immediately rebukes his son, dismissing the truth that he undoubtedly knows. Tyrone lamely claims that his wife was in the spare bedroom to avoid his snoring, and even Jamie seems to be satisfied with this claim, although it is clear that both men are deceiving themselves. Again, the conflict between Apollonian illusion and Dionysiac honesty is evident. Tyrone would rather believe a useful fiction instead of faithfully engaging his wife's condition.

Mary returns to the parlor and interrupts the argument between Jamie and his father, and the Jamie hastily reminds the elder Tyrone that they are wasting a fine morning and that they should be outside trimming the hedges. To avoid explaining the 
argument to Mary, Tyrone hastily agrees with his son. At a functional level, O'Neill uses the hedge-trimming excuse as a means to get Jamie and Tyrone offstage in order to set up a dialogue between Mary and Edmund, however even the Tyrone's hedge-trimming reveals certain Nietzschian qualities to the audience. After returning to the parlor, Mary looks out of the window and notices that as one of the wealthy neighbors drives by in their new Mercedes, Jamie hides beneath the hedges to avoid being seen, while James pauses in his work to bow to them "as if he were taking a curtain call."14 Mary is embarrassed that her husband would make such a show of himself in a filthy suit of clothes that she has tried to throw away, and she is also embarrassed that instead of paying a gardener to trim the hedges, her husband, one of the most esteemed actors in America, chooses to do it himself. In Mary's critique of Tyrone, one is able to appreciate a tension in his mode of being in the world that might be described in terms of Apollo and Dionysus. On the one hand, as an upstanding and important member of the small New London community, Tyrone is obligated to keep the grounds of his estate appropriately manicured, to perpetuate a carefully managed aesthetic in order to keep up appearances. On the other hand, however, Tyrone who comes from a very humble working class background cannot bring himself to pay a hired hand to care for his property. In this manual labor, Tyrone reveals his authentic nature as a working class Irish immigrant who has little concern for the trappings appropriate for an American of his means. However, when confronted with other members of his community, he quickly, but awkwardly, adopts a demeanor that conforms to social expectations and bows ridiculously to his pretentious neighbors. Mary's remarks demonstrate the absurdity of Tyrone's life: he is attempting to occupy two worlds, and even he, a great

\footnotetext{
${ }^{14}$ Ibid., 43.
} 
performer, cannot authentically accomplish such a feat. Jamie realizes the absurdity of such a position and hides from the passersby, further pointing up the silliness of his father's position.

Though Mary sees clearly the artificiality of her husband's position, at this point in the play, (in the sober light of day) she is unable to recognize her own struggle between the Dionysian and Apollonian impulses. In her conversation with Edmund she reveals that she has never felt at home in the New London house, and one of her chief complaints is that she is always alone. Immediately the conversation turns toward the direction of Mary's struggle with morphine addiction, and she asks him not to remind her of the past. Edmund responds, "Please, Mama! I'm trying to help. Because it's bad for you to forget. The right way is to remember, so you'll always be on your guard. You know what's happened before." ${ }^{\prime 15}$ Here, the reader sees what might be read as a rejection of Nietzsche's Zarathustran doctrine of the affirmation of life in favor of a Dionysian doctrine of the affirmation of life. Edmund's admonition to his mother to remember might best be understood both as a way to manage her addiction and as an encouragement to her to affirm her suffering. However, Mary is incapable of doing this alone; her loneliness exacerbates her suffering, and instead of facing her past and present difficulties, she attempts to drown her sorrows in the haze of a morphine induced high. Ironically, in such states of intoxication, Mary does not escape the horrors of her existence; as the play progresses into the last act, the audience sees Mary from behind the veil. Under the influence of the drug, Mary sees her world and herself for who she is and faces this reality with courage. Here in act one, this theme is only suggested for a brief moment in Edmund's dialogue with his mother, but nearly as quickly as this discussion

\footnotetext{
${ }^{15}$ Ibid.,45.
} 
begins, it ends with Mary admonishing her son to go outside and read so that she can nap upstairs. It is clear to both Edmund and the audience that Mary's worry about Edmund's condition is getting the best of her, and that she intends to go upstairs to dose herself with morphine. Instead of protesting, Edmund adopts a joking tone and agrees to go get some fresh air. The act closes with Mary sitting in the parlor, struggling with a state of "nervous panic." As the curtain for Act 1 falls, Mary "begins a desperate battle with herself. Her long fingers, warped and knotted by rheumatism, drum on the arms of the chair, driven by an insistent life of their own, without her consent."16

Act II begins shortly before lunch. Edmund sits in the parlor reading, and the servant Cathleen brings a in a bottle of bonded bourbon from which he sneaks a quick drink, despite knowing that he should not, given his poor health. Jamie enters a takes a drink of his own, pausing to fill the bottle of whiskey with enough water to compensate for what he had taken. He scolds his brother for having a drink in his condition. Edmund responds by saying that after he has officially receive the bad news, he will give up alcohol in the interest of his recovery. Again, Jamie, in his typical Dionysian mode, praises his brother for preparing for the worst. Jamie next asks Edmund about the whereabouts of his mother and is shocked to discover that Edmund had allowed Mary to go upstairs "to take a nap" in the spare room. Edmund attempts to defend Mary, claiming that she was merely taking a nap and scolding Jamie for his distrust of his mother. Jamie responds,

Listen, Kid, I know you think I'm a cynical bastard, but remember I've seen a lot more of this game than you have. You never knew what was really wrong until you were in prep school. Papa and I kept it from you. But I was wise ten years or more before we had to tell you. I know the

\footnotetext{
${ }^{16}$ Ibid., 49.
} 
game backwards and I've been thinking all morning of the way she acted last night when we were asleep. ${ }^{17}$

In this speech, the reader catches a glimpse of the unity produced in tragedy that Nietzsche describes in Birth of Tragedy. Jamie, the Dionysian, is using his knowledge of past events to predict the outcome of Mary's current behavior, an Apollonian move. Embodied in Jamie in this moment is the Apollonian ability to prophesy based upon past patterns, coupled with the Dionysiac spirit of authentically gazing upon the horrors of life.

Mary comes downstairs, and it is clear to the audience that she is under the influence of a narcotic. She no longer appears nervous, her eyes are brighter, and her demeanor is one of "peculiar detachment."18 In her ensuing dialogue with her sons, the reader is struck by her frankness. When Jamie criticizes his father for delaying lunch so that he might put on airs with a passing neighbor, Mary bitterly scolds her son, "Everyone else admires him and you should be the last to sneer-you, who thanks to him, have never had to work hard in your life!" When Edmund asks his mother why she feels the need to attack Jamie so suddenly, she replies:

Because he's always sneering at someone else, always looking for the worst weakness in everyone... But I suppose life has made him like that, and he can't help it. None of us can help the things life has done to us. They're done before you realize it, and once their done they make you do other things until at last everything comes between you and what you'd like to be, and you've lost your true self forever. ${ }^{19}$

Mary, under the influence of the drug, does not delude herself about the nature of her son.

In her accusation of him, she faithfully articulates the horror of reality, and she recognizes in her own life the impossibility of living authentically. As the play closes,

\footnotetext{
${ }^{17}$ Ibid., 57.

${ }^{18}$ Ibid., 58.

${ }^{19}$ Ibid., 60-61.
} 
the audience will come to understand that morphine addiction is ultimately not what has prevented Mary's authentic existence; in point of fact, as Mary slips more deeply into her intoxication through the progression of the play, she becomes more self-aware, selfaffirming, and honest. Intoxication, like the fog, reveals the true nature of reality instead of obscuring it. At this point in the play, this is only suggested, however this theme will become clear as the play develops.

Mary’s frankness in interrupted by Jamie's accusation. As Edmund steps out onto the porch to hurry his father along, Jamie tells his mother that she is not fooling him; he knows what she has done. Mary attempts to veil her intoxication, but Jamie tells her to look at her eyes in the mirror. Based upon the dilation of her pupils, Jamie easily discerns that she has been using drugs, but she flatly denies it and when Edmund returns, she scolds Jamie for his accusations. This scolding raises Edmund's ire, and the brothers quarrel, diverting their direct attention away from Mary, though they are arguing about her. Mary leaves the parlor before Tyrone enters, and he and his sons have a drink, though he has reservations about giving the ailing Edmund whiskey. When Mary returns and sees Edmund's empty whiskey glass, she turns her frank accusation toward Tyrone and says, "You're to blame, James. How could you let him? Do you want to kill him? Don't you remember my father? He wouldn't stop after he was stricken. He said doctors were fools! He thought, like you, that whiskey is a good tonic!"20 At this point in the act, it seems as if the effects of Mary's morphine dose are weakening, because she is nearly immediately able to mask her terror and check her tone by adding, "But, of course, there's no comparison at all. I don't know why I-forgive me for scolding you, James. One small drink won't hurt Edmund. It might be good for him, if it gives him an

\footnotetext{
${ }^{20}$ Here Mary is referencing her own father's death from tuberculosis.
} 
appetite. ${ }^{21}$ Because of the lessening influence of the narcotic, Mary is better able to assume an Apollonian, calm demeanor, though as the scene closes, the audience observes her oscillate rapidly between this demeanor and one associated more closely with the Dionysian. As James realizes that Mary is under the influence and expresses his anger, she fluctuates from begging for his understanding and forgiveness to denying that she has any idea why she is being accused.

The second scene of Act II begins as the family is returning to the parlor after lunch. Mary speaks dully about the poor quality of help that she has with the housekeeping, and she claims to look forward to James' return to his performing season so that she can no longer concern herself with the difficulty of running the house. Though she is becoming more capable to sustain small talk without delving into the nature of her suffering, this speech leads her back to her claim that the New London house has never been a home for the Tyrones. James attempts to point out that this house could have been a home had Mary not been mired in addiction, to which she replies,

No, no. Whatever you mean, it isn't true, dear. It was never a home. You've always preferred the Club or a barroom. And for me it's always been as lonely as a dirty room in a one-night stand hotel. In a real home one can never be lonely. You forget I know from experience what a home is like. I gave up one to marry you-my father's home. ${ }^{22}$

Again, Mary underscores the theme of isolation, but as she brings up her father's home, she is drawn back to present familial concerns, and she expresses her worry that Edmund is not eating as he ought. Mary's concerns are interrupted by the ringing of the phone, and Tyrone takes the call. He has a conversation with Doctor Hardy, the Tyrone family

\footnotetext{
${ }^{21}$ Ibid., 67-68.

${ }^{22}$ Ibid., 72.
} 
doctor, in which the Doctor asks to meet with Edmund at four o'clock that afternoon. At the mention of Hardy, Mary again attacks her husband,

Oh, we all realize why you like him, James! Because he's cheap! But please don't try to tell me! I know all about Doctor Hardy. Heavens I ought to know after all these years. He's an ignorant fool! There should be a law to keep men like him from practicing. He hasn't the slightest idea-When you're in agony and half insane, he sits and holds your hand and delivers sermons on will power!

Her mood intensifies,

He deliberately humiliates you! He makes you beg and plead! He treats you like a criminal! He understands nothing! And yet it was exactly the same type of cheap quack who first gave you the medicine-and you never knew until it was too late! I hate doctors! They'll do anything to keep you coming to them. They'll sell their souls! What's worse, they'll sell yours, and you never know it till one day you find yourself in hell! ${ }^{23}$

Mary's bluntly accurate attack on James' cheapness, clearly fueled by the intoxicating effects of the morphine, leads her into a monologue that resonates with Nietzsche's understanding of the tragic. Mary finds herself prisoner in an intractable situation; she is both a prisoner of fate as well as her own actions. Again, her intoxication allows her to gaze at the horror of existence; it is important to note that she is recognizes this existence as terrifying; she is not somehow overcoming her terror by acknowledging it. However, in her inebriation, she does not attempt to sugar-coat the truth of her life: she is humiliated, addicted, and wrecked by the world.

Mary regains control of herself and apologizes for her outburst. She then informs her family that she needs to go upstairs to fix her hair - that is, if she can find her glasses. As the play moves forward, at Mary's most intensely emotional moments, she will retreat upstairs, presumably to administer more morphine. She obviously believes, as is the common assumption, that taking the drug will dull her senses to the concerns of life;

\footnotetext{
${ }^{23}$ Ibid., 74.
} 
however, as she becomes more inebriated, the audience observes that her demeanor becomes more and more direct with her family, and her intoxication reveals many of the conflicts within the family that were hidden as the play began. A similar phenomenon occurs as each of the Tyrone men become more and more intoxicated through their consumption of alcohol as the day progresses. As the effects of the morphine are subsiding, Mary even apologizes to her husband for her bitterness. She claims that James is not at fault for her current predicament, a fact which, under the influence of the truthtelling drug, she will undoubtedly deny.

As Mary goes upstairs, Jamie bitterly and ironically points out, "Another shot in the arm!" ${ }^{24}$ This apparently disrespectful statement provokes both Edmund and Tyrone, with the latter threatening to throw his eldest out "into the gutter" for his lack of "pity or decency." Again, Jamie's Dionysiac truth-telling puts him at odds with the rest of the family, as Edmund and Tyrone wish to hold out hope that Mary may one day be cured. Interestingly, at this moment, Jamie reveals that he is not without pity for his mother, and he expresses empathy for his mother, "I understand what a hard game she's up againstwhich is more than you ever have." 25 Jamie recognizes that Mary's condition is his own, trapped in addiction, under pressures beyond ability to conquer. Edmund rebukes his brother's cynicism, to which Jamie replies that he thought his brother shared such feeling, given the kind of poetry Edmund is fond of. He refers to the bookcase, and Edmund's "pet with an unpronounceable name." Edmund defends Nietzsche, saying "You don't know anything about him. You haven't read him." ${ }^{.26}$ At the mention of Nietzsche's name, Tyrone's ire is raised, and he scolds his sons for abandoning their Christian faith,

\footnotetext{
${ }^{24}$ Ibid., 75.

${ }^{25}$ Ibid., 76 .

${ }^{26}$ Ibid., 76-77.
} 
"You've both flouted the faith you were born and brought up in - the one true faith of the Catholic Church — and your denial has brought nothing but self-destruction!"27 Edmund and Jamie both scoff at such a suggestion, and they point out Tyrone's hypocrisy in practice and belief. In practice, Tyrone has not been to Mass in years, and in belief, he admits that he has abandoned hope that Mary might ever recover from her addiction. Edmund points to the lack of efficacy of Tyrone's prayers for his mother as Nietzsche does in Thus Spake Zarathustra, "Then Nietzsche must be right, 'God is dead: of his pity for man hath God died'.,28

In the "Critical Backward Glance" Nietzsche writes fourteen years after the publication of The Birth of Tragedy of the "consistently cautious and hostile silence about Christianity - Christianity as the most excessive, elaborately figured development of the moral theme that humanity has ever had to listen to.. ${ }^{29}$ He writes that behind the Christian moral code there lies, "a hostility to life, a furious, vengeful enemy towards life itself...From the very outset Chirstianity was essentially and pervasively the feeling of disgust and weariness which life felt for life, a feeling which merely disguised, hid, and decked itself out in its belief in 'another' or 'better' life." 30 James' prayers for his wife are a powerful illustration of such a hatred of life. Instead of accepting the reality of Mary's addiction, James has prayed and hoped that somehow she will be granted Divine aid in her efforts to overcome the hold morphine has over her life. At this moment in Act II, Tyrone acknowledges, in part, the illusion of Christian religious belief, although he does not affirm his suffering as Nietzsche asserts the Overman would. James' problem,

\footnotetext{
${ }^{27}$ Ibid.

${ }^{28}$ Ibid., 78.

${ }^{29}$ Friedrich Nietzsche, The Birth of Tragedy and Other Writings, Translated by Ronald Spiers, (Cambridge: Cambridge University Press, 2010), 9.

${ }^{30}$ Ibid.
} 
conceived in terms of Birth of Tragedy, is not primarily that James is that religious, but that he places his hope in illusion instead of confronting the immediate reality of existence before him in the form of his wife's addiction.

Edmund goes upstairs to get dressed for his afternoon appointment with Doctor Hardy, making sure to make a great deal of noise so that his mother will not accuse him of sneaking upstairs to spy on her. When he is out earshot, Jamie asks his father what Doctor Hardy told him on the phone regarding Edmund's condition. Tyrone confirms Jamie's suspicions of Edmund's tuberculosis. Tyrone informs Jamie that Edmund must be committed to a sanatorium for six months to a year, and he has high hopes that if Edmund follows the treatments he will be prescribed, he will make a full recovery. Jamie points out that Edmund should be sent to a quality institution, and he warns his father not to be a cheapskate when selecting the treatment facility for Edmund. Jamie fears that his father, because of his Irish acquaintance with the horrors of tuberculosis, will send Jamie to a second-rate facility. He says, "What I'm afraid of is, with your Irish bogtrotter idea that consumption is fatal, you'll figure it would be a waste of money to spend any more than you can help." ${ }^{\prime 31}$ Again, Jamie sees his father for who is, cheap and Irish, and although Tyrone attempts to deny his son's charges, it is clear that he does not believe Doc Hardy's prediction that Edmund will recover. This is underscored by the fact that he uses the phrase, "I have every hope Edmund will be cured." 32 Tyrone's use of the term hope here is significant, as just moments before, when describing Mary's condition, he had bluntly stated that he has lost all hope that she will recover. Now, after declaring the futility of hope, he expresses his "hope" that his son will not die. As if attempting to

\footnotetext{
${ }^{31}$ Long Day's Journey into Night, 80.

${ }^{32}$ Ibid.
} 
avoid Jamie's scrutiny on this point, Tyrone quickly attacks Jamie for insulting his homeland, and in doing so, he successfully dodges the attention the Dionysian Jamie would give to such a remark. Jamie does not pursue the point and informs his father that he will go with Edmund to his appointment to see Doc Hardy.

Mary returns to the parlor, still searching for her glasses, but her manner is more detached, and it will grow increasingly detached as the scene continues. She looks out the window and remarks that the fog is returning. Again, O'Neill is connecting the returning fog to the intoxication into which the family will sink as the night approaches. In nearly every line that Mary delivers, the reader detects an oscillation from Dionysian authenticity and Apollonian illusion. For example, when Mary discovers that James has an appointment at the club, she states that he'll be drunk that evening. Tyrone denies that he is ever drunk, and instead of pressing the point, Mary says, "Don't think that I'm finding fault, dear. You must do as you please, I won’t mind." ${ }^{33}$ When Mary asks him not to leave, James replies that it is she who is leaving them, Mary ignores his implication and instead momentarily perpetuates an illusion by replying, "I? That's a silly thing to say, James. How could I leave?" but the morphine's truth-speaking powers immediately engulf her, and she again harshly chides James' cheapness as illustrated in his purchase of a second-hand car and his lack of desire to pay a "real" chauffer. Again, the Apollonian breaks through in Mary's dialogue, and she seems to momentarily extend understanding to her husband,

You mustn't be offended, dear. I wasn't offended when you gave me the automobile. I knew you didn't mean to humiliate me. I knew that was the way you had to do everything. I was grateful and touched. I knew buying the car was a hard thing for you to do, and it proved how much

\footnotetext{
${ }^{33}$ Ibid., 83.
} 
you loved me, in your way, especially when you couldn't really believe it would do me any good. ${ }^{34}$

Again, by the end of this speech, the spirit of Dionysus, manifested in offering an unvarnished glimpse at the truth, appears again, and one can assume that the drugs in Mary system empower to offer such a glimpse. At this, James begs his wife to stop taking morphine, if not for her own sake, for the sake of her sons. Sensing his distress, Mary immediately adopts the calm of Apollo, denying that she knows what he is talking about, but merely for a moment as she puts her arms around her husband and says, James! We've loved each other! We always will! Let's remember only that, and try not to understand what we cannot understand, or help things that cannot be helped - the things that life has done to us we cannot excuse or explain. ${ }^{35}$

This line, reflecting a Dionysian sentiment, expresses a Nietzschian rejection of the traditional, received method of knowing another person through abstraction and explanation. Instead, Dionysus, through the words of Mary, implores Tyrone to simply accept and affirm the suffering of this life. At this point in the play, this is not an acceptable option for Tyrone, and he again implores her to stop. Mary complains again of feeling alone, and she reflects upon how she never felt alone when she was in Catholic boarding school. She reminds Tyrone that she lost that community after she married an actor, as the profession of acting carried with it a negative stigma because of the reputation many actors have as men of loose morals.

Tyrone encourages his wife not to dwell on past losses, and Mary informs him that she intends to drive into town to go to the drug store. Though she claims that she only intend to collect tooth powder, toilet soap, and cold crème, James recognizes that

\footnotetext{
${ }^{34}$ Ibid., 85.

${ }^{35}$ Ibid.
} 
she is likely going to fill a prescription for morphine. He bitterly encourages her to collect a good supply of the drug so that "we'll never have another night like the one where you screamed for it, and ran out of the house in your nightdress half crazy, to try and throw yourself off the dock!"”36 At mention of this incident, Mary cries out to her husband not to remember, as such memories are too painful to bear, but the power of Dionysus to illuminate pain is too strong for Mary to resist. She reflects aloud about the birth of Edmund and how the intense pain of childbirth and later complications had compelled the doctor to prescribe morphine to give her relief. Again, Tyrone implores her to forget the past, to which she replies, "Why? How can I? The past is the present, isn't it? It's the future, too. We all try to lie out of life but life won't let us. ${ }^{, 37}$ Here, Mary points out that temporality is an illusion, and that putting the past behind oneself is merely a lie perpetuated so that one might ignore the magnitude of the horror of existence. She goes on to recall another painful past event, one that occurred before the birth of Edmund: the death of her second son, Eugene. She reveals to the audience that Eugene had contracted measles spread to him by the seven-year-old Jamie who, perhaps purposefully, went into the baby's room. The baby contracted the illness, and died soon afterward. Because Mary felt guilty for allowing this to happen, she claims that she always felt as if she had another child, something terrible would happen. She believes that Edmund's affliction with consumption may be due to the fact that she has visited some sort of Divine curse upon him. She rightly points out that Edmund has always been sickly and nervous, and she believes this to be her fault. As she acknowledges her fear and guilt over the birth of Edmund, she regains control of her overflowing emotions and

\footnotetext{
${ }^{36}$ Ibid., 86.

${ }^{37}$ Ibid., 87.
} 
once again adopts the calm façade of Apollo, stating that "Oh. I know it's foolish to imagine dreadful things when there's no reason for it. After all, everyone gets colds and gets over them." 38

At this moment, Edmund enters from the front hall, dressed to go into town for his doctor's visit. He asks his father for cab fare, and James begins to lecture him about the value of a dollar, but as Tyrone looks at his son's sick face, and instead of giving Edmund exact change for the cab, he is filled with guilt and generously gives his son a ten dollar bill. This moment of genuine compassion is cut short by Tyrone once again quickly adopting a tone of sarcasm, however Edmund does not allow his father off the emotional hook. Edmund is touched and genuinely thanks his father with an affectionate - albeit one-armed - embrace. This moment is one of the few in the play where the audience finds itself privy to true Tyrone compassion, and this sense is quickly shattered as James hurries off to his meeting at the Club and Mary asks Edmund to come sit in the parlor with her.

Mary encourages Edmund not to travel into town and meet with Doctor Hardy, claiming that such a trip would not be good for him and that she will care for him throughout the afternoon. Here she adopts the façade of the dutiful mother, attempting to dissuade Edmund from learning of the results of the doctor's tests. By encouraging Edmund to avoid his meeting, she is encouraging him to continue living under the illusion that he merely has a summer cold and will recover in a few days. Though neither Mary and Edmund have received confirmation of Edmund's condition, they both suspect that he has consumption, and Mary's attempt to get Edmund to stay with her through the afternoon is best explained as an Apollonian attempt to thwart the facts of reality. In the

\footnotetext{
${ }^{38}$ Ibid., 88.
} 
face of such an attempt, Edmund pleads with his mother to try to resist the pull of her addiction, but her ability to deny reality is getting stronger, presumably as the effects of the drugs subside as they did in the previous scene. However, Mary does still oscillate between the Dionysian and Apollonian modes of expression. On the one hand, she implicitly tells Edmund that his illness has caused her the stress that has driven her back to the narcotic, while on the other hand she attempts to assure him that she does place any blame upon him for her condition. In a powerful monologue, Mary explains this some day, when Edmund is happy and healthy again, she will find the strength to defeat her addiction,

some day when the Blessed Virgin forgives me and gives me back the faith in her love and pity I used to have in my convent days, and I can pray to her again - when She sees no one in the world can believe in me even for a moment any more, then She will believe in me, and with Her help it will be so easy. I will hear myself scream with agony, and at the same time I will laugh because I will be so sure of myself. ${ }^{39}$

Nietzsche's criticisms of Christianity ring powerfully in opposition to Mary's words. In this Apollonian mode, Mary is looking for an easy fix to her problems in the form of help from the Blessed Virgin. She claims that at some point in the future, she will find redemption, and then her recovery will be effortless. However the play in its entirety makes clear that no such relief will ever be available to Mary. Even she dismisses such an idea almost immediately, telling Edmund — and herself—“Of course, you can't believe that either." ${ }^{40}$ On a Nietzschian view, if Mary is ever to recover, she must affirm and thereby master her suffering without aid from outside herself, even from the Divine.

As Edmund, Jamie, and their father leave the house, Mary finds herself alone in the parlor, and she delivers the following lines, "It's so lonely here...You're lying to

\footnotetext{
${ }^{39}$ Ibid., 94.

${ }^{40}$ Ibid.
} 
yourself again. You wanted to get rid of them Their contempt and disgust aren't pleasant company. You're glad they're gone...Then Mother of God, why do I feel so lonely?"41 Mary is, in this speech articulating an important and complex theme within the play. In order for her to affirm life, Mary must do so by accepting the truth of reality, in this case this means accepting that bears responsibility for her addiction, but she cannot do this alone. She needs the company of others, even - and perhaps especiallyif that company sees her with contempt and disgust. It is only through this shared honesty that Mary will be enabled to stand bravely in the face of her suffering.

Act III begins at six in the evening, and O'Neill points out that the fog coming in from over the Sound is prematurely ushering in the dusk. This fact will be evidenced to the audience by the pervasive and regular sound of the foghorn, warning approaching sea vessels of the dangers of the coast. The presence of the fog is intentional, signifying not only Mary's descent into narcotic intoxication, but the descent of the rest of the Tyrones into intoxication as well. Throughout the final two acts, Mary will complain about the foghorn, but she is not merely complaining about the noise. The foghorn seems to represent an Apollonian deception, a contraption devised to pierce the void of existence and provide safe and Socratic direction to port. The ship's captain can use the foghorn for direction and guidance through the fog of existence, and this may more or less safely direct him to shore, however ultimately the foghorn will provide no relief from the horror of the reality of suffering. The captain who follows such direction and believes himself safe from a horrific fate is deluding himself, and the foghorn is the instrument of such a delusion. For Mary, the sound of the foghorn is an Apollonian attempt to draw her away from the fog of her intoxication and to center her attention on the charade of human life.

${ }^{41}$ Ibid., 95. 
As Cathleen babbles on in the opening of the scene about the chauffer Smythe, Mary says of the fog, "I really love fog...It hides from the world and the world from you. You feel that everything is changed, and nothing is what it seemed to be. No one can find you or touch you any more...It's the foghorn that I hate. It won't let you alone. It keeps reminding you, and warning you, and calling you back.",42

The audience discovers Mary and the servant Cathleen as the scene opens. Cathleen is visibly intoxicated, holding an empty whisky glass in her hand. Mary also displays the signs of intoxication, as

her eyes shine with unnatural brilliance. The strange detachment in her manner has intensified. She has hidden deeper within herself and found refuge and release in a dream where present reality is but an appearance to be accepted and dismissed unfeelingly — even with hard cynicism—or entirely ignored. $^{43}$

O’Neill here accurately characterizes the Dionysiac impression of the Apollonian world. Mary finds herself almost entirely under the power of morphine, and this will enable her to see through the constructed reality of her family and pierce the deep mysteries of Being, insofar as those mysteries are revealed in her relationship to her family. On fewer and fewer occasions throughout the final acts will Mary second guess or apologize for the words of Dionysus, and her presence increasingly points those around her to the central theme of Long Day's Journey.

Cathleen and Mary have taken a trip into town where Mary has filled another prescription for morphine, and as a reward for her assistance, Mary has treated Cathleen to several drinks of her husband's whiskey. In her desperation for companionship, Mary reveals many details of her past to a servant girl, from her formative years in the convent,

\footnotetext{
${ }^{42}$ Ibid., 98-99.

${ }^{43}$ Ibid., 97.
} 
to her marriage to James. Cathleen asks Mary why she had never been involved in theatrical performing like her husband, to which Mary replies,

I've never felt at home in the theatre. Even though Mr. Tyrone has made me go with him on all his tours, I've had little to do with the people in his company, or with anyone on the stage. Not that I have anything against them. They have always been kind to me, and I to them. But I've never felt at home with them. Their life is not my life. ${ }^{44}$

In order to appreciate the force of Mary's sentiment, it is important to bear in mind the kind of theatrical performers Mary refers to here. Here, Mary is likely not referring to "Method Actors," theatrical performers who harness sophisticated psychological method to attempt to create a kind of "emotional truth" onstage for the audience. Though such performance styles were developing in the American theatre during the time James was performing, it is likely, considering the fact that James Tyrone is based upon Eugene's own father, that the players in Tyrone's High Romantic matinee drama did not employ such methods. Instead, their work would likely consist of melodramatic, presentational acting that would, by contemporary standards, be considered "hammy."45 Such acting relied heavily on the creation of an illusion, and this is why Mary could never feel comfortable with people within James' circle, people whose profession rested upon their ability to simulate and distract audiences from life. As a Dionysian, Mary cannot feel at home in a group of people who perpetuate a fiction.

Mary then reveals to Cathleen that as a girl she had aspirations toward two professions: that of a nun, or of a concert pianist. Both options, she claims, were taken from her when she married James. According to Mary, the church gave her a sense of

\footnotetext{
${ }^{44}$ Ibid., 102.

${ }^{45}$ For further discussion of this, see Daniel J. Watermeier, "O'Neill and the Theatre of his Time," in Cambridge Companion to Eugene O'Neill, Edited by Michael Manheim, (Cambridge: Cambridge University Press, 1998), 44.
} 
belonging, and the piano gave her access to beauty. The reader might recall that the full title of Nietzsche's first work is The Birth of Tragedy out of the Spirit of Music, and Nietzsche often portrays the spirit of Dionysus, the unifying god of intoxication, as the founder of instrumental music. In Birth of Tragedy, Nietzsche follows Schopenhauer's story of the nature of such music as the "essence of nature ( $B T \S 2) . "$ In music, Schopenhauer and Nietzsche contend that people are presented with the ground of being, and the understanding they derive from such an experience is unmediated by language and an authentic presentation of the world. ${ }^{46}$ It is consistent with Mary's character as a Dionysian that she would desire interconnectedness with community as well as immediate access to the ground of being by way of music. However, her infatuation with and eventual marriage to a man of the Apollonian arts took away her opportunity to live authentically in either mode of being; perhaps this is one reason Mary always reports feeling "homeless" and "lonely."

Mary delivers a long monologue to Bridgett describing how she met James, concluding with the following lines of deception:

Thirty-six years ago, but I can see it as clearly as if it were tonight! We've loved each other ever since. And in all those thirty-six years there has never been a breath of scandal about him. I mean with any other woman. Never since he met me. That has made me very happy, Catheleen. It has made me forgive him so many other things. ${ }^{47}$

This statement to Cathleen demonstrates that once again the power of the morphine upon Mary's mind is receding again, as she has mentioned earlier in the play a scandal that

\footnotetext{
${ }^{46}$ For further development, consult Christopher Cox, "Nietzsche, Dionysus, and the Ontology of Music," in A Companion to Nietzsche, Edited by Keith Ansell Parsons, (Boston: Blackwell Publishing, 2006), 495513.

${ }^{47}$ Long Day's Journey into Night, 105.
} 
James was involved in with another woman. ${ }^{48}$ Cathleen does not realize this, of course, not being privy to the earlier conversation, and she drunkenly asks to be released to go about her duties. When she is gone, Mary delivers a short soliloquy that confirms she is feeling the return of her Apollonian capacity to cover the truth. She reveals herself to be a woman involved in a Nietzschian conflict with herself. Reflecting upon the beautiful memory she had just related to Cathleen, she says, "You're a sentimental old fool. What is so wonderful about that first meeting between a silly romantic schoolgirl and a matinee idol? You were much happier before you knew he existed, in the Convent, when you used to pray to Blessed Virgin...If I could only find the faith I lost, so I could pray again." The Socratic hope of a better life expressed in the optimism of prayer emerges in Mary's mind, and she attempts to say a "Hail Mary," but she stops herself and the Spirit of Dionysus corrects her illusory hope: "You expect the Blessed Virgin to be fooled by a lying dope fiend reciting words! You can't hide from her!"49 Mary recognizes that she is at war within herself, and she jumps up to go administer more of the drug to silence the conflict. She is interrupted by the arrival of Edmund and James, but had she been allowed to give herself another injection, it is clear she would have descended further into the world of Dionysian reality. As a result, Mary's dialogue with her family continues in the pattern of difficult oscillation from one extreme to the other, from Apollonian to Dionysian, from denial to confession. and from forgiveness to accusation.

As Edmund and James enter, it is clear that they have been drinking and, though they bear their alcohol well, they are perceptibly drunk. This scene begins the family's “journey into night," as O'Neill begins to draw a contrast between two modes of

\footnotetext{
${ }^{48}$ Ibid., 86.

${ }^{49}$ Ibid., 107.
} 
Dionysiac intoxication, Mary's narcotic intoxication, which allows her only to see life as it is but does not enable her to affirm it, and the alcoholic intoxication of the Tyrone men, which not only presents the horrors of existence to those under its power, but allows them to understand their interconnectedness with others in the midst of such horror. At sight of them, for a moment Mary adopts the role of dutiful wife and mother, expresses her gladness that they have returned home in time for dinner. She is able to adopt this façade to such an extreme that she even pours Edmund a drink as an appetizer, despite her earlier outburst about the dangers of consumptive drinking and how drinking while afflicted with tuberculosis is what killed her father.

The men recognize that Mary's cheerfulness is an act, and neither touches the drink that she has poured for them. They simply stare as Mary slips into Dionysian voice again. She remarks the Jamie will not likely be home for dinner, "so long as he has the price of a drink left." ${ }^{50}$ This, according to Mary, is evidence that Jamie is lost to them, and has been so for a long time. She then tells her husband, "But we mustn't allow him to drag Edmund down with him, as he's like to do. He's jealous because Edmund has always been the baby—just so he used to be of Eugene. He'll never be content till he makes Edmund as hopeless a failure as he is." ${ }^{, 51}$ Edmund attempts to ignore his mother's warning, however James chimes in and somewhat confirms what she is saying, "All the same there's truth to your mother's warning. Beware of that brother of yours, or he'll poison life for you with his damned sneering serpent's tongue!"52 Tyrone's agreement with his wife on this truth, a truth that Jamie will admit to in Act IV, is evidence of the power of the Dionysiac urge rising within him as he becomes further

\footnotetext{
${ }^{50}$ Ibid., 109.

${ }^{51}$ Ibid.

${ }^{52}$ Ibid.
} 
intoxicated. More and more, James and his sons will be able to face the world for what it is as the night progresses, the fog thickens, and they continue to drink. Edmund, not yet drunk enough to realize the reality his parents point to, dismisses his father's warning as easily as he had his mother's.

Mary again speaks hard truths to her husband and son, reminiscing about how Jamie and their second son were such happy babies, noting that she had allowed Eugene to "die through my neglect." 53 She detachedly outlines Jamie's decline from promising and likable young student to a drunken waste, and she places the blame for this decline upon the shoulders of James, because he brought Jamie up "to be a boozer" by giving him teaspoonfuls of whiskey to calm him after nightmares as a child. Tyrone protests that he should not be held responsible for Jamie's current state of being, and Mary once again retreats to a tone of Apollonian understanding, denying that Tyrone is to blame, as his Irish upbringing did not prepare him to behave any better. At this, Edmund encourages his father not to listen anymore to Mary's narcotic accusations, and for the moment, Tyrone concedes. Edmund drinks the whiskey Mary has poured for him, although it is unlikely that it adds substantially to their inebriation, as he notices how watered down it is. In the bottle, Mary has replaced the drinks she gave to Cathleen with water, as Jamie did earlier in the day.

Mary seems to soften somewhat in the following dialogue with her husband, and it would seem that the power of the narcotics in her system is waning enough that she is able to present herself to him in affectionate, albeit less-than-truthful, terms. She expresses her gratitude that James has chosen to come home, because "It's very dreary

\footnotetext{
${ }^{53}$ Ibid., 110.
} 
and sad to be here alone in the fog with the night falling." ${ }^{\text {,5 }}$ Mary's reference to the fog is paired here with her feeling of disconnectedness with other people. Though her narcotic intoxication gives her access to the world as it is, in doing so, it isolates her from those for whom she ought to care. However, for a moment, she finds herself able to sustain the illusion of Romantic love directed toward her husband. She tells her husband that she knows he still loves her in spite of all that has happened; he assures her that she is correct. As if to test that love, Mary's Dionysiac tone returns, and she recalls that on their honeymoon, James had left her alone in the hotel room while he went to a bar and after hours of drinking had become so drunk that he had to be carried back to his room. Tyrone denies this ever happened, but there is a ring of truth to this claim that causes Edmund to cry out "with a look of accusing hate toward his father,", 55 that it is no wonder things have turned out as they have. Instead of pursuing his criticism of Tyrone, however, Edmund checks himself and attempts to change the subject.

Mary continues to reminisce aloud about her mother's objections to her marrying James instead of becoming a nun. Her mother claimed that she had been too spoiled by her father to ever make a good wife, and Mary asks her husband if she has in fact been a good wife. Tyrone attempts to placate his wife and lies, "I'm not complaining, Mary."56 Mary acknowledges a "vague guilt" as she replies, “At least, I’ve loved you dearly, and done the best I could — under the circumstances." 57 Her capacity to deny the truth again evinces the decline of morphine in her system. She continues to reflect on the beauty of her wedding gown, saying that she wished she had a daughter who might be able to use

\footnotetext{
${ }^{54}$ Ibid., 112.

55 Ibid., 113.

${ }^{56}$ Ibid., 114.

57 Ibid.
} 
it. She wonders what she has done with, saying that someday she'll take a look in the trunks in the attic to see if she might be able to find it.

Finally, James drinks the watered-down whiskey Mary had poured for him, and for a moment he believes that Mary has taken to alcohol in addition to drugs. She quells his worries by pointing out that she had given Cathleen and Bridgett drinks in exchange for their efforts around the house. Additionally, she reveals that Cathleen had helped her go into town and procure her prescriptions from the drug store. Edmund responds to this by scolding his mother because Cathleen will tell everyone of the transaction. His initial reaction is to shield his mother's reputation, to maintain the illusion of the Tyrone family; this is ironic because earlier in the day he had showed little concern for the opinions of the families of "this hick berg." Edmund is not yet detached enough from the Apollonian world by way intoxication to lose his care for the value of false reputation.

James goes to collect a fresh bottle of liquor from the cellar, leaving Edmund and his mother alone. Mary is successfully maintaining an Apollonian voice now, and she speaks amusedly about her husband's miserliness, citing the fact that Tyrone's father abandoned him and his family when James was a ten year old boy as a reason for his tight-fisted handling of money. Edmund dismisses this, instead attempting to cajole his mother into asking about his doctor's appointment. Edmund is trying to get his mother to face the reality of his condition, but she refuses to hear him, as this will break the illusion of reality she has chosen to construct—-for the moment. Edmund tells her that a specialist has been called in to verify his consumption, and that he will have to go away to a sanatorium, but she dismisses this as the machinations of Doctor Hardy. She recalls the evening when, in a fit of withdrawal-induced madness fueled by Doc Hardy's 
"treatment," she had attempted to commit suicide by throwing herself from the dock. Edmund describes this evening as the time when Mary's addiction was first revealed to him by his family, and as his eyes fill with tears, he says, "God, it made everything in life seem rotten!"58 In earlier acts, Edmund might not have recalled this event so frankly, but under the influence of alcohol, he is beginning to face the truth of his own pain, and in his authenticity, he continues to try to make his mother understand the truth of his situation.

When Edmund insists to his mother that his condition requires convalescence, she flies into an angry speech of denial, accusing Hardy of trying to take her baby away simply to hurt her. Edmund responds to the outburst by again drawing Mary's attention to the fact that she has never seemed to care when he has gone away before, to which she bitterly replies, "I'm afraid you're not very sensitive, after all." ${ }^{, 59}$ In order to avoid the truth, Mary has attacked Edmund and hurt him deeply. After attempting to no avail to get Mary to recognize the peril of his illness, Edmund bluntly states, "It's pretty hard to take at times, having a dope fiend as a mother." ${ }^{\prime 60}$ Mary winces as her son utters these lines, and for a moment the veil is torn away and she recognizes the truth of what Edmund's loose, intoxicated tongue has revealed. He immediately apologizes, and Mary quickly assumes the distracted air of the Apollonian, commenting on how lonely and sad the foghorn sounds. Edmund has heard enough. He leaves the house, telling his mother he does not want any dinner.

Tyrone returns with a new bottle of whiskey, and he asks where Edmund has gone. Mary tells her husband that Edmund does not have any appetite for dinner, assuring herself that his "summer cold" is the explanation for this. Suddenly, she can

\footnotetext{
${ }^{58}$ Ibid., 118.

${ }^{59}$ Ibid. 119.

${ }^{60}$ Ibid., 120.
} 
maintain the illusion of Edmund's condition no longer and cries out as she clutches her husband, "Oh, James, I'm so frightened!...I know he's going to die!”61 Tyrone attempts to console his wife, who is honestly facing the horror of existence. In her terror, she utters lines eerily reminiscent of Dionysus' words to Silenmus, “...And it will be my fault. I should never have borne him. It would have been better for his sake. I could never hurt him them. He wouldn't have had to know his mother was a dope fiend—and hate her!",62 Though James has an opportunity here to experience deep sorrow with his wife, as she is facing the terror of Edmund's illness, he instead tells her to regain composure of herself, as Cathleen might witness her fit. On cue, Cathleen enters and announces that dinner is served, and Mary immediately regains the Apollonian mastery of herself. She excuses herself from dinner, explaining that her rheumatism is bothering her and that she is going to bed. Tyrone knows that she is going upstairs to administer another injection of morphine, and he says that she will be "like a mad ghost before the night is over." ${ }^{, 63}$ Of course, she denies that she knows what he is talking about. Mary goes out of the parlor, and the curtain falls on Tyrone as a "sad, bewildered, broken old man." ${ }^{\circ 4}$ What Tyrone has failed to realize is that he had an opportunity to help Mary face her fear. She has honestly expressed her terror at the thought of Edmund's consumption, and instead of affirming her pain, Tyrone told her to muster her dignity. This rejection of her true impulse of fear has driven Mary back to morphine, where she mistakenly believes she will find solace. The irony is that the deeper she sinks into intoxication, the more authentic and fearful she becomes.

\footnotetext{
${ }^{61}$ Ibid., 122.

${ }^{62}$ Ibid.

${ }^{63}$ Ibid., 123.

${ }^{64}$ Ibid.
} 
The final act takes place at around midnight. Tyrone sits alone in the parlor, playing solitaire. He is very drunk, and a half-empty whisky bottle sits on the table next to him, accompanied by another fresh bottle next to it. Edmund enters, and because the house is almost completely dark, he crashes into the hat stand. He is also visibly drunk. Edmund and his father quarrel about putting on the electric light; because of his thift, Tyrone refuses to turn on only the lights that are absolutely necessary. Tyrone lectures his son on the "value of a dollar," and the conversation eventually turns to the whereabouts of Jamie. Both men know where he is, with a share of Edmund's ten dollar bill, Jamie has gone down to the whore-house. Tyrone pours a drink and invites Edmund to do the same. Edmund pours a very large drink despite his father's protests, and they drink.

In the haze of their intoxication, Edmund claims that he needed his walk home through the fog this evening. His father scolds him, suggesting that he should have more sense than to walk all that way in the damp air given his condition. Edmund responds, "To hell with sense! We're all crazy. What do we want with sense?"65 The audience member attuned to Nietzsche's Dionysian/Apollonian distinction will appreciate the significance of Edmund's statement. Edmund is dismissing the conventional Socratic wisdom that provides illusory comfort to those who follow "doctor's orders." To emphasize this, Edmund quotes two stanzas from Dowson's "Vitae Summa Brevis:"

"They are not long, the weeping and laughter, Love and desire and hate:

I think they have no portion in us after We pass the gate.

They are not long, the days of wine and roses: Out of a misty dream

${ }^{65}$ Ibid., 130. 
Our path emerges for a while, then closes

Within a dream.",66

The message Edmund is delivering is clear. The concerns of life, concerns as

fundamental as health, weeping and laughter are ultimately transient and illusory. The

recitation of this poem leads Edmund to describe his walk in the fog in significantly

Nietzschian terms:

The fog was where I wanted to be. Halfway down the path you can't see this house. You'd never know it was here. Or any of the other places down the avenue. I couldn't see but a few feet ahead. I didn't meet a soul. Everything looked and sounded unreal. Nothing was what it is. That's what I wanted - to be alone with myself in another world where truth is untrue and life can hide from itself. Out beyond the harbor, where the road runs along the beach, I even lost the feeling of being on land. The fog and the sea seemed part of each other. It was like walking on the bottom of the sea. It felt damned peaceful to be nothing more than a ghost within a ghost... Don't look at me as if I'd gone nutty. I'm talking sense. Who wants to see life as it is, if they can help it? It's the three Gorgons in one. You look in their faces and turn to stone. Or it's Pan. You see him and you die - that is, inside you - and you have to go on living as a ghost. $^{67}$

In Edmund's description, he has married his intoxication with the fog, and the result is a glimpse at Being itself. Orr describes Edmund's walk in the fog as his experience of alienation from the world, drawing from Edmund's rhetorical question, "Who wants to see life as it is, if they can help it?" 68 However, if one takes into account the extent to which O'Neill has developed themes drawn from Birth of Tragedy, she understands that Edmund is not describing alienation at all, but unity with all that exists. Given this line of interpretation, when Edmund suggests that one would not want to see life as it is, he is referring to the Apollonian illusion of life instead of life at its most basic. This is

\footnotetext{
${ }^{66}$ Qtd. in Long Day's Journey into Night, 131.

${ }^{67}$ Ibid., 132.

${ }^{68}$ John Orr, “Eugene O'Neill: The Life Remembered,” in Eugene O'Neill's Long Day's Journey into Night, Edited by Harold Bloom, (New York: Chelsea House Publishers, 1987), 122.
} 
confirmed when he identifies such a life as the "three Gorgons" who "turn one to stone," a reproduction of the image of oneself. In the fog, one loses her individuality, and according to a Nietzschian reading, comes to terms with all existence. Edmund loses his sense of location and instead experiences the unity of all that is.

Tyrone dismisses Edmund's vision of reality as poetic, but "damned morbid." $\mathrm{He}$ encourages his son to remember his Shakespeare for a clearer articulation of Dowson's point, "We are such stuff as dreams are made on, and our little life is rounded with a sleep." Edmund sharply contrasts Tyrone's "sentimental" ${ }^{69}$ Shakespearean statement with a sharp Dionysian one, "We are such stuff as manure is made on, so let's drink up and forget about it." ${ }^{70}$ While James is still rapt in an Apollonian illusion of life as expressed in the eloquence of the Bard, Edmund recognizes the horror of existence and finds intoxication as the appropriate mode of being in light of this. James rebukes his son for his morbidity, saying that he should never have given him a drink. Edmund replies by asking, “What's wrong with being drunk? It's what we're after, isn't it? Let's not kid each other, Papa. Not tonight. We know what we're trying to forget." ${ }^{, 71}$ His line here makes a distinct connection between intoxication and honesty. Interestingly, Edmund assumes, as does Mary, that intoxication will enable him and his father to hide from the horror of existence, however the rest of the scene reveals that their drunkenness will take the blinders away, and they will be confronted in direct terms with the reality of their suffering.

Edmund's theme of self-forgetting is again emphasized as he quotes a lengthy passage from Baudelaire's prose poem commonly referred to as "Be Drunk,"

\footnotetext{
${ }^{69}$ See Schiller's distinction between the "naïve" and "sentimental" poet, referenced in $B T \S 4$.

${ }^{70}$ Long Day's Journey into Night, 131.

${ }^{71}$ Ibid., 132.
} 
"Be always drunken, Nothing else matters: that is the only question. If you would not feel the horrible burden of Time weighing on your shoulders and crushing you to the earth, be drunken continually.

Drunken with what? With wine, with poetry, or with virtue, as you will. But be drunken.

And if sometimes, on the stairs of a palace, or on the green side of a ditch, or in the dreary solitude of your own room, you should awaken and the drunkenness be half or wholly slipped away from you, ask of the wind, or of the wave, or of the star, or of the bird, or of the clock, or whatever flies, or sighs, or rocks, or sings, or speaks, ask what hour it is; and the wind, wave, star, bird, clock, will answer you: 'It is the hour to be drunken! Be drunken, if you would not be martyred slaves of Time; be drunken continually! With wine, with poetry, or with virtue, as you will'., 72

James initial reaction to the piece is an attempt at humor, "I wouldn't worry about the virtue part of it, if I were you!" He quickly changes his tone, and condemns this piece as "more morbid nonsense," however it is clear to him that there is something authentic about the sentiment it expresses, or at least, the beauty of its deliver. He compliments his son's delivery of the piece and inquires about the author, perhaps demonstrating that his intoxication is opening his mind to the truth of reality that Baudelaire expresses.

Edmund points out that Baudelaire has written about the pleasures of whore houses, pleasures that Jamie no doubt is indulging in as they speak. He quotes from Baudelaire's "Epilogue," emphasizing the final stanza which states that, "Harlots and/Hunted have pleasures of their own to give,/The vulgar herd can never understand." This reference to the debauchery of his firstborn causes James to cry out in disgust, "Morbid filth! Where the hell do you get your taste in literature? Filth and despair and pessimism! Another atheist, I suppose! When you deny God, you deny hope!"73 His Apollonian response to the "authentic" poetry his son has recited is typical, as James will be the last character to deny the illusions of life (in this case, those perpetuated by the

\footnotetext{
${ }^{72}$ Qtd. in Long Day's Journey into Night, 132.

73 Ibid., 134.
} 
church) and affirm the true nature of existence. Edmund continues despite his father's reply, poking fun at Jamie for sleeping with fat whores and reciting Dowson to them, "kidding himself that he is superior and enjoys pleasures 'the vulgar herd can never understand ${ }^{\prime, 74}$ In his drunken honesty, Edmund admits that he has done the same thing, comparing himself to Dowson. He concludes his reflection by saying, "Poor Dowson! Booze and consumption got him." ${ }^{, 75}$ Though he quickly changes the subject, Edmund has articulated his own fate; again, the power of the Dionysian spirit to reveal reality through intoxication has been manifested, but Edmund does not yet have the courage to face and affirm the reality of his own demise.

After a fruitless appeal to his son to disregard the Modernist writers he is so fond of in favor of Shakespeare, Tyrone and Edmund have another drink. Under the power of liquor, it is James' turn to face and affirm, in small part, the truth of Edmund's condition. In a brief monologue, James reflects on the "ordinary" home that Mary grew up in. $\mathrm{He}$ points out the hypocrisy of Mary's criticisms of his drinking, in light of her father's own alcoholism, "She condemns my drinking but she forgets his. It's true that he never touched a drop till he was forty, but after that he made up for lost time...Well, it finished him quick — that and the consumption—." Tyrone stops, realizing that he has breached the line of propriety, however Edmund does not attempt to change the subject, as he had before; instead, he sardonically points out, "We don't seem to be able to avoid unpleasant topics, do we?" ${ }^{, 76}$ Though his father will again divert the conversation by inviting Edmund to play a game of cards, the audience is witnessing both men's steady progression toward a state of honest, interdependent affirmation of their suffering.

\footnotetext{
${ }^{74}$ Ibid., 134.

${ }^{75}$ Ibid., 135.

${ }^{76}$ Ibid., 137.
} 
As the men absently play Casino, Tyrone continues to criticize the myth Mary has constructed of her happy past. He discounts her promise as pianist as well as her desire to become a nun. On this point, he remarks, "She was a bit of a rogue and a coquette, behind all her shyness and blushes. She was never made to renounce the world. She was bursting with health and high spirits and the love of living."77 Of course, Tyrone is recognizing that Mary's authentic mode of existence is not suited for a world of abstraction, but that she has always been rooted in pleasures that the actual world offers. Edmund encourages his father to play his hand in an attempt to change the subject. Tyrone explains that Mary's recent relapse is due to her worry about Edmund's condition, and he reminds his son to "remember she's not responsible. Once that cursed poison gets a hold on anyone_-.,"78 These words set Edmund off and he and his father finally have the argument that they have been avoiding throughout the entire play. Edmund blames his father for Mary's addiction, asserting that if James had not employed such a cheap doctor to help her after his birth, she would never have been exposed to morphine. Tyrone responds in his defense, claiming that he had been ignorant of the effects of morphine and that he had attempted to find the best doctor he could to help Mary recover. Edmund refuses to believe his defense, and he further blames his father for her condition by asserting that Tyrone had left her to raise her children alone. At this point, Tyrone loses complete control of his temper and blurts out, "Or for that matter, if you insist on judging things she says by what she says when she's not in her right mind, if you hadn't been born she'd never-.",79 He stops before finishing his sentence, but Edmund knows that what James has said rings true. He concedes his father's point,

\footnotetext{
${ }^{77}$ Ibid., 138.

${ }^{78}$ Ibid., 139.

${ }^{79}$ Ibid., 142.
} 
admitting that he - through no fault of his own—bears some of the responsibility for his mother's condition. Though Tyrone attempts to take back his harsh words, both he and Edmund have faced an awful truth together, and Edmund seems to feel closer to his father somehow. He says. "I'm like Mama. I can't help liking you, in spite of everything." ${ }^{, 0}$ Despite the fact that Edmund and his father have realized a horrible reality of his existence, they find themselves connected in kinship, as they are both culpable for Mary's condition.

Now that the blinders are off, and the two drunk Tyrones are looking boldly at the horrors of existence, they examine another reality, one equally as horrific. Tyrone attempts to comfort his son about his condition, assuring him that if he will follow the doctor's orders, he will fully recover. Instead of responding to his father's Socratic optimism, Edmund looks into his father's heart, “Don't kid me. You don't believe that...you think I'm going to die." ${ }^{\prime 1}$ As evidence for this claim, Edmund points to the fact that his father is sending him away to the Hilltown Sanatorium, a publicly funded tuberculosis ward instead of a private institution. Edmund asserts that his father does not wish to waste the money for the private sanatorium because he has the Irish belief that consumption is fatal; he would rather send his son to a tax-funded hospital and cut his losses. Tyrone, of course, denies this assertion, but Edmund persists, working himself up into such a rage that he breaks into a fit of coughing. The intensity of Edmund's speech, coupled with the sound of his coughing, causes James to relent. He tells Edmund that all he desires is for his son to be well, and that he will send Edmund anywhere he wishes to

\footnotetext{
${ }^{80}$ Ibid.

${ }^{81}$ Ibid., 143.
} 
go in order to recover. James tells his son to have another drink, as a "bracer," Edmund obeys, and they each have a large glass full of whiskey.

Tyrone is now drunkenly "loose-mouthed," and he begins to tell his son about growing up in poverty, how his father had taken the family to America and then abandoned them to go back to Ireland and commit suicide. As a ten year old boy, Tyrone took a job in a machine shop, working twelve hours a day for fifty cents a week. It was in those days, he claims, that he had learned the value of a dollar. After painting the bleak picture of his upbringing for his son, he reveals something to Edmund that he had never told anyone before because "tonight I'm so heartsick I feel at the end of everything, and what's the use of fake pride and pretense." ${ }^{82}$ He confesses,

That God-damned play I bought for a song and made such a great success in - a great money success - it ruined me with its promise of an easy fortune. I didn't want to do anything else, and by the time I woke up to the fact I'd become a slave to the damned thing and did try other plays too, it was too late. They had identified me with that one part, and didn't want me in anything else. And they were right, too. I'd lost the great talent I once had through years of easy repetition, never learning a new part, never really working hard. Thirty-five to forty thousand dollars net profit a season like snapping your fingers! $!^{83}$

At one point in his early career, Tyrone claims that he had possessed such drive and talent that Edmund Booth, esteemed as one of the greatest American actors, had said of James' Othello that "That young man is playing Othello better than I ever did!" 84 However, at the age of 27, he purchased the production rights to the play that would make him a matinee icon, and he has spent the rest of his career doing nothing but performing the same role. In the lateness of the hour, exposed by an evening of drinking, James expresses his regret for chasing only money in his artistic career, "I don't

\footnotetext{
${ }^{82}$ Ibid., 149.

${ }^{83}$ Ibid., 149-150.

${ }^{84}$ Ibid., 150.
} 
know what the hell it was I wanted to buy." He recognizes how inauthentic his career has been—how he had never actualized his true talent as an actor—and he tells Edmund, "I'd be willing to have no home in the poorhouse in my old age if I could look back now on having been the fine artist I might have been." ${ }^{85}$ James recognizes that his pursuit of an easy fortune has transformed him into an Apollonian, rote performer who might have been artistically significant had he not discovered his signature role.

In his honest revelation of himself, brought on by the power of strong drink, Tyrone has revealed something significant of himself to his son, and this boldness has once again bred produced kinship between the two. Edmund says, "I'm glad you've told me this, Papa. I know you a lot better now." ${ }^{86}$ Father and youngest son are increasingly facing their demons, and instead of rapidly changing the subject to more pleasant topics in the interest of Apollonian distraction, they continue to face life as it is, though this act is only produced through violent and harsh Dionysian conflict.

The men hear Mary moving around upstairs, and Edmund pours himself another drink. After Edmund consumes the whiskey, "his expression changes. When he speaks it is as if he were deliberately giving away to drunkenness and seeking to hide behind a maudlin manner." ${ }^{87}$ In an effort to give his father a window to his soul as Tyrone has given to him, Edmund then delivers his most famous speech of the play,

You've just told me some high spots in your memories. What to hear mine? They're all connected with the sea. Here's one. When I was on the Squarehead trigger rigger, bound for Buenos Aires. Full moon in the Trades. The old hooker driving fourteen knots. I lay on the bowsprit, facing astern, with the water foaming into spume under me, the masts with every sail white in the moonlight, towering high above me. I became drunk with the beauty and singing rhythm of it, and for a moment

\footnotetext{
${ }^{85}$ Ibid., 151.

${ }^{86}$ Ibid., 151.

${ }^{87}$ Ibid., 152.
} 
I lost myself - actually lost my life. I was so free! I dissolved in the sea, became white sails and flying spray, became beauty and rhythm, became moonlight and the ship and the high dim-starred sky! I belonged, without past or future, within your life, or the life of Man, to Life itself! To God, if you want to put it that way. Then another time, on the American Line, when I was lookout in the crow's nest in the dawn watch. A calm sea, that time. Only a lazy ground swell and slow drowsy roll of the ship. The passengers asleep and none of the crew in sight. No sound of man. Black smoke pouring from the funnels behind and beneat me. Dreaming, not keeping lookout, feeling alone, and above, and apart, watching the dawn creep like a painted dream over the sky and sea which slept together. Then the moment of ecstatic freedom came. The peace, the end of the quest, the last harbor, the joy of belonging to a fulfillment beyond men's lousy, pitiful, greedy fears and hopes and dreams! And several other times in my life, when I was swimming far out, or lying alone on a beach, I have had the same experience. Behind the sun, the hot sand, green seaweed anchored to a rock, swaying the tide. Like a saint's vision of beatitude. Like the veil of things as they seem drawn back by an unseen hand. For a second you see - and seeing the secret, are the secret. For a second there is meaning! Then the hand lets the veil fall and you are alone, lost in the fog again, and you stumble toward nowhere, for no good reason. ${ }^{88}$

Esther Olsen points out that this speech is very reminiscent of two passages in Thus Spake Zarathustra (Z III §15, IV §19), in which "he affirmed the joy of life in the moment and enunciated the doctrine of eternal recurrence. ${ }^{\prime 89}$ Edmund claims to have briefly found meaning in those moments when he has lost himself in the rhythm of the sea. He describes this state as one of drunkenness, beyond "men's lousy, pitiful, greedy fears and hopes and dreams." Each of these pejoratives readily describes man's Apollonian impulses, and in moments when Edmund loses himself in the sea, he sees his connection with all that exists; he realizes the illusion of individuation, and this realization provides momentary peace. At the end of the speech, he remarks that he cannot sustain such peace, because of the power of the Apollonian world in his life, "As

\footnotetext{
${ }^{88}$ Ibid., 153.

${ }^{89}$ Esther Olsen, “An Analysis of the Nietzschian Elements in the Plays of Eugene O'Neill," PhD diss., (University of Minnesota, 1957), 575.
} 
it is, I will always be a stranger who never feels at home, who does not really want and is not really wanted, who can never belong, who must always be a little in love with death. ${ }^{90}$ Edmund her describes the isolation that has resulted from Socratic optimism and false Apollonian calm. In moments of Dionysian ecstasy, Edmund feels authentic inter-connectedness with the world; however, in his daily life, that kinship is taken from him through the false Apollonian coping mechanisms culture has developed to avoid the horror of reality.

After this revelation, Tyrone sees something authentic in his son, and he responds, "Yes, there's the makings of a poet in you all right." At this point, however, Edmund finds himself bound by the forces of Apollo, at the limits of language, and he replies,

The makings of a poet. No, I'm afraid I'm like the guy who is always panhandling for a smoke. He hasn't even got the makings. He's got only the habit. I couldn't touch what I tried to tell you just now. I just stammered. That's the best I'll ever do. I mean, If I live. Well, it will be a faithful realism, at least. Stammering is the native eloquence of us fog people. $^{91}$

Edmund knows the immediate experience of Dionysian being, and though he has tried to put this experience into words, he cannot adequately describe it. There is something familiar in this experience to Tyrone, and this is why he praises his son's poetic prowess. Though James and Edmund have both revealed themselves to be sufferers and inflictors of suffering, they have come to terms with themselves—at least for the evening — and they have only been able to do so in concert with one another. Though Jamie's arrival breaks this moment of authentic, affirming kinship, the audience has been privy to an important moment in the lives of Edmund and his father.

\footnotetext{
${ }^{90}$ Long Day's Journey into Night, 153-154.

${ }^{91}$ Ibid., 154.
} 
When Tyrone hears his firstborn arrive on the front steps, he goes out onto the porch $\mathrm{t}$ avoid confrontation with his drunken son. Jamie enters the room, "as drunk as a fiddler's bitch."92 He quotes Kipling as he activates every electric light bulb in the house. In the brightness of electric illumination, he discovers the full bottle of whiskey on the table and pours himself a big drink, despite Edmund's warning that in his current state of intoxication, it will "knock him stiff."93 Edmund reaches to pour himself a glass, but Jamie momentarily stops him, saying, "Not while I'm around. Remember doctor's orders. Maybe you don't give a damn if you die, but I do. My kid brother. I love your guts, Kid. Everything else is gone. You're all I've got left."94 Jamie is assuming the role of the protective older brother; however this is merely a fictional ruse that will be shattered by the end of their conversation.

Jamie drunkenly sets off on a familiar theme, his father's cheapness, saying "What a bastard to have for a father! Christ, if you put him in a book, nobody would believe it!" Edmund, still aware of his kinship with his father displayed in their previous conversation, defends Tyrone, “Oh, Papa's all right, if you try to understand him—and keep your sense of humor." 95 Jamie dismisses Edmund's claim, saying that he will never again make the mistake of believing his father's "old sob act." Jamie has another drink, hoping that this one will deliver him into unconsciousness. Instead, he becomes even more loose-lipped, describing an encounter he has just had with Fat Violet, a prostitute at the brothel in town. Violet was on the verge of being unemployed, because she was not popular with the customers, so out of pity, Jamie takes her upstairs for the price of two

\footnotetext{
${ }^{92}$ Ibid., 155 .

${ }^{93}$ Ibid., 156

${ }^{94}$ Ibid.

${ }^{95}$ Ibid., 157.
} 
dollars. He qualifies his intentions toward Vi, "I like them fat, but not that fat. All I wanted was a little heart-to-heart talk concerning the infinite sorrows of life. ${ }^{.96}$ However, Violet was offended by Jamie's preference for talk over action, and she accused him of simply taking her upstairs as some kind of joke. She broke into tears, and out of pity, Jamie slept with her. He reflects on this act:

This night has opened my eyes to a great career in store for me, my boy! I shall give the art of acting back to the performing seals, which are its most perfect expression. By applying my natural God-given talents in their proper sphere, I shall attain the pinnacle of success! I'll be the lover of the fat women in Barnum and Bailey's circus!...Pah! Imagine me sunk to the fat girl in a hick town hooker shop! Me! Who made some of the best lookers on Broadway sit up and beg!...But you're right. To hell with repining! Fat Violet's a good kid. Glad I stayed with her. Christian act. Cured her blues. Hell of a good time. ${ }^{97}$

The general critical consensus on this passage is that Jamie sleeps with Fat Violet as an act of defilement toward his mother. Törnqvist, for example, points out that Mary has complained throughout the opening act of the play that she has gotten too fat and that Fat Violet is too fat even for Jamie's tastes. Additionally, both Mary and Violet play the piano, but lately Violet has been too drunk to even do this. Jamie connects morphine use and prostitution, saying that he could not imagine women other than prostitutes took dope. ${ }^{98}$ These facts, and several others, lead O'Neill commentators to conclude that Jamie's relationship with Violet is an Oedipal attack on his mother. Such readings certainly have significant merit, however on a Nietzschian interpretation such as the one suggested in this essay, there is a much more straightforward understanding of this act. Jamie's drunkenness has diminished his preoccupation with appearance; he rightly sees

\footnotetext{
${ }^{96}$ Ibid., 160.

${ }^{97}$ Ibid., 160-161.

${ }^{98}$ Egil Törnqvist, "Life in Terms of Lives," in Eugene O'Neill's Long Day's Journey into Night, Edited by Harold Bloom, (New York: Chelsea House Publishers, 1987), 53.
} 
himself, in this state, as inter-connected with all beings, and in this state, he is able to give Fat Violet a brief opportunity to affirm her own existence. Though Jamie knows he should be ashamed because he could certainly aim for a higher caliber lover, he easily dismisses these concerns because he realizes that such concerns are illusions pushed upon him by inauthentic, Apollonian tensions. His momentary expression of disgust with his act with Fat Violet gives way to an affirmation of his own suffering.

Jamie's willingness to directly face the horror of existence is displayed in his ensuing conflict with his brother. Looking around for his mother, he asks, sneeringly, "Where's the hophead? Gone to sleep?"99 Edmund cannot bear this insult to his mother's dignity, and he springs from his chair and strikes his brother on the cheek. Jamie rises from his chair to do battle, but he stops himself, realizing the severity of what he has just said, and admits, “Thanks kid, I certainly had that coming. Don't know what made me-booze talking. You know me Kid.” Again, Jamie has referred to his mother as she is, refusing to pull punches or assume some stance of illusion in order to skirt the horror of reality. He is even willing to face the consequences of such speech without resistence. He explains his bitterness toward Mary, "I suppose it's because I feel so damned sunk. Because this time Mama had me fooled. I really believed she had it licked. She thinks I always believe the worst, but this time I believed the best...I suppose I can't forgive her-yet. It means so much. I'd begun to hope, if she'd beaten the game, I could too." Here, Jamie expresses kinship with his mother. Her suffering is his own, and though he sobs at this thought, he is facing the facts of reality, and he refuses to obscure his suffering.

\footnotetext{
${ }^{99}$ Long Day's Journey into Night, 163.
} 
Jamie has another drink but does not allow Edmund to do the same. Fully expressing himself in the voice of Dionysus, in the ensuing conversation Jamie confirms Mary and Tyrone's earlier warning about his intentions toward Edmund. Mary had previously described Jamie as never being content "until he makes Edmund as hopeless a failure as he is," and now, since veil has been torn back through Jamie's extreme intoxication, Jamie verifies his mother's concern:

You listen! Did it on purpose to make a bum of you. Or part of me did. A big part. That part that's been dead so long. That hates life. My putting you wise so you'd learn from my mistakes. Believed that myself at times, but it's a fake. Made my mistakes look good. Made getting drunk romantic. Made whores fascinating vampires instead of poor, stupid, diseased slobs they really are. Made fun of work as a sucker's game. Never wanted you to succeed and make me look even worse by comparison. Wanted you to fail. Always jealous of you. Mama's baby, papa's pet! ${ }^{100}$

Though Edmund dismisses this claim, it is clear that there is truth to what Jamie is saying. In order to ensure the sabotage of Edmund's life, Jamie sees himself as crafting a myth of a life of excess. Though he certainly may have inhibited his brother's success in an Apollonian sense, he has enabled Edmund to see through the ruse of culture and provided him with the tools to authentically face the horror of existence. Edmund will not be happy in such a life, but he is able to face it honestly under Jamie's intoxicating influence. Jamie gives Edmund frank, honest advice about the danger of facing such a world, "When you come back, look out for me. I'll be waiting to welcome you back with that 'old pal' stuff, and give you the glad hand, and at the first good chance I get stab you in the back."

\footnotetext{
${ }^{100}$ Ibid., 165 .

${ }^{101}$ Ibid., 166.
} 
Jamie collapses onto the couch in a drunken stupor, and Tyrone returns to the room, counseling Edmund not to take heed of Jamie's exaggerations. Jamie wakes, and after scornfully making fun of father's profession of acting, the men sit together at the table, waiting for Mary to go to bed so that they can do the same. Mary then makes her first appearance in this act. She enters the parlor dragging her wedding dress that she must have retrieved from a trunk in the attic. She goes to the piano in the back parlor and begins to play one of Chopin's waltzes in “a forgetful, stiff-fingered groping, as if an awkward schoolgirl were practicing for the first time."102 By the power of the morphine in her system, Mary is completely removed from the reality of the parlor, and she speaks as a schoolgirl still in the convent. She does not seem to recognize or acknowledge her family. In a bitter, harsh tone, Jamie observes, "A Mad Scene. Enter Ophelia!"103 Enraged by Jamie's frank disrespect, Edmund strikes his brother again, and again, Jamie apologizes, “All right, Kid. Had it coming. But I told you how much I'd hoped."104 He breaks into tears, and his father who had momentarily cheered Edmund's response to his disrespect, finds himself feeling compassion for his son, begging him to stop.

Mary finishes playing and wonders aloud why her hands are so knotted. She then comes into the parlor dragging her wedding gown. James takes it from her to protect it, and Mary responds, "It's a wedding gown...I found it in the attic hidden in the trunk. But I don't know what I wanted it for. I'm going to be a nun - that is, if I can only find...what is it I am looking for? I know it's something I lost."105 Realizing that Mary is rapt in her own past and wholly removed from reality, the Tyrones each pour

\footnotetext{
${ }^{102}$ Ibid., 170 .

${ }^{103}$ Ibid.

${ }^{104}$ Ibid., 171.

${ }^{105}$ Ibid., 172.
} 
themselves a drink and sit at the table, listening to Mary's final speech. She complains about something that she had lost and needs terribly. Edmund attempts to interrupt her to tell her that she has consumption, but she simply asks him not to touch her, telling him that she plans to become a nun. Then, as the men listen and lift their glasses without drinking, Mary recalls,

I had a talk with Mother Elizabeth. She is so sweet and good. A saint on earth. I love her dearly. It may be sinful of me but I love her better than my own mother. Because she always understands, even before you say a word. Her kind blue eyes look right into your heart. You can't keep any secrets from her. You couldn't deceive her, even if you were mean enough to want to. ..All this time. I don't think she was so understanding this time. I told her I wanted to be a nun. I explained how sure I was of my vocation, that I had prayed to the Blessed Virgin to make me sure, and to find me worthy. I told Mother I had had a true vision when I was praying to the shrine of our Lady of Lourdes, on the little island in the lake. I said I knew, as surely as I knew I was kneeling there, that the Blessed Virgin had smiled and blessed me with her consent. But Mother Elizabeth told me I must be more sure than that, even, that I must prove it wasn't simply my imagination. She said, if I was so sure, then I wouldn't mind putting myself to a test by going home after I graduated, and living as other girls lived, going out to parties and dances and enjoying myself; and then if after a year or two I still felt sure, I could come back and see her and we would talk again....I never dreamed Holy Mother would give me such advice! I was really shocked. I said, of course, I would do anything she suggested, but I knew it was simply a waste of time. After I left her, I felt all mixed up, so I went to the shrine of the Blessed Virgin and found peace again because I knew she heard my prayer and would always love me and see no harm ever came to me so long as I never lose my faith in her...that was the winter of senior year. Then in the spring something happened to me. Yes, I remember, I fell in love with James Tyrone and was happy for a time. ${ }^{106}$

Mary has fully revealed herself. The source of her suffering is her loss of faith. Her relationship with James and subsequent addiction to narcotics had opened her eyes to the illusory nature of Christian belief, but as she lay it aside, she also lost the sense of peace, community, and happiness she felt while at the convent. Though Dionysus has given

\footnotetext{
${ }^{106}$ Ibid., 175-176.
} 
hear a clear, unmediated view of the horror of existence, she has lost the benefits of Apollonian illusion, chief among those benefits, the ability to experience joy. Though Mary faces the world in her intoxicate haze, the intoxication she experiences is ultimately not of a sort that Nietzsche would describe as fully Dionysiac, because instead of drawing her into kinship with those around her, her morphine will isolate her from everyone who cares for her. By contrast, the Tyrone men have come to terms with one another, stripping away their self-delusion before each other, and though they remain unhappy, they no longer attempt to hide behind Apollonian, plastic perceptions of themselves. They gaze collectively into the horror of existence, and in this act they find themselves depending upon one another.

\subsection{Conclusion}

Through a careful examination of the text of Long Day's Journey into Night, I have demonstrated that the entire body of the play may best be understood in terms expressed in Nietzsche's work, particularly Birth of Tragedy. Through the exposition of the first act, the reader comes to understand that the reality displayed in the bright morning light of the Tyrone's home veils a more horrible truth beneath the surface. This truth is first suggested as Mary begins taking morphine through the second act, and it is expanded and further explored as the Tyrone men drink until drunk in the final two acts.

In their intoxication, the Tyrone's blame and the men accept blame for the suffering they are inflicting as well as experiencing. The men are able to come to terms with and affirm one another's suffering, but they are only able to do so in kinship with

the other men in the family. Mary's intoxicated, Dionysian gaze at reality does not yield 
affirmation of self, however, because the morphine causes her to withdraw from her family. She's is experiencing the reality of existence, but she is not the sort of suffer who would welcome Nietzsche's demon described in The Greatest Weight.

The reading developed in this chapter is intended as the first horn of my larger argument, one that endeavors to describe the pleasure audiences take from Long Day's Journey into Night. In this chapter I have developed what I believe to be the thematic message O'Neill intends to deliver to his audience, that one can only affirm one's life in concert with others. In the next chapter, I will utilize this data to build a resolution to the problem of negative emotion and Journey. In the earlier chapters of this essay, I have analyzed the text for clues with respect to the kinds of emotions he intends to elicit in the viewer's response to the play The problem presented in this project is primarily a problem of the language of emotions, but in order to provide a probabilistic resolution to the paradox, it was important to examine the message O’Neill wishes to deliver to his audience in order to tease out the audience feels about that message. 


\section{CHAPTER SIX SYNTHESIS AND POTENTIAL SOLUTIONS}

\subsection{Introduction}

In the first three chapters of this study, I have offered good reasons to reject the claim that Long Day's Journey into Night does not arouse significant negative emotional states in those who watch it in performance. I have demonstrated that attempts to resolve the paradox of emotion posed by Journey by denying the negative affective power the play possesses ignore key features of the viewer's experience of Journey in performance. One might rightly point out that I have not yet offered a solution to the problem of negative emotion and Long Day's Journey, and it is to this task I will now turn. In the following chapter, I will attempt to synthesize the analysis done in chapters 1-3 with the interpretation of Journey I have presented in chapters 4 and 5. To review, the Paradox of Journey has been formulated as follows, and a good solution should modify (2):

1.People generally avoid situations that arose negative emotions, and pursue situations that arouse positive emotions.

2.People have negative emotional responses to performances of Long Day's Journey into Night.

3.People pursue performances of Long Day's Journey into Night.

This following synthesis will offer good reason to accept the formulation I will present of the second statement of the paradox of Long Day's Journey into Night.

The critique I have offered in the first three chapters of this work has served a dual purpose: first, it ruled out a series of popular resolutions to the Paradox of tragedy as 
they apply to Long Day's Journey into Night, and secondly, these critiques established a set of criteria an appropriate solution to the problem ought to include. Most generally, I have shown that a solution to the Paradox of Long Day's Journey must account for the fact that audiences viewing the play experience significant and prolonged negative emotional states (sadness, anger, pity, etc.) when viewing the play. Through my emotional analysis in chapter 3 of Long Day's Journey, I have established that O'Neill intends viewers of the play commonly experience such emotions in response to the play, and if Journey is produced in a manner faithful to the text, it is likely that these negative emotional states are actualized in audience response. Therefore, any formulation of the second step of the paradox must affirm that audiences watching performances of Journey standardly experience powerful negative emotional states.

More specifically, a reformulation of (2) ought to be compatible with the idea that audiences watching Long Day's Journey into Night actually care about and feel empathy for the characters portrayed onstage. A key reason to reject the "better you than me" approach to resolving the paradox present in responses to Journey is that this approach denies that viewers care about the characters' suffering as it is displayed for them. It seems intuitively appropriate to assert that interested audiences care for and feel empathy toward the suffering Tyrone family, and I have suggested, based upon empirical data, that this empathy is actually heightened given the fictionality of the portrayal of this suffering. For these reasons, any potential reformulation of (2) must be compatible with the idea that viewers are expected to, and standardly do care about the characters portrayed in Journey. 
In addition to the empathy requirement, a solution to the problem at hand ought to take seriously people's capacity to experience mixed emotional states of opposing valence. One shortcoming of Hume's theory of tragic enjoyment is that it consolidates affective positive and negative states into one enhanced experience of "pleasurepain." Based upon current cognitive psychological understanding of how people experience emotional states, I have shown that this is an unnecessary move, and a precise reformulation of (2) ought to acknowledge that in response to Long Day's Journey into Night, it is possible that people experience both intentional and distinguishable positive and negative emotional states as they respond to the play, perhaps even simultaneously.

The most significant worry I expressed about the "control" theory of tragic pleasure is that it does not address the heart of the paradox I have articulated. I have framed the paradox of Long Day's Journey into Night in terms of motivation. In other words, here I am most interested in what motivates audiences to willingly subject themselves to the negative emotional address of Journey when they would attempt to avoid such stimuli in their real lives. Control theories, even if they successfully characterize one's experience of tragedy, do not provide an adequate motivational answer to this question. Therefore, in addition to considerations of mixed emotions, legitimate care, and powerful negative emotional states, an appropriate resolution to the emotional problem posed by the play must provide some reason people pursue performances of the play. That reason has to account for how tragedy generally (and Journey specifically) offers a unique emotional experience that audience members cannot typically obtain in real-world negative affective experiences. 
My thematic analysis of Long Day's Journey into Night has offered the final consideration by which to test a solution to the emotional problem presented by the play. An accurate resolution to the paradox should take seriously the cognitive address and message O'Neill delivers in Journey in conjunction with the emotional effect the play elicits. It seems reasonable that one draft her formulation of (2) with reference to the overall theme of the play, and I intend to show how a Nietzschian reading of the play inspires a resolution to the problem of Journey.

With these conditions established, I will now turn my attention to two other candidate formulations of (2). These approaches differ from those presented in chapters 1-3 in that they accept that tragedy evokes powerful negative emotional responses, but they attempt to resolve the problem by clarifying what one means when she claims to "enjoy" tragedy. Both the "rich-experience" theory and the "meta-response" theory I will discuss seem to meet the minimal acceptable criteria I have established above (provided they are slightly modified to take into consideration the specific thematic data offered in relation to Journey), but I will ultimately show that an improved "meta-response" theory provides the most coherent account of what goes on when people willingly subject themselves to performances of Long Day's Journey into Night and report enjoyment of that experience.

\subsection{Rich Experience}

After careful consideration, one might examine her responses to tragedy and recognize that perhaps she is mistaken when she characterizes her experience of a play like Long Day's Journey into Night as "enjoyable." At the heart of the Paradox of tragedy is the 
strangeness of such a characterization. Alex Neill, taking seriously this recognition, approaches the paradox of tragedy by denying that consumers of painful art experience pleasurable responses at all. Instead, Neill proposes what some have referred to as a "rich experience" theory. Neill believes that the force of the paradox of tragedy lies in a misconception about what we derive from tragedy. He writes: "denying that the responses in question are characteristically pleasurable seems to me to be a very plausible way of addressing the paradox of tragedy; the idea that we commonly enjoy or take pleasure in seeing Oedipus or Gloucester stumbling around with their eyes out is after all somewhat peculiar."1 According to Neill, people do not derive positive emotional affect from the consumption of tragedy, but they do value such experiences as important. When someone claims to "enjoy" Long Day's Journey into Night, she is expressing the fact that she thinks the experience valuable, not that she experiences a pleasant emotional state when watching it. If one were to try to appropriate such an approach in this context as a formulation of (2), such a formulation would appear as follows:

Revised Statement of PoT: Though people experience significant negative emotions in response to performances of Long Day's Journey into Night, they experience such emotions as part of a "rich experience," an experience they value as significant and meaningful.

In the context of the problem at hand, this statement of (2) offers a potentially powerful and plausible reconciliation. After all, it does seem somewhat strange for me to say that I actually enjoy watching Mary's intoxicated trance or the fact that the Tyrones constantly harangue one another in the cruelest manner possible. Perhaps I am mistaken then, when I characterize my experience of watching the play in terms of positive feelings. The fact that I value the experience of watching Long Day's Journey into Night need not be

\footnotetext{
${ }^{1}$ Alex Neill, "On a Paradox of the Heart,” Philosophical Studies 65 (1992), 61.
} 
characterized in simple, Humean, hedonic terms. When I say, "I enjoyed that performance of Journey," on Neill's view, I am saying that I found the performance meaningful, not that I actually experience anything resembling joy or hope (on the whole) as a result of my consumption of the play.

The rich experience theory generally seems to comport with the criteria I have established throughout this essay as requirements for (2), as I will defend below, though I find the rich experience theory somewhat implausible (for reasons I shall describe later) and costly. Nevertheless, a defender of Neill's rich experience solution to the problem of emotion posed by Long Day's Journey into Night can sustain her theory in the face of the challenges I have posed for any such solution. The rich experience theory provides a depiction of the negative address of the play, allowing for significant viewer empathy while potentially remaining uncommitted to the reality/non-reality of mixed emotional states. Perhaps most powerfully, Neill's theory provides a good motivational account that squares with the viewer's understanding of the Nietzschian tone and theme of the play, provided one adopts a "cognitivist" view of the value of literature, as I will describe below.

Negative Address: Neill's theory is built upon the reality of powerful negative emotional responses to tragedy, and if one uses his theory to describe audience response to Long Day's Journey into Night, she is able to easily account for such responses. Unlike "control" or "conversion" theories, the rich-experience theory affirms our immediate intuitions about our reception to the play: Long Day's Journey into Night makes us feel badly—perhaps very badly—and the rich experience theory does not compel us to deny those feelings. Additionally, Neill accepts, perhaps prima facie, that 
viewers can care deeply about the characters within a tragedy, and this is precisely why negative emotional states are aroused when we observe the struggles the Tyrones face. ${ }^{2}$ Nothing in Neill's iteration of (2) complicates the reality of our negative emotional responses to the play, as he affirms their existence and accepts their significant power over the viewer's experience of tragedy. Appropriated for our purposes, this component of Neill's theory makes his approach the most likely candidate we have thus far encountered as a solution to the problem posed by Journey.

Mixed Emotions: Neill's own view of whether or not viewers experience simultaneous emotions of opposing valences in their response to tragedy is unclear at best, but it is likely that he does not believe these mixed emotional states are possible. ${ }^{3}$ For example, Neill asserts that "it would be odd coming out a particularly harrowing performance of Death of a Salesman or King Lear to hear one's companion exclaim 'I really enjoyed that!' or 'that was fun!'," apparently denying that anything resembling positive emotional states occur in the viewer's response to Miller's tragedy to King Lear. ${ }^{4}$ To complicate this position, though, in his discussion of the Paradox of Horror (a slightly different, but related problem) Neill does seem to admit that he feels mixed emotions when viewing tragedy. He writes, "I wouldn't take much pleasure in a performance of Lear (or of Schubert) that didn't evoke these so-called 'negative' responses in me; at least part, and a central part, of the pleasure they give seems to be intrinsically related to the

\footnotetext{
${ }^{2}$ For Neill's take on how one might experience such feelings, the reader might consult his "Fear, Fiction and Make-Believe," Journal of Aesthetics and Art Criticism 49.1 (1991), pp. 47-56, where in his discussion of Walton's resolution to the Paradox of Horror, he affirms that Charles genuinely fears the slime in the horror movie.

${ }^{3}$ It is worth noting that Neill has defended a cognitivist view of the emotions in his discussion of the Paradox of Fiction, but perhaps his views on the nature of emotions have changed. For more on this, the reader should see, "Fiction and the Emotions," American Philosophical Quarterly 30:1 (January 1993), 113. It makes a great deal of sense that a cognitivist should have a significant interest in resolving problems of fiction and emotion, as on a cognitivist model, these problems are most acute.

${ }^{4}$ Alex Neill, "On a Paradox of the Heart," 62.
} 
fact that they do evoke such responses, ${ }^{, 5}$ Contextually, however, he writes this to present the paradox as forcefully as possible, merely reflecting our intuitions on the subject, but not his final position. By the end of "On a Paradox of the Heart," Neill has rejected the notion that tragedy is pleasurable at all, thus resolving the paradox. It seems fair to characterize Neill's theory of tragic emotions as constrained by the belief that viewers of tragedy only experience one emotional state at a time, and that on the whole, these emotional states are negative.

This denial would seem to count against the rich experience theory as a candidate reformulation of (2), as I have established in my criticism of Humean conversion theory that mixed emotional states are possible and likely responses to the events and characters of Long Day's Journey. This is not a damning feature of the theory, however, for one who holds to the rich experience theory could easily nuance the view espoused by Neill, accepting the possibility of mixed emotional affective states, but merely denying that these states occur when audiences view Long Day's Journey into Night. The rich experience theorist might rightly point out that none of the cognitive science that suggests that people can experience mixed emotions in reference to aesthetic stimuli have not demonstrated that this occurs when one watches theatrical tragedy. The rich experience theory does not explicitly deny that mixed emotions are possible, just that this is not what is going on when one views tragedy. Again, the rich experience theorist is only claiming that people are using inaccurate language when they claim to "enjoy" Long Day's Journey; people are merely inaccurately expressing that they value the experience of watching the play, not that they derive positive affect from it.

${ }^{5}$ Ibid., 57. 
Motivation: On its face, the rich experience theory provides an easy answer to why audiences might pursue the negative emotional states that are aroused by Long Day's Journey into Night: people watch the play because it gives them an experience they value as significant and meaningful. Again, to be precise, this theory asserts that when we claim to "enjoy" Journey, we are informally expressing that we find the experience desirable, not that it produces positive qualia in our field of experience. It is a mistake to claim that we derive positive affect from the play.

One might complain, however, that the "rich experience" I have been describing is an ill-defined term, because it is unclear what makes such an experience rewarding if it is not hedonically satisfying. It is to this concern I now turn. The rich experience theory, at least in Neill's iteration of it, seems to assert that something unique is gained from the consumption of tragedy, something that one cannot gain from other experiences in life. What exactly is the "rich experience" Neill refers to? Unfortunately, Neill has not elaborated on this claim, though Aaron Smuts and Paul Bloom have offered a contribution to this discussion that is worth considering.

Smuts describes his conception of "rich experience" as follows:

I argue that the motive for seeking out painful art is complex, but what we desire from such art is to have experiences on the cheap-not life experience on the cheap, as one theory puts it, but experiences of strong emotional reactions. Art safely provides us the opportunity to have rich emotional experiences that are either impossible, or far too risky to have in our daily lives. We can feel fear without risking our lives, pity without seeing our loved ones suffer, thrills without risk of going to jail, and a variety of other experiences that come with unwelcome pitfalls. Outside of art, it is almost impossible to have many of these kinds of experiences without completely wrecking our lives-murdering our loved ones, destroying our relationships, being sent to jail, or suffering fatal injuries. ${ }^{6}$

\footnotetext{
${ }^{6}$ Aaron Smuts, "The Paradox of Painful Art," Journal of Aesthetics Education 41:3 (Fall 2007), 74.
} 
This seems compelling on its face, but the reader might wonder how putatively negative art is able to accomplish in a way that other "thrill seeking" activities do not. What is the difference between one's experience of negative emotional states while watching evening news reports that elicit strong negative affective states and those one experiences when she watches Long Day's Journey? Cognitive psychologist Paul Bloom offers a potentially helpful distinction between "real world" thrills and those one obtains when she views tragedy. He suggests that there are three features of narrative art that compel attention more forcefully than narratives of actual events. He asserts that fictional characters are generally more interesting than those in the real world, and "their adventures are usually much more interesting." Secondly, in the words of Clive James, "fiction is life with the dull bits left out." In other words, the events depicted in fiction are intensified because in the real world, "there are long spans where nothing much happens. However, in fictional worlds, these boring bits are consolidated, so that each event is full of energy." Bloom's last assertion is that in narrative, the technology utilized by the artist allows the audience to connect with the characters portrayed in ways more intimate than those available in real life. In the case of a play like Long Day's Journey into Night, the reader is able to glimpse into the minds of those characters portrayed (for example, through Mary's soliloquy at the end of Act III) and understand the characters' motivation and desires clearly; in the real world one rarely obtains such a glimpse of others mental lives. ${ }^{7}$

Bloom's criteria suggest why people find narrative art compelling, and he uses this backdrop to defend a motivational account for the consumption of tragedy similar to Smuts. When considering the paradox of tragedy, Bloom asks the reader to consider why

\footnotetext{
${ }^{7}$ Paul Bloom, How Pleasure Works: The New Science of why We Like what We Like, (New York: W.W. Norton and Company, 2010),175-176.
} 
people "play fight." He asks, "Why do children get pleasure ${ }^{8}$ from grappling and punching and knocking each other down? It's not just the desire to exercise one's muscles; if it were, they would do push-ups or sit-ups instead. It's not sadism or masochism. The pleasure is in the fighting, not the hurting and being hurt." ${ }^{\prime 9}$ Bloom continues by answering that play is "safe practice." In the real world, when one involves herself in combat, she is bound to be injured, perhaps seriously. When one engages in such play, she is able to practice her combat skills without the negative consequencesnamely injury or death. Bloom argues that people pursue negative emotional states elicited by works of art because it allows them to cultivate coping skills for the negative emotional states they will likely experience in the real world. On Bloom's view, people are interested by tragedy because it enables them to fully explore and experience emotional states that can be otherwise messy in the real world. Because of the clarity offered in tragedy through the careful construction of plot, character, setting, etc., the viewer can cultivate psychic fortitude, and he asserts that tragedy is an evolutionary product similar to the wrestling performed by young homo sapiens and lion cubs alike. Though Bloom's account might be somewhat problematic for the "rich experience" theorist because Bloom seems to assert that tragedy gives pleasure (and thereby offering no help with the paradox of tragedy), a rich experience advocate could likely adopt an account like Bloom's to explain what motivates people to view a play like Journey though they may not "enjoy" the experience.

\footnotetext{
${ }^{8}$ It is interesting that he uses the term "pleasure" here, and Bloom is obviously not as careful with his usage of terms that denote positive emotional states as Smuts and Neill (who hail from an analytic tradition). Based upon his discussion, Bloom seems to see no trouble in asserting that tragedy is pleasurable, so invoking Bloom might prove problematic for the rich experience theorist. This conflict seems to be somewhat beside the point, however, as I am using Bloom here to clarify what Neill and others mean when they describe "rich experience."

${ }^{9}$ Ibid., 192-193.
} 
The Nietzschian Theme of Journey: Those readers uncomfortable with the reductive nature of the evolutionary account of motivation presented above have another option available to them that allows them to retain a rich-experience style solution to the paradox of emotion and Long Day's Journey into Night. ${ }^{10}$ Instead of a kind of an emotional "safe practice" that creates a rich experience for the viewer, perhaps the appeal of the play has little to do with the negative emotions one experiences while viewing it. Instead, perhaps the play is valuable to viewer because of the sophisticated and important Nietzschian theme I have argued is present in the play. It is conceivable and consistent with the evidence to assert that when people find performances of Journey desirable, they do so because of the lesson they learn while viewing the play-namely, that an affirmative attitude toward life's suffering can only be achieved in community with others.

One might refer to this sort of rich experience as a cognitive experience. By using the term cognitive, I refer to something akin to the view of literature that asserts that literature "at its best is a form of understanding and, as such, though it differs greatly in other respects, is to be accorded the same evaluative status as a science, a status which its undoubted capacity to entertain and give us pleasure could not justify."11 Such a view of literature generally is a controversial one, but essentially those who hold this view claim that literature is valuable because it teaches the reader something about the world that she could not learn through other means. In the scenario at hand, one might argue that people value Long Day's Journey into Night because they see a Nietzschian message of life-

\footnotetext{
${ }^{10}$ Perhaps the evolutionary account could be married with the cognitive account that follows. It is not my intention to assume that each account excludes the other.

${ }^{11}$ Gordon Graham, "Aesthetic Cognitivism and the Literary Arts," Journal of Aesthetic Education 30:1 (Spring 1996), 1.
} 
affirmation in community embodied uniquely in the interactions of the Tyrone family. One might claim that the experience of the play is a rich one because the audience member can see that a Nietzschian flourishing life is a livable reality in the face of (or because of!) immense hardship and suffering.

Even though the play elicits negative emotional states, one might argue that this cognitive understanding makes the experience of the play valuable to the audience wholly without eliciting positive emotions. People are attracted to the play because of the embodied lesson it teaches. Even if a cognitive view of literature as a whole is ultimately unsuccessful, it does seem conceivable to assert that in the case of Journey, there is a lesson that it is teaching, and one could not be significantly faulted for valuing her experience of the play based upon the lesson that she has learned. This lesson does not necessarily produce positive emotional states, but it is valuable to the viewer nonetheless.

Based upon its satisfactory answers to the challenges of negative address, mixed emotions, motivations, and the thematic problem, one might readily and coherently embrace the solution offered by Neill and those of his persuasion. Though I believe there is a better candidate solution the problem, it would be wholly appropriate for one to accept a rich experience solution here, provided she is willing to accept the cost of abandoning the idea of tragic pleasure.

I find that rich experience-styled solution comes at too high a price, however. People often characterize their experience of negative literature in terms of enjoyment, and Neill would require them to deny this characterization. He repeatedly asserts that it would be strange to hear someone exit the theatre claiming to "enjoy" Death of a Salesman or King Lear, but would that really be such a strange experience? I contend that 
it would not be strange at all, and that people often characterize their experience of tragedy in exactly those terms.

Even if one were to grant that people do not generally leave the theatre immediately after Death of Salesman or Long Day's Journey reporting that they had enjoyed the experience, does it seem unlikely they would never characterize their feelings in that way. One might easily imagine a couple of theatregoers sitting in a café the morning after attending such a play, reflecting on the experience, and it is certainly conceivable that each might remark, "that was fun!" Rich experience theorists would correct their assertions, insisting that the theatregoers did not have fun; instead the couple had witnessed something important, akin to a presidential inauguration and that their lives had been changed as a result. Might not the incredulous couple reply, "Perhaps, but we had a really good time"?

Further complicating such a solution is a well-established tenet of behavioral psychology. In the essay, "Choice and the Relative Pleasure of Consequences," Barbara Mellers concludes her survey of the scientific literature on hedonism's role in motivation by stating that "Anticipated pleasure is the critical determinant of choice" as it has "stronger predictive power than standard utility constructs." ${ }^{12}$ According to behavioral psychologists, potential pleasure and pain, though not the only motivators, are the best indicators of what choice we will make in our daily lives. I would argue that this is further heightened in the context of the consumption of tragedy, particularly performances of Journey, as we are under no obligation to consume such performances at all. If a choice does not provide people with potential positive emotional reward, they are

\footnotetext{
${ }^{12}$ Barbara Mellers, "Choice and Relative Pleasure of Consequences," Psychological Bulletin 126:6 (November 2000), 921.
} 
very unlikely to pursue it. For a rich experience approach to be palatable, one would have to offer an account of why people's motivation toward "rich experience" of Journey is different than other choices they make in our lives, and how this motivation would supersedes their general desire to pursue pleasure and avoid pain. Bloom and Neill's description of "rich experience" is a good start, but these frameworks present the consumption of a play like Journey as some sort of obligation, akin to brushing one's teeth or safely preparing oneself for the psychic consequences of loss, and they do not seem to provide a justifying reason one might violate the pleasure/pain principle Mellers (and virtually all cognitive psychologists working in the area) defend. Even in his discussion of the paradox of tragedy, Neill seems to do little more than appeal to intuition on this point, and he does not address the almost overwhelming evidence from the science of human behavior that calls his approach into question. We choose whether or not to view art, and the positive emotion that we will receive from that viewing is an important component of our choice. Which is more likely, that people view Long Day's Journey because it is good for them, or that they like it?

\subsection{Meta-Response}

The last significant theory I will discuss in my .essay can be found in Susan Feagin's essay “The Pleasures of Tragedy." Feagin's approach affirms the reality of negative affective emotional responses to tragedy, but unlike rich experience theory, Feagin's "meta-response" theory also affirms the reality of positive affective states in response to tragedy. Feagin argues that when we experience negative emotions as a result of art, we are compensated with a "meta-response" that we might label as positive. Initially, as we observe the suffering of the tragic hero, we experience negative emotional states - fear, 
pity, and the like — but we also experience a meta-response, an emotional response to our direct response. To put Feagin's theory into the vernacular of philosophy of emotion, when exposed to negative art, one experiences negative emotional states directed intentionally at the horror depicted, but the viewer experiences a second-order response directed toward the first order response. This "meta-response" has positive qualia. She claims that viewers enjoy tragedy because they recognize that they are the kinds of people who are shocked by such suffering, and this realization is pleasing. Thus, audiences are motivated to pursue that pleasure.

As evidence that such mixed emotional experiences are possible, she points to accessibly similar experiences in everyday life:

For example, the remains of a spectacular car crash may titillate our curiosity, and we may feel disgusted with ourselves for being so morbid. On the other hand, we may enjoy the enticements of hawkers outside of seamy strip joints, and be pleased with ourselves for having overcome our puritanical upbringing...It should be noted that in ordinary as well as aesthetic contexts the two kinds of responses cannot be distinguished merely by what words we use to describe them. 'Pleasure,' 'shock,' 'melancholy,' and 'delight' may all describe direct or meta-responses, and the two are not always clearly distinguishable from each other. A blush of embarrassment may be intensified by embarrassment over the blush. The two things being distinguished cannot be infallibly distinguished, and that there are unclear cases of how and even whether the two are distinguishable, does not necessarily undermine the utility of the distinction. ${ }^{13}$

Though these emotional states may seem difficult to parse with the aid of experience and introspection alone, Feagin (writing during the height of the popularity of cognitivism of emotion) believes that these emotional states can be rationally plumbed and described utilizing the methods of analytic philosophy of emotion.

\footnotetext{
${ }^{13}$ Susan Feagin, “The Pleasures of Tragedy,” American Philosophical Quarterly 20:1 (January 1983), 97.
} 
Feagin argues that though second order meta-responses occur all the time in daily life, she insists that there is a unique emotional response available in the experience of negative art. She writes, "The pleasure from giving vent to one's pent-up feelings of anger, frustration, or sadness is different from the pleasure of being aware of the fact that you are the kind of person who feels those emotions in response to particular situations as represented in tragic works of art." ${ }^{" 14}$ Because the negative emotional states aroused in tragedy do not have real-world consequence, the viewer is in a unique position to appreciate her capacity for being horrified or saddened, and this vantage point is what provides the occasion for the second-order, pleasant emotional response.

To sum up, according to Feagin, the initial response to the suffering depicted in art is shock and horror, but the viewer experiences a pleasure in the fact that she feels compassion and sympathy for the sufferer. The worse things get for the sufferer, the more the viewer is horrified initially and gratified by her negative response to the horror. Feagin argues that people who enjoy tragedy in art find pleasant the fact that they are horrified by things that should, morally, horrify them. When we observes painful aesthetic representation, our shock reminds us that we "care for the welfare of human beings and that we deplore the immoral forces that defeat them." ${ }^{15}$ The meta-response is a kind of self-congratulation of a viewer's own moral sensibilities, and this selfcongratulatory "pleasure" is what she pursues when she views putatively painful art. This framework navigates the paradox by appealing to a moral sense that the horrors of tragedy arouse, and it seems to provide a plausible solution to this problem. In the current context Feagin's framework offers a revision of (2) as follows:

\footnotetext{
${ }^{14}$ Ibid., 98.

${ }^{15}$ Ibid.
} 
Revised Statement of PoT: Though people experience negative emotions in response to Long Day's Journey into Night, they receive a compensatory "meta-response" of self-congratulation that is pleasurable.

The meta-response theory best satisfies the criteria I have laid out earlier in this chapter, provided one noticeably alter the second half of (2). Below I will describe how each of these criteria is met by the meta-response approach, and I will offer a slightly altered version of (2) as follows:

Revised Statement of PoT: Though people experience negative emotions in response to performances of Long Day's Journey into Night, they receive a compensatory, Dionysian "meta-response" directed toward the community created during the performance.

This iteration of the meta-response theory satisfies the criteria of legitimate pain, mixed emotion, motivation, and thematic content that I have established throughout this essay, as I will describe below.

Negative Address: The meta-response theory that Feagin has proposed as well as my modification of it does not even get off the ground if one denies that Long Day's Journey into Night produces significant negative affective states. This is because one cannot obtain a positive meta-response without first experiencing a negative direct emotional response. On Feagin's solution, the meta-response of self-congratulation can only conceivably occur if the subject first experiences the appropriate negative emotional states in response to the play for which she can congratulate herself. Similarly, on my revision of (2), the communal satisfaction one receives when watching a performance of Journey can only be achieved if negative emotional responses are significant for the viewer (I will elaborate on my revision later). Because negative emotional reaction to tragedy figures so prominently in the meta-response theory, this theory should be a 
serious candidate as I have established fairly conclusively that negative emotional responses to Journey are intended and likely elicited by the play during performance.

Mixed Emotions: The meta-response theory again seems to be the best theory because it not only allows for the possibility of mixed emotional states, it is built upon the reality of such affective responses. Feagin does not attempt to deny that one can experience both "pleasure" and "pain" simultaneously, and she even identifies the objects of such states. Negative direct responses have the negative representation of action as their objects, while the positive meta-responses are intentionally directed at these negative responses within the context of the play.

Feagin admits that these emotional states may be difficult to separate, but this does not count against their divisibility, as has been demonstrated in chapter one of the essay in the discussion of Hume's conversion theory. A powerful method for rendering the paradox of Journey intelligible to is to accept the intuition that one experiences both positive and negative emotional states in response to Journey, and as in its description of the negative address of the play, the meta-response theory does not hedge its bets on the reality of such experiences. Instead, meta-response is predicated on such a reality.

Motivation: The rich experience theory suggested that there was something unique to be gained by pursuing Journey (and tragedy generally), and the meta-response theory agrees with such a claim. Feagin's discussion of the uniqueness of tragic experience provides an important insight into why people pursue such experiences in art, but avoid those experiences in the real world. In actual, real-world scenarios involving the witness of events that arouse negative emotion, the subject does not have the opportunity to evaluate her response and congratulate herself for possessing the moral 
sensibilities appropriate to the harrowing circumstances she witnesses. It would seem strange for one to witness a fatal car accident and afterward praise herself for the negative emotional response she displayed as a result of the event. Tragedy, on the other hand, puts one in the position to evaluate the propriety of such responses, and Feagin would argue that this affirmative evaluation provides a unique positive emotional response that audiences are justified to pursue.

The Nietzschian Theme: Feagin's meta-response theory is difficult to square with what seems to be the central theme of Long Day's Journey into Night. A key component of the pleasure derived from tragedy is the moral evaluation of the horror of suffering. It would be difficult to congratulate oneself for being appropriately sad or angered at the fate of the protagonist if one had no sense that there was something objectively bad about suffering. Yet I have argued that one of Nietzsche's chief contentions throughout his writing on tragedy (and life itself) is that suffering is a reality that is beyond good and evil. O'Neill seems to accept this depiction of life's suffering, as he offers no escape for the Tyrones and no relief from the suffering for the audience. There is a strong sense in which it seems difficult to sustain the idea the play is enjoyable at all, and it seems incoherent to claim that Journey places the viewer in an evaluative moral position where she can recognize that suffering is terrible and congratulate herself for being empathetic. As I have shown in chapter 3, O’Neill constructs the play in many instances to disable the viewer's capacity for empathy toward the characters in the play. In one instant, O’Neill will compel compassion for one of the Tyrones, and then immediately that character will go on the offensive, arousing disgust and likely erasing that compassionate feeling. On a Nietzschian view, sustained throughout Long Day's 
Journey into Night, suffering simply exists, and the best thing to do is bear up under it, or, as Silenmus' wisdom imparts, “to die soon.” Feagin's theory assumes a moral position that is not sustained by the text of Journey or O'Neill's Nietzschian heritage. It is unlikely that the meta-response theory as Feagin has presented it can provide an adequate account of the enjoyment of Journey.

What I would like to suggest, however, is that the meta-response theory not be jettisoned so hastily. Perhaps such an approach, as it has a good deal of explanatory power, might be adjusted somewhat to provide a more satisfying account. Interestingly enough, Nietzsche himself seems to defend a sort of meta-response theory, and though his account is not fully fleshed out, Nietzsche's story of tragic pleasure may offer a compelling modification that will salvage a meta-response styled formulation of (2). In The Birth of Tragedy, Friedrich Nietzsche offers a solution to the paradox of tragedy which serves as a starting point for my own thesis. Nietzsche writes that during the tragic event, "We are really for brief moments Primordial Being itself, and feel its indomitable desire for being and joy in existence...In spite of fear and pity, we are happy living beings, not as individuals, but as the one living being, with whose procreative joy we are blended (BT 17)." Here Nietzsche describes both the problem and a solution to the paradox. During the play, viewers experience fear and pity, but they are compensated with a hedonic emotional state whose intentional object is the "oneness" of all living things. In a moment (that only tragedy can adequately provide), individuality is stripped away, those participating find themselves in connection with others around them, and this experience is pleasurable. If one were to attempt to describe this phenomenon in terms similar to Feagin's, she might argue that the direct response of pity and fear brings about 
pleasure in the fact that the viewer experiences solidarity with other viewers who have the same experience.

One might rightly complain that the idea of "Primordial Being" or "the oneness of all living things" is far too esoteric a concept to fit within any sort of rigorous analysis of the emotional address of a play like Long Day's Journey into Night, but perhaps there is a simpler and more precise way to understand the object of positive emotional states one might obtain in response to performances of the play. Though it is likely that many readers will reject Nietzschian metaphysics, perhaps looking at Nietzsche's claim here more modestly might be helpful. I contend that Nietzsche here is loosely describing a phenomenon with which the reader has immediate experience.

To elaborate on the idea of "oneness" Nietzsche describes, perhaps it would be valuable to examine the phenomenon of theatrical performance generally. After all, when one leaves a performance of Long Day's Journey into Night claiming to have enjoyed it, she does not seem to be claiming to have enjoyed all the negative depictions that likely aroused negative emotional states. Instead, she claims to have enjoyed the event of the performance. The object of her positive affective state is the performance. This assertion does not seem to resolve the problem, but only perhaps moves back one level. How can one enjoy performances of negative acts? One might characterize a public hanging as a sort of performance, but such an event ought not be "enjoyable." How then can a theatrical performance that elicits similar emotional responses be sensibly regarded as such?

The key, of course, is the distinction one ought to draw between the concepts "theatrical performance" and other sorts of "performance." David Osipovich has teased 
out this difference very effectively for our purposes, though much of his discussion of what counts as theatrical performance is intended to undermine definitions of theatrical performance that argue it is merely an interpretation of a play. Osipovich defends the following definition of theatrical performance:

A theatrical performance is a particular kind of interaction between performers and observers (actors and audience members) in a shared physical space. A necessary component of this interaction is that the performers pretend that the interaction is something other than what it actually is and that the observers are aware of this pretense. ${ }^{16}$

What makes Osipovich's definition unique among others (for example, the definition Woodruff defends in The Necessity of Theatre ${ }^{17}$ is the priority Osipovich places upon the imaginative component of the performance. It is vital on Osipovich's definition that the audience recognizes the element of make-believe within the performance. This makebelieve can be seen as a collaborative effort with the actors to suspend disbelief and allow oneself to be affected by the actions portrayed onstage. Additionally, in theatrical performance "audiences and performers have to contend with each other in a way not available to audiences and performers in either film or live television. Each affects the other and is affected by the other." ${ }^{18}$ This unique collaborative element of theatrical performance helps bolster the account of tragic enjoyment that I present here.

Perhaps the "oneness" Nietzsche speaks of as a positive feeling in his discussion of the paradox of tragedy might be understood in terms of imaginative collaboration. When an audience member is negatively moved by Long Day's Journey into Night, she is responding imaginatively to the actors portraying the negative events, collaboratively

\footnotetext{
${ }^{16}$ David Osipovich, "What is a Theatrical Performance?" Journal of Aesthetics and Art Criticism 64:4 (Fall 2006), 461.

${ }^{17}$ Where he asserts that "theatre is the art of making human action worth watching in a measured time and place." Paul Woodruff, The Necessity of Theatre: The Art of Watching and Being Watched, (Oxford: Oxford University Press, 2008), 18.

${ }^{18}$ Ibid., 466,
} 
allowing herself to be affected, and I contend that this response to the negative events portrayed in the context of communal effort between performers and the audience produces positive emotional states. The pleasure of Journey is not, as Feagin argued, derived from a sense of one's capacity for correct moral evaluation; instead, perhaps she better characterizes this experience when she writes that tragedy "reduces one's sense of aloneness in the world, and sooths, psychologically, the pain of solipsism." ${ }^{19}$ Such language seems to directly refer to the Nietzschian sense of "oneness," but again, this need not be viewed as some sort of metaphysical contention. Instead, it is a fair characterization, provided Osipovich's definition of theatrical performance reflects the reality of the concept, to assert that people take pleasure in operating collaboratively with others.

My modification of the "meta-response" theory in light of the Nietzschian theme of the play provides what I view as a palatable solution to the Paradox of Long Day's Journey into Night. An added feature of this solution is that is closely resembles what I have argued to be the central theme of the play—namely that a positive disposal toward life only occurs in collaboration with others. In performances of Journey, if the audience experiences enjoyment, it is because they agree to work in a kind of temporary community, contending with one another and allowing what is presented to them to negatively affect them. This emotional vulnerability enables the viewer to experience community, and she is able to fairly characterize her experience in positive emotional terms because of that momentary sense of collaborative effort.

\subsection{Conclusion}

\footnotetext{
${ }^{19}$ Susan Feagin, "The Pleasures of Tragedy," 98.
} 
As my earlier assessment has led me to conclude that theories of tragic pleasure which deny negative emotional responses, I turned in this chapter to an examination of two theories which affirm the reality of such responses. I then subjected each theory to the conditions I have established as components for any acceptable resolution to the paradox. I examined "rich experience" theories that deny the reality of positive emotional responses to tragedy. I put such theories to the test and determined that generally, they do provide a coherent account of an audience's experience of Long Day's Journey into Night, I argued that such approaches are costly, and there is some evidence from cognitive psychology that compels the reader to look for a better alternative.

I next turned to the "meta-response" theory of tragic emotion proposed by Susan Feagin. I argued that the meta-response theory is a powerful resolution to the problem of Journey, and in most respects, Feagin's solution meets most of the conditions needed to satisfy the demands posed by the paradox. I then augmented Feagin's resolution by making reference to a theory of tragic emotion posed by Friedrich Nietzsche, and I demonstrated that such a meta-response theory is the most sturdy resolution to the problem of Long Day's Journey in performance. I argued that people pursue performances of Journey because, though they experience significant negative emotional states in response to the play, they are compensated by a positive meta-response directed toward the community created during the event. 


\section{CONCLUSION}

Utilizing a generally Socratic method, I have examined the philosophical problem presented by the positive reception of Long Day's Journey into Night. In chapter one, I examined a group of theories that attempt to resolve the paradox by denying that plays such as Journey elicit significant negative emotional responses, and I found each of these approaches lacking in certain key respects. The "Better You than Me" Theory, finding its inspiration in pre-Socratic pessimism about human nature, asserts that people are merely secret sadists who enjoy watching others in pain, and this is why people pursue plays such as Journey. I pointed out that there is good reason to reject such a claim, drawing from intuitive and psychological evidence that makes clear empathic responses are central to the viewer's experience of tragedy, and that we do feel delight that Edmund "got what was coming to him." Instead, our feelings about Edmund are much more complicated, a mix of empathic pity and fear.

Farther along in chapter one, I examined Hume's own "conversion" theory, namely that when suffering is artfully presented in tragedy, the aesthetic beauty of the representation transforms the negative emotion one experiences into an amplified pleasure. I criticized Hume's reductive model of human motivation, the idea that the only motivators for human effort are pursuit of pleasure and avoidance of pain. I pointed out that most philosophers find Hume's account incomplete because he does not establish 
some sort of mechanism for the conversion of pain to pleasure. Perhaps the most damning critique of Hume's account is the evidence drawn from philosophy as well as cognitive psychology that it is possible that people can experience emotions of opposing valences simultaneously, rendering Hume's account wholly superfluous. For these reasons, the reader is wise to reject a Humean solution to the paradox of Long Day's Journey.

To conclude chapter one, I then turned to another intuitively promising theory, the "control" theory of tragic enjoyment. Control theories suggest that one can enjoy tragedy because the negative emotions aroused are not significantly powerful in the context of aesthetic experience. Because one has significant control over how tragedy is consumed, she is able to enjoy the experience. I demonstrated that Morreall's criteria for control were fundamentally misguided and perhaps internally incoherent. Even more troubling for control-based theories is the fact that they have no answer for the motivational component of the paradox. Such theories provide no reason why an audience member would willingly subject herself to tragedy, even if one grants that they correctly characterize one's experience of tragedy.

In chapters two and three, I turned my attention to a refutation of the claim that while people may experience negative emotional states while watching Journey, on the whole they experience positive emotional states because of some sense of resolution that they derive from the play. I defended a method of emotional analysis proposed by Nöel Carroll that I then utilized in the next chapter to carefully evaluate the emotional address of Long Day's Journey into Night. This evaluation disconfirmed the claim that O'Neill intends the audience derive some sense of emotional resolution from the play, and if the 
play is produced faithfully, it is unlikely that a sense of emotional resolution would be obtained by the audience.

After determining that this family of theories does not coherently characterize one's appraisal of Journey, I turned my attention to a thematic analysis of the play, as I believe that any localized solution to the paradox of tragedy must take into account the nature and message of the artifact that it seeks to describe. In chapter four, I established the link between O'Neill's work and that of Friedrich Nietzsche, and I claimed that though the late O'Neill may have abandoned Neitzsche's Zarathustrian teachings about individuality, there is good reason to believe that O'Neill agreed with the early Nietzsche's theory of communal life-affirmation in tragedy. In chapter five, I demonstrated that this is a central thematic element present in Long Day's Journey through careful close reading. The message O'Neill intends to deliver is that suffering is inevitable, and the proper attitude to is to affirm such suffering. This affirmation cannot be achieved in isolation, however, but only through connection with other sufferers.

After establishing the theme of the play, in chapter six, I turned my attention back to the paradox of negative emotion presented by Long Day's Journey. Using the conditions established in my critique of the earlier theories of tragic pleasure, I presented two possible candidate theories, the "rich experience" and "meta-response" theories. Both of these approaches affirm that audiences experience powerful negative emotions in response to works of art such as Journey, but they differ in that rich experience theory denies that viewers experience pleasure as well, while meta-response theories accept the reality of such positive emotional responses. I demonstrated how both theories might be modified slightly to provide coherent accounts describing an audience's response to 
Journey, but I presented several objections to rich experience theory that seem to make it less plausible than meta-response theory. Finally, I defended a modified version of Susan Feagin's meta-response theory, integrating the Nietzschian theme of Journey as a contributing component of the resolution. I argued that the theory that best accounts for the positive reception one has to the play is one that accepts that though audiences experience significant negative emotional states as a result of Long Day's Journey into Night, they are compensated with a positive "meta-response" directed toward the community created during the performance.

The reader might complain that there is insufficient evidence drawn from cognitive psychology to support my final formulation of the second step of the paradox. This is a worry that I am sensitive to, and as I continue in this area of research, I plan to empirically test this claim. Such a research program can only begin, however, by eliminating other possible resolutions to the problem presented here, and this essay has demonstrated that if the paradox of Long Day's Journey into Night is considered in light of the multi-disciplinary approach I have developed, only one available resolution remains. 


\section{REFERENCES}

Andrade, Eduardo, \& Cohen, Joel B. "On the Consumption of Negative Feelings.” Journal of Consumer Research 34 (2007). 283-300.

Argo, Jennifer J., Rui Zui, and Darren W. Dahl. "Fact or Fiction: An Investigation of Empathy Differences in Response to Emotional Melodramatic Entertainment." Journal of Consumer Research, 34 (2008). 614-623.

Berridge, Kent C. and Morten Kringlebach. "Building a Neuroscience of Pleasure and Well-Being.” Psychology of Well-Being 1:3 (2011).

Berridge, Kent C. and Terry E. Robinson. "Parsing Reward." TRENDS in Neurosciences 38, 9 (September 2003). 507-513.

Berridge, Kent C., Terry E. Robinson, and J. Wayne Aldridge. "Dissecting Components of Reward: 'Liking', 'Wanting', and Learning." Current Opinion in Pharmacology 9 (2009). 65-73.

Bloom, Paul. How Pleasure Works: The New Science of Why We Like What We Like. New York: W.W. Norton and Company, 2010.

Brustein, Robert. “The Theatre of Revolt.” in Eugene O'Neill's Long Day's Journey into Night. Edited by Harold Bloom, 21-34. New York: Chelsea House Publishers, 1987.

Bogard, Travis. "The Door and the Mirror." in Eugene O'Neill's Long Day's Journey into Night. Edited by Harold Bloom. 61-81. New York: Chelsea House Publishers, 1987.

Came, Daniel. "The Aesthetic Justification of Existence," in A Companion to Nietzsche. Edited by Keith Ansell Pearson. 41-57. Boston: Blackwell Publishing, 2006.

Carpenter, Frederich I. Eugene O’Neill. New Haven, Connecticut: College and University Press, 1964. 
Crane, Tim. "The Intentional Structure of Consciousness." in Consciousness: New Philosophical Perspectives. Edited by Aleksandar Jokie and Quentin Smith. 3356. Oxford: Oxford University Press, 2003.

D’Arms, Justin. "Prinz's Theory of Emotion.” Philosophy and Phenomenological Research 76 (May 2008): 712-719.

Davis, M.H., Hull, J.G., Young, R.D., \& Warren, G.G. "Emotional reactions to dramatic film stimuli: The influence of cognitive and emotional empathy." Journal of Personality and Social Psychology 52 (1987). 126-133.

Deigh, John. "Primitive Emotions." in Thinking About Feeling: Contemporary Philosophers on Emotions. Edited by Robert Solomon. 9-27. Oxford: Oxford University Press, 2004.

Eaton, Marcia. “A Strange Kind of Sadness.” Journal of Aesthetics and Art Criticism 41:1 (Autumn 1982). 51-63.

Elster, Jon. "Emotion and Action." in Thinking About Feeling: Contemporary Philosophers on Emotion. Edited by Robert Solomon. 151-162. Oxford: Oxford University Press, 2004.

Emotion and the Arts. Edited by Mette Hjort and Sue Laver. New York: Oxford University Press, 1997.

Evans, Dylan. Emotion: A Very Short Introduction. Oxford: Oxford University Press, 2001.

Falk, Doris. Eugene O'Neill and the Tragic Tension: An Interpretive Study of the Plays. New Brunswick, NJ: Rutgers University Press, 1958.

---. “Long Day's Journey.” in Eugene O'Neill's Long Day’s Journey into Night. Edited by Harold Bloom. 9-20. New York: Chelsea House Publishers, 1987.

Feagin, Susan. “The Pleasures of Tragedy.” American Philosophical Quarterly 20 (1983): 95-104.

Galgut, Elisa. "The Poetry and the Pity: Hume's Account of Tragic Pleasure." British Journal of Aesthetics 41, 4 (October 2001): 411-424.

Glaveanu, Vlad Petre. "Creativity as Cultural Participation." Journal for the Theory of Social Behavior 41:1 (2010). 48-67.

Goldie, Peter. "Emotion.” Philosophy Compass 2/6 (2007): 928-938.

Griffiths, Peter. "Is Emotion a Natural Kind?" in Thinking About Feeling. Edited by Robert Solomon. 233-249. Oxford: Oxford University Press, 2004. 
Harold, James. "Mixed Feelings: Conflicts in Emotional Response to Film." Midwest Studies in Philosophy 34:1 (September 2010). 280-294.

Hume, David. “Of Tragedy.” Hume: Selected Essays. S. Copley and A Edgar (Eds.). Oxford: Oxford University Press, 1993.

Larsen, Jeff T. and A. Peter McGraw. "Can People be Happy and Sad at the Same Time?" Journal of Personality and Social Psychology 81:4 (October 2001). 684696.

LeDoux, Josepth. The Emotional Brain: The Mysterious Underpinnings of Emotional Life/ New York: Touchstone Publishing, 1996.

Loeb, Paul S. "Identity and Eternal Recurrence," in A Companion to Nietzsche. Edited by Keith Ansell Pearson. 171-188. Boston: Blackwell Publishing, 2006.

---. "The Moment of Tragic Death in Nietzsche's Dionysian Doctrine of Eternal Recurrence: an Exegesis of Aphorism 341 in The Gay Science." International Studies in Philosophy 30 (1998). 131-143.

Magnus, Bernd. “Eternal Recurrence.” Nietzsche-Studien 8 (1979). 362-377.

McCauley, Clark. "When Screen Violence is not Attractive." in Why We Watch: The Attractions of Violent Entertainment, J. Goldstein (Ed.), 144-162. New York: Oxford University Press, 1998.

Miller, Jordan Y. Playwright's Progess: O'Neill and his Critics. Chicago: Scott, Foresman, and Company, 1965.

Morreall, John. "Enjoying Negative Emotions in Fiction," Philosophy and Literature 9.1 (1985): 95-103.

Murphy, Brenda. O'Neill: Long Day's Journey into Night. Cambridge: Cambridge University Press, 2001.

Neill, Alex. "Art and Emotion." in Oxford Handbook of Aesthetics. Edited by Jerrold Levinson. 421-433. Oxford: Oxford University Press, 2003.

---. “A Paradox of the Heart.” Philosophical Studies 65 (1992). 53-65.

---. “Hume's Singular Phenomenon,” British Journal of Aesthetics 39, 2 (April 1999): 112-125.

Nietzsche, Friedrich, The Birth of Tragedy. Edited by Raymond Guess and Ronald Spiers. Cambridge: Cambridge University Press, 1999.

---. The Gay Science. Edited by Bernard Williams. Cambridge: Cambridge University Press, 2001. 
---. On The Genealogy of Morals and Ecco Homo. Edited by Walter Kaufmann. New York: Vintage Books, 1989.

---. Human, All Too Human. Edited by R.J. Hollingdale. Cambridge: Cambridge University Press, 1996.

Nussbaum, Martha. "Emotions as Judgments of Value and Importance." in Thinking About Feeling: Contemporary Philosophers on Emotion. Edited by Robert Solomon. 183-199. Oxford: Oxford University Press, 2004.

O'Neil, Eugene. Long Day's Journey into Night. New Haven: Yale University Press, 1956.

Ospivich, David. "What is a Theatrical Performance?" Journal of Aesthetics and Art Criticism 64 (2006): 461-470.

The Poetics of Aristotle. Translated and with Commentary by Stephen Halliwell. University of North Carolina Press, 1987.

Price, Amy. "Nietzsche and the Paradox of tragedy." British Journal of Aesthetics 38:4 (1998). 384-393.

Prinz, Jesse. "Embodied Emotions," in Thinking About Feeling: Contemporary Philosophers on Emotion, Edited by Robert Solomon. 49-55. Oxford: Oxford University Press, 2002.

---. Gut Reactions: A Perceptual Theory of Emotion. Oxford: Oxford University Press, 2004.

Ridley, Aaron. "Nietzsche's Greatest Weight.” Journal of Nietzsche Studies 14 (1997). $19-25$.

---. "Tragedy." in The Oxford Handbook of Aesthetics. Jerrold Levinson, Ed. 408-420. Oxford: Oxford University Press, 2003.

Schechner, Richard, Performance Theory. London: Routledge, 2003.

Schimmack, Ulrich. "Pleasure, Displeasure, and Mixed Feelings? Are Semantic Opposites Mutually Exclusive?" Cognition and Emotion, no. 15:1 (2001); 81-97.

Smuts, Aaron. "Art and Negative Affect.” Philosophy Compass 4, no. 1 (2009): 39-55.

---. "The Paradox of Painful Art." The Journal of Aesthetic Education 41, no. 3 (Fall 2007): 59-75.

Solomon, Robert. "The Rationality of the Emotions." The Southwestern Journal of Philosophy 8 (1977); 105-114.

Staging Philosophy: Intersections of Theatre, Performance, and Philosophy. Edited by David Krasner and David Z. Saltz. Ann Arbor, MI: University of Michigan Press, 2006. 
States, Bert. Great Reckonings in Little Rooms: On the Phenomenology of the Theatre. Berkeley: University of California Press, 1985.

Tamborini, R., \& Stiff, J. "Predictors of Horror Film Attendance and Appeal: An Analysis of the Audience for Frightening Films." Communication Research 14 (1987). 415-436.

Tamborini, R., Stiff, J., \& Zillman, D. "Preference for Graphic Horror Featuring Male Versus Female Victimization: Personality and Past Film Viewing Experiences." Human Communication Research 13 (1987). 529-552.

Thom, Paul. For an Audience. Philadelphia: Temple University Press, 1993.

Tiusanen, Timo. “Through the Fog into the Monologue." in Eugene O'Neill's Long Day's Journey into Night. Edited by Harold Bloom. 39-50. New York: Chelsea House Publishers, 1987.

Tornqvist, Egil. "Life in Terms of Lives." in Eugene O'Neill's Long Day's Journey into Night. Edited by Harold Bloom. 51-59. New York: Chelsea House Publishers, 1987.

---. "Nietzsche and O’Neill: A Study in Affinity." Orbits Literatim 23 (June 1968). 97126.

---. "Philosophical and Literary Paragons." in The Cambridge Companion to Eugene O'Neill. Edited by Michael Manheim. 18-32. Cambridge: Cambridge University Press, 1998.

Wander, Matthew H. "O'Neill and the Cult of Sincerity." in The Cambridge Companion to Eugene O'Neill. Edited by Michael Manheim. 217-235. Cambridge: Cambridge University Press, 1998.

Watermeier, Daniel J. "O'Neill and the Theater of His Time." in The Cambridge Companion to Eugene O'Neill. Edited by Michael Manheim. 33-50. Cambridge: Cambridge University Press, 1998.

Watson, David, L.A. Clark, and A.Tellegen. "Development and Validation of Brief Measures of Positive and Negative Affect: The PANAS Scale." Journal of Personality and Social Psychology 54:6 (June 1998). 1063-1070.

Williams, Paul, and Jennifer Aaker. “Can Mixed Emotions Peacefully Co-Exist?' Journal of Consumer Research 28 (March 2002). 636-649.

Woodruff, Paul. The Necessity of Theatre: The Art of Watching and Being Watched. Oxford: Oxford University Press, 2008.

---. "Theatre." in The Oxford Handbook of Aesthetics. Jerrold Levinson, Ed. 594-604. Oxford. Oxford University Press, 2003. 
Yanal, Robert. "The Paradox of Tragedy." The Paradoxes of Emotion and Fiction. Philadelphia, PA: Penn State University Press, 1999. 


\title{
CURRICULUM VITAE
}

\author{
Jeremy Killian \\ 303 Bingham Humanities Building \\ University of Louisville \\ Louisville, KY 40292 \\ (850)377-5520 \\ jscottkill@aol.com
}

\section{Education}

Ph.D. Humanities, University of Louisville. 2013.

Dissertation: A Paradox of American Tragedy: Long Day's Journey into Night and the Problem of Negative Emotion in Theatre.

Committee: John Gibson (director), Osborne Wiggins, and Ying Kit Chan

M.A. Interpretive Speech, Pensacola Christian College. 2003.

Culminating Graduate Recital: John Donne: Christ Crucified on the Anchor.

\section{B.A. Speech Communications, Pensacola Christian College. 2001}

Areas of Specialization: Modernism, Theatre Studies, Aesthetics/Philosophy of Art

Areas of Competence: Medieval/Renaissance Studies, Ethics, Greco-Roman Culture

Publication

Journal Article

"That Deceptive Line: Plato, Linear Perspective, Visual Perception, and Tragedy." in The Journal

of Aesthetics Eduation, Vol. 46, no. 2 (Summer 2012).

Book Review

Review of Ted Nanicelli, A Philosophy of the Screenplay, (Routledge 2013), in The Journal of

Aesthetics and Art Criticism, (forthcoming).

Under Review

"Faulkner, Scofield, and Descartes: The Sound and the Fury and the Mind-Body Problem,"

Interdisciplinary Literature Studies.

In Progress

"Amae and the Paradox of Negative Emotion in Theatre."

"The Fog of Intoxication: Long Day's Journey into Night, Nietzsche, and Dionysus."

"I should Be Glad of Another Death: Navigating the Paradox of Negative Emotion in Religious

Art"

"Revisiting the Pleasures of Tragedy: In Defense of Feagin."

"The United States of Nature: Locke, the Vote, and Problem of the 'Judge of his own Case'."

\section{Work Experience}

Lecturer, Coastal Carolina University, Conway, SC. Fall 2013-Present.

Online Instructor, Western Kentucky Community and Technical College, Louisville, KY. Spring 2013

Lecturer, Spalding University, Louisville, KY. Fall 2012-Present.

Lecturer, University of Lousiville, Fall 2012-Present. 
Writing Center Consultant, Jefferson Community and Technical College, Louisville, KY. Spring 2009Present.

Graduate Teaching Assistant, University of Louisville, Lousiville, KY. 2009-Spring 2012.

Lecturer, Quality Leadership University, Panama City, Panama. Summer 2011.

Adjunct Instructor, Jefferson Community and Technical College, Louisville, KY. Spring 2009.

English/Bible as Literature Teacher, Gulf Breeze High School, Gulf Breeze, FL. 2005-2008.

English/Drama Teacher, Fellowship Christian High School, Roswell GA. 2003-2005.

Graduate Assistant, Pensacola Christian College, Pensacola, FL. 2001-2003

\section{Conference Presentations}

"I should be Glad of another Death: Navigating the Paradox of Negative Emotion in Religious Art." Wesleyan Philosophical Society Conference. Nashville, Tennessee. March 1, 2012.

"That Deceptive Line: Plato on Linear Perspective and Visual Perception.” Kentucky Philosophical Association 2011 Meeting. Lexington, Kentucky. April 9, 2011.

"Faulkner on Descartes: The Sound and the Fury and the Mind/Body Problem." the Association of Humanities Academics 2011 Graduate Student Conference. Louisville, Kentucky. March 25, 2011.

"The Walking Dead: An Application of Corpse Theory to John Donne's Monument and Lavinia in Titus Andronicus." Massachusetts Center for Renaissance Studies 2010 Graduate Conference.Amherst, Massachusetts. October 3, 2010.

"It Turns out Aristotle was Right All Along: Theseus as the Tragic Hero of Euripides' Hippolytus." at the Association of Humanities Academics 2010 Graduate Conference. Louisville, Kentucky. April 16, 2010.

\section{Professional Memberships}

American Philosophical Association

Association of Humanities Academics

Wesleyan Philosophical Society

\section{College/University Teaching Experience}

Western Kentucky Community and Technical College, Louisville KY

Primary Online Instructor

Medical Ethics, (in development)

Introduction to Philosophy, 1 Section, Spring 2013

Spalding University, Louisville $K Y$

Primary Instructor

Ethics, 2 Sections, Fall 2012

Political Philosophy, 1 Section, Spring 2013 (Scheduled)

University of Louisville, Louisville $K Y$

Primary Instructor

Cultures of America, 10 Sections, Fall 2009- Spring 2011, Fall 2012

Creativity and the Arts, 4 Sections, Fall 2012-Spring 2013

Quality Leadership University, Panama City, Panama

Primary Instructor

Cultures of America, 1 Section, Summer 2011

Jefferson Community and Technical College, Lousiville KY

Primary Instructor

Introduction to Public Speaking, 2 Sections, Fall 2009

Pensacola Christian College, Pensacola FL

Primary Lab Instructor 


\section{Graduate Coursework}

Pensacola Christian College Introduction to Graduate Research

Ron Smith

Advanced Oral Interpretation of Poetry

Bethany Crawford

Advanced Oral Interpretation of Dramatic and Narrative Literature Claudene Wooten

Advanced Acting

Rhonda Autrey

Advanced Lighting and Scenic Design

Bethany Crawford

Advanced Costuming and Makeup

John Grainger

Advanced Directing

Charlene Monk

Advanced Group Interpretation

Readings in Oral Interpretation

Claudene Wooten

Private Lessons in Oral Interpretation

Matthew Beemer

Graduate Recital

John Grainger

John Grainger

University of Louisville

Humanistic Studies I

Humanistic Studies II

Interdisciplinary Theory

Capstone Symposium

Playscript Interpretation

Perspectives in Ancient Culture

Studies in Modernism

Studies in Religion and Culture

Political Philosophy

Studies in Aristotle

Studies in Plato

Studies in Heidegger

Studies in Nietzsche

Philosophy of Tragedy

Philosophy and the Arts (Audit)

Pamela Beattie, Linda Gigante

Annette Allen, Osborne Wiggins

Mary Makris, Elaine Wise

Mark Blum

Amy Steiger

Karen Gray

Annette Allen

Mary Ann Stenger

Avery Kolers

Nancy Potter

John Gibson

Osborne Wiggins

John Gibson

Nancy Potter

John Gibson 